Portland State University

PDXScholar

Winter 3-9-2016

\title{
An Investigation into Intermediate Grades Teachers' Noticing of the Mathematical Quality of Instruction
}

\author{
Krista Lynn Strand \\ Portland State University
}

Follow this and additional works at: https://pdxscholar.library.pdx.edu/open_access_etds

Part of the Educational Methods Commons, Junior High, Intermediate, Middle School Education and Teaching Commons, and the Science and Mathematics Education Commons Let us know how access to this document benefits you.

\section{Recommended Citation}

Strand, Krista Lynn, "An Investigation into Intermediate Grades Teachers' Noticing of the Mathematical Quality of Instruction" (2016). Dissertations and Theses. Paper 2709.

https://doi.org/10.15760/etd. 2705

This Dissertation is brought to you for free and open access. It has been accepted for inclusion in Dissertations and Theses by an authorized administrator of PDXScholar. Please contact us if we can make this document more accessible: pdxscholar@pdx.edu. 
An Investigation into Intermediate Grades Teachers' Noticing of the Mathematical Quality of Instruction

by

Krista Lynn Strand

A dissertation submitted in partial fulfillment of the requirements for the degree of

\author{
Doctor of Philosophy \\ in \\ Mathematics Education
}
Dissertation Committee:
Eva Thanheiser, Chair
Mary Beisiegel
Sean Larsen
Nicole Rigelman

Portland State University

2016 
(C) 2016 Krista Lynn Strand 


\begin{abstract}
The Mathematical Quality of Instruction (MQI) is an important feature of a classroom mathematics lesson. Before teachers can strengthen the MQI of their own lessons, however, teachers must first be able to notice MQI-related features of instruction. The purpose of this dissertation is to investigate intermediate grades teachers' MQI-related noticing as they go through a ten-week research-based MQI professional development (PD) program. Specifically, this dissertation is guided by two research questions: (1) How do individual teachers' noticing of MQI-related features of instruction shift as they go through an MQI-focused professional development program? and (2) How do teachers approach the task of noticing students' engagement in mathematical practices?
\end{abstract}

To address the first research question, I developed a multi-level framework out of a priori noticing categories in combination with data from 73 PD teachers' individual typed responses to two video clips of mathematics instruction, in order to characterize degrees of individual teachers' noticing of MQI-related features of instruction. I then used a mathematized version of the framework along with nonparametric statistical analyses to explore shifts in the teachers' noticing of MQIrelated features of instruction at three different time-points throughout the PD. I also illuminated the nature of these shifts by exploring snapshots of two teachers' MQI Noticing journeys as they progressed through the PD. To address the second research question, I used thematic analyses of transcripts of one group of five teachers' discussions in order to identify noticing perspectives exhibited by the 
group as they engaged in the specific task of discussing potential instances of students' engagement mathematical practices during the PD sessions.

The findings highlight and explicate the variation in teachers' MQI Noticing, and it establishes that shifts in such noticing are possible as teachers progress through research-based MQI PD. 
For our son and future little one(s). 


\section{Acknowledgments}

Thank you, Eva, for the years of thoughtful mentoring that shaped me into the math educator I am today. Thank you for the hours (and hours) of time that you gave so that I could complete this dissertation. Thank you for being an example of professional integrity, generosity, enthusiasm, and collegiality.

Thank you, Mary, for taking me under your wing and allowing me to be part of the MQI PD project. Thank you for the hours (and hours) of time that you gave so that I could complete this dissertation. Thank you for being an example of thoughtful professional mentorship and high academic standards.

Thank you, Sean, for profoundly impacting my intellectual growth, and thank you for your unwavering faith in my academic strengths. I would not have finished this program if it were not for your persistent encouragement.

Thank you, Nicole, for inspiring me with the work that you do, and for your insightful feedback on this project.

Thank you, Krista Hocker, Carolyn James, Stephanie Renfro, and Andy Riffel, for volunteering your time to help with my data collection and analysis.

Thank you, my close friends and my sister, for your handwritten cards, texts, emails, hugs, gifts of cheese and coffee, and for your listening ears of support.

Thank you, Grandma and Mom, for taking on days upon days of toddler-sitting to make it possible for me to finish this.

Most importantly: Thank you, Steve, for your daily quiet sacrifices, unconditional love, and friendship. (P.S. You're next!) 
Table of Contents

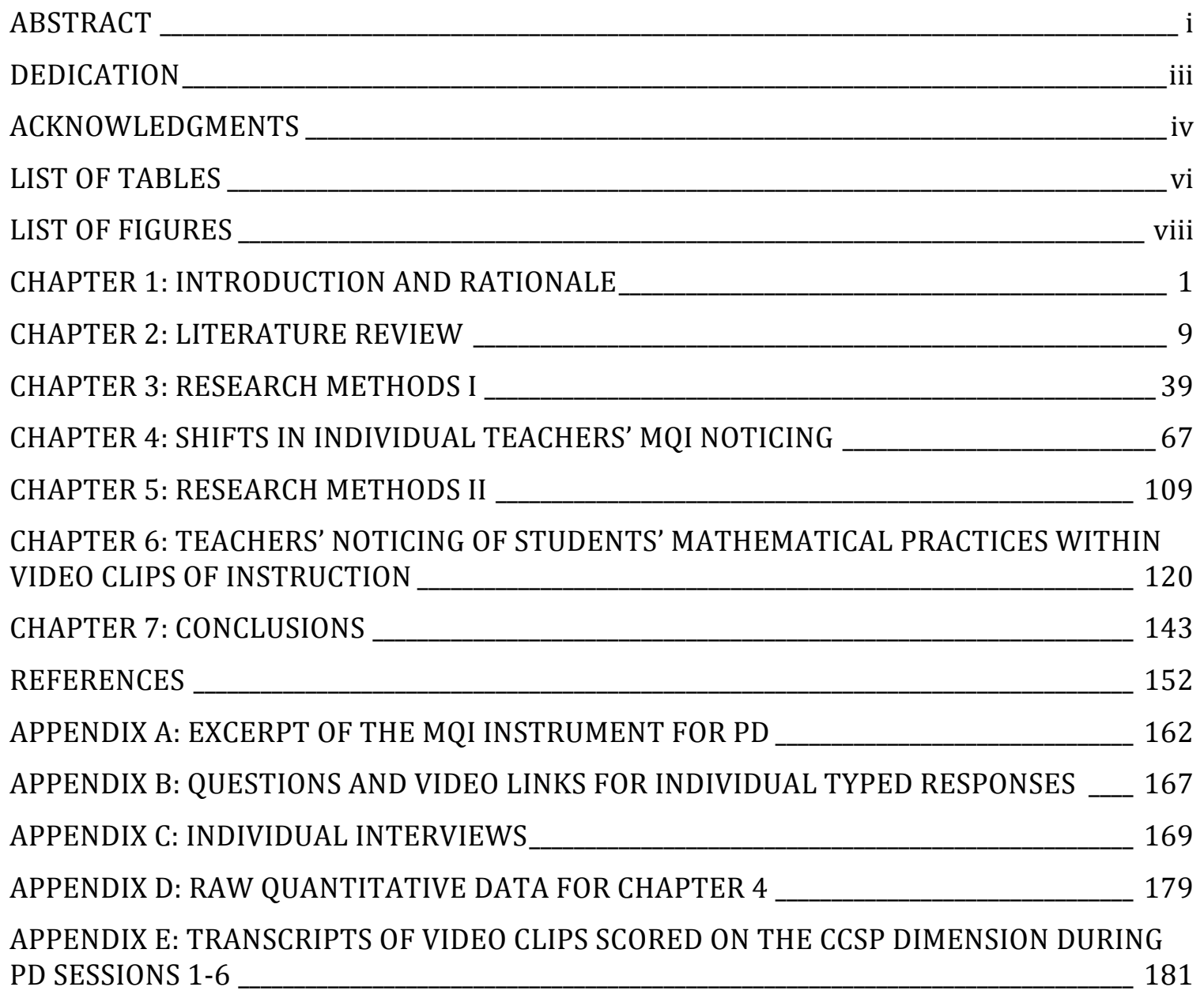




\section{List of Tables}

Table 1: $\quad$ Features of instruction that do and do not pertain to the MQI (LMT 2011)

Table 2: $\quad$ Summaries of Modern Research-Based Mathematics-Specific Classroom Observation Instruments

Table 3: $\quad$ Mathematical Quality of Instruction Dimensions and Items (MQI PD instrument 2014)

Table 4: $\quad$ Summary of parent study conditions

Table 5: $\quad$ Timeline of data collection activities for the parent study

Table 6: Examples of actual dates of data collection activity completion

Table 7: $\quad$ Expert MQI scores for the six video response clips

Table 8: $\quad$ The number of statements within each of 146 video clip responses used to develop the MQI Noticing Framework

Table 9: The MQI Noticing Framework

Table 10: $\quad$ The MQI Noticing Framework mathematized into one dimension of levels

Table 11: Example statements for each level of the uni-dimensional version of the MQI Noticing Framework

Table 12: Percentage of participants by maximum MQI Noticing statement scores at pre, mid, and post-PD

Table 13: Percentage of parti15cipants according to change (decrease, maintenance, or increase) in maximum MQI Noticing statement scores across PD time intervals.

Table 14: Frequencies and percentages of MQI PD teachers' and comparison teachers' individual responses to Clip 3 (midway through the PD), according to their MQI Noticing level.

Table 15: $\quad$ Michael's six video clip responses (two pre- $P D$, two mid-PD, and two post-PD), broken into statements and assigned to MQI Noticing levels 
Table 16: Percentages of MQI Noticing Levels of Michael's video response statements at Pre-PD, Mid-PD, and Post-PD

Table 17: Hope's six video clip responses (two pre-PD, two mid-PD, and two post-PD), broken into statements and assigned to MQI Noticing levels

Table 18: $\quad$ MQI Noticing Levels of Hope's video response statements at pre$P D$, mid- $P D$, and post- $P D$

Table 19: Description of video clips scored on the SEMP and ETCA codes during PD sessions 1-6

Table 20: Foundational decisions for the thematic analyses (Braun \& Clarke, 2006) I conducted for Research Question 2

Table 21: Summary of approaches exhibited by the group by week of the PD 


\section{List of Figures}

Figure 1. Instruction as Interaction (Cohen, Raudenbush, \& Ball, 2003)

Figure 2. The four dimensions of the MQI instrument shown on Cohen, Raudenbush, and Ball's (2003) model of instruction as interaction

Figure 3. van Es' (2011) developmental framework for groups of teachers' learning to notice children's mathematical thinking

Figure 4. The eight Common Core Standards for Mathematical Practice (NGA \& CCSSO, 2010)

Figure 5. Venn diagram of the relationship between Common Core Mathematical Practices and the Math Practices in the MQI

Figure 6. Agenda for Fall session \#4 of the MQI PD

Figure 7. Visual representation of all participants in the parent study

Figure 8. A teacher's video clip response broken up into statements

Figure 9. Flow chart for statistical tests of differences for one independent variable with three or more levels (BettanySoltakov \& Whittaker, 2014)

Figure 10. Figure 10. Flow chart for statistical tests of differences for one independent variable with two levels (Bettany-Soltakov \& Whittaker, 2014)

Figure 11. Figure 11. The score points for the Student Engagement in Mathematical Practices and Enacted Task Cognitive Activation codes, with explicit references to the phrase "student engagement in mathematical practices" underlined and bolded

Figure 12. Figure 12. Examples of initial codes for RQ 2 for Phase 2 of analysis

Figure 13. Figure 13. PD teachers' approaches when discussing potential instances of students' engagement in math practices within a video clip

Figure 14. Figure 14. Students' Utterances as Instances of Math Practices 
approach in relation to the other three approaches

Figure 15. Figure 15. Students' Utterances that Suggest Cognitive Engagement in Math Practices approach in relation to the other three approaches

Figure 16. Figure 16. Teachers' Utterances as Instances of Math Practices approach in relation to the other three approaches

Figure 17. Figure 17. Teachers' Utterances That Prompt For Students' Engagement in Math Practices approach in relation to the other three approaches 


\section{CHAPTER 1: INTRODUCTION AND RATIONALE}

In this introductory chapter, I argue that (a) the mathematical education of children in the US could be stronger, according to national and international measures of students' mathematical achievement; (b) a promising avenue for improving mathematics education in the US is teachers' professional development (PD) through collaborative inquiry into their own and/or real artifacts of practice;

(c) the Mathematical Quality of Instruction (MQI) is particularly deserving focus for such professional development; and (d) a critical way of examining teachers' understandings is through the exploration of their professional noticing - that is, teachers' attention to, and making sense of, particular events in the mathematics classroom. In light of this argument, I conclude by introducing my research focus on teachers' noticing of MQI-related features of instruction.

\section{The Mathematical State of the Union}

With respect to the mathematical education of our children, the US has developed a concerning reputation. In 2013, the Organization for Economic Cooperation and Development released the updated rankings of its Program for International Student Assessment (PISA), which showed that the United States was outperformed by 29 other nations in mathematics, based on average scores on a survey administered in 2012 to tens of thousands of fifteen-year-old students across the globe (OCED, 2013). Students in the US performed significantly below the OCED average score in mathematics, where "mathematics scores for the top-performer, Shanghai-China, indicate a performance that is the equivalent of two years of formal schooling ahead of those observed in Massachusetts - itself a strong-performing US 
state" (p. 1). The PISA study, which has administered its surveys every three years since 2000, shows the US slipping in the rankings, with flat-lining average scores in mathematics while other countries have improved. Meanwhile, results from the most recent Nation's Report Card (National Center for Education Statistics, 2012) showed that while US fourth- and eighth-graders have shown small-but-steady improvement in mathematics scores on the NAEP standardized assessment in the years since 1990, fewer than 50\% of US students met the level of "proficient" in 2013.

\section{Strengthening Mathematics Teaching}

In light of these and other concerning indicators of the status of mathematics education in the US, researchers have worked for decades to identify factors that correlate with measures of student success in mathematics education. Research has pointed to the "teacher variable" (i.e., which teacher a student has) as a factor that has a significant impact on student achievement, and the field has turned to attempting to understand why a student's teacher is such an important factor in his or her mathematical success or lack thereof. Studies of teacher characteristics, teacher testing, teacher certifications, and how much college coursework the teacher has completed, have been shown to have only modest correlations to student learning (e.g., Hanushek, 1996; Wayne \& Youngs, 2003) and have not been able to completely explain variation in student achievement (cf. Hill, Umland, Litke, \& Kapitula, 2012 for a review).

This has been a precursor to a recent shift in the mathematics education community: from a focus on teachers towards a focus on teaching as a professional 
endeavor. Hiebert \& Morris (2012) argue that - particularly in the United States math educators and policymakers have been overly focused on teachers and underfocused on teaching, due to the deeply ingrained belief that good teaching is simply achieved by getting the right people into the profession. On the contrary, Hiebert and Morris, along with other prominent mathematics educators, call for the professionalization of teaching, with its own set of teaching-specific knowledge and standards for quality that are based on what happens in the classroom (Cohen, Raudenbush, \& Ball, 2000; Hill \& Herlihy, 2011; Hill \& Ball, 2004;).

In line with this, there are calls for PD to be collaborative, teacher-centered, and inquiry-oriented (e,g,, Cohen \& Ball, 1999; Hiebert \& Morris, 2012; Little, 1993; Smith, 2001; Stigler \& Hiebert, 2004; Wei, Darling-Hammond, \& Adamson, 2010). In contrast to lecture-style information-dissemination-style PD, many argue that sessions should be modeled after the type of teaching that teachers are expected to enact (Loucks-Horsley, Stiles, Mundry, Love, \& Hewson, 2009). Little (1993) argued that "the most promising forms of professional development engage teachers in the pursuit of genuine questions, problems, and curiosities, over time in ways that leave a mark on perspectives, policy, and practice" (p. 133). In this way, teaching is problematized as a complex social activity, embedded in specific contexts, and implications for changes in teachers' practice result from their collective and longterm examination into the details of practice - both their own and their colleagues' (Borko, Jacobs, Eiteljorg, \& Pittman, 2008; Hiebert \& Morris, 2012; Smith, 2001; Stigler \& Hiebert, 2004). 
An equally compelling recommendation is that mathematics PD should be practice-based and grounded in artifacts of practice, such as classroom video recordings or student work samples (Borko et al., 2008; Cohen \& Ball, 1999; LoucksHorsley et al., 2009; Stigler \& Hiebert, 2004). In 1999, Cohen and Ball made a powerful argument that "practice cannot be wholly equipped by some wellconsidered body of knowledge," and instead, "teaching occurs in particulars...learned in and from practice" (p.10). As such, artifacts from real practice should be the focus of teachers' analyses during PD. And there is empirical evidence to suggest that collaborative PD grounded in artifacts of practice indeed improves teacher learning (e.g., Borko et al., 2008; Kazemi \& Franke, 2004).

\section{The Mathematical Quality of Instruction}

The Mathematical Quality of Instruction (MQI) instrument formed a basis for the collaborative, inquiry-oriented, and practice-based PD that the participants in my study engaged in during the data collection phase of my research. Below, I introduce the MQI and argue for its importance and relevance as a foundation for PD.

The Learning Mathematics For Teaching research team (LMT), which consists of Heather Hill, Deborah Ball, and their colleagues, formally introduced the $\mathrm{MQI}$ as a construct specifically and exclusively meant to capture the nature of the mathematics available to students during classroom instruction (2011). By way of example, consider a hypothetical high-contrast illustration used by the LMT team to demonstrate instruction that has low MQI, despite its strong pedagogical aspects: 
Imagine, for example, a fourth-grade classroom in which students are learning about properties of circles. The teacher begins class by reading a playful storybook, Sir Cumference and the Dragon of Pi, with puns on the words pi and pie and then assigns students to first cut "pies" out of paper and then work with partners to measure the circumference of the different "pies." After about 40 minutes of the teacher supervising cutting and measuring, the lesson wraps up with the teacher's reminder that the circumference is "how far around you can go on a circle" (LMT, 2011, p. 26). There are many aspects of this lesson that might be considered pedagogically desirable: the students seem engaged, there is integration of literature into a mathematics lesson via the storybook, and the lesson is largely activity-based. However, there are many concerns about this lesson, in terms of its mathematical quality. For example, the students spend most of their time cutting and measuring, and there is little evidence that students are engaging in mathematical reasoning during the task; the teacher's definition of circumference is vague and possibly misleading; and there is no evidence to suggest that the teacher engaged with students' thinking about circumference. These features speak to what would be considered the low MQI of the lesson. The quality of the mathematics that students have access to during this lesson is limited, yet this could go unnoticed if the mathematics in the lesson is not considered explicitly and independently of its more general pedagogical features.

To date, there is a strong and growing body of work establishing the importance of the MQI. The MQI is positively correlated with a teacher's 
Mathematical Knowledge for Teaching (Hill et al., 2008) and is also associated with students' learning outcomes (Charalambous, Hill, \& Mitchell, 2012; Hill, Ball, Blunk, Goffney, \& Rowan, 2007; Hill \& Charalambous, 2012; Hill, Rowan, \& Ball, 2005; Hill et al., 2012; Lewis \& Blunk, 2012). Given the importance of the MQI and its applicability to artifacts from classroom lessons (namely, video clips of classroom lessons), its use as a basis for teacher-centered and practice-based PD is promising for strengthening mathematics teaching 1 .

\section{Mathematics Teachers' Noticing}

Current reform efforts in United States Mathematics Education call for adaptive and responsive instruction (Loucks-Horsley et al., 2009; NCTM, 2014; Smith, 2001). For example, teachers are asked to attend to students' thinking, relate students' thinking to mathematical objectives of the lesson, and decide how to proceed based on this (Sherin, Jacobs, \& Philipp, 2011). Further, we know that experienced teachers draw on what they notice to make on-the-spot decisions during instruction (Ainley \& Lutley, 2007). This collection of mathematics-teachingspecific skills - attending, interpreting, and responding - are collectively referred to as noticing (van Es \& Sherin, 2008).

Researchers have pointed to the importance of empirical inquiry into what teachers notice about classroom mathematics instruction because of its relationship to enacted instruction (e.g., Ainley \& Lutley, 2007; Mason, 2002; Sherin, et al., 2011). What teachers notice within their instruction forms the basis for what they act on,

${ }^{1}$ In this chapter, I use the terms teaching and instruction interchangeably. In Chapter 2, I formally define the term instruction and use that term for the remainder of the dissertation. 
and make adjustments for, both within a lesson and in subsequent lessons. Said another way, teachers are unlikely to improve aspects of their teaching to which they do not notice (Schoenfeld, 2011). Thus, for aspects of instruction that we know are important for students' learning- for example, the MQI - teachers' noticing of these is critical.

\section{The Current Research: Teachers' MQI-Related Noticing}

Thus far, I have argued that K-12 mathematics education in the US needs improvement and that a promising avenue for improvement is through teachers' collaborative participation in video-based PD based on the MQI. Further, I have argued that teachers' noticing is important, and that the MQI is an aspect of instruction worth noticing.

My study is an empirical investigation into teachers' MQI-related noticing as they go through a carefully designed, collaborative and practice-based MQI PD program. The goals of my study are: (1) to build on recent teacher noticing literature by developing an MQI-specific noticing framework that will gauge the level of MQI-related noticing reflected in teachers' responses to video clips of instruction; (2) to use that framework to explore shifts in teachers' MQI-related noticing throughout the MQI PD, and (3) to zoom in on one particular aspect of the MQI, instances of students' engagement in Common Core Mathematical Practices (CC Math Practices; NGA \& CCSSO, 2010), exploring the approaches used by one group of MQI PD teachers as they discuss potential instances of students' math practices within video clips of instruction during the PD sessions. 
In completing this study, I anticipate that my research will contribute to the field of mathematics education in multiple ways, including: uncovering the nature of, and various degrees of, teachers' MQI-related noticing and its development, thereby (1) informing the possible modification or development of future MQIbased professional development programs, (2) deepening our understanding of how teachers gauge the strength of one particular MQI-related aspect of instruction: students' engagement in Math Practices, and (3) generally contributing to the current focus in the field of mathematics education on research of teachers' noticing. Additionally, my research will begin to inform our understanding of how intermediate and middle grades teachers learn about the MQI. As a lens for viewing and evaluating the quality of mathematics instruction, the MQI is a promising foundation for improving teaching in the US. But the profession of teaching can only be moved forward in this way if teachers learn to hone in on features of instruction that pertain to its mathematical quality. My study will inform ways in which this can happen. 


\section{CHAPTER 2: LITERATURE REVIEW}

In this chapter, I present my review of background literature for the purposes of situating my research within this prior work, and pointing to empirical and theoretical conclusions that call for my particular inquiries into teachers' noticing of MQI-related features of instruction. The review consists of four main sections. The first section focuses on the MQI, how it is measured in a classroom, and research supporting its importance. In the second section, I introduce the field of research on teachers' noticing. The third section of the review focuses on features of successful PD, and I describe how the MQI PD program aligns with these features.

After these first three sections of the literature review, I introduce my first (of two) research questions pertaining to teachers' noticing of MQI-related features of instruction. Following this, I review a fourth section of literature that establishes the importance of teachers' noticing of students' mathematical practices - a feature of instruction that is part of the MQI. I conclude the chapter by introducing my second research question pertaining this specific aspect of MQI-related noticing.

\section{The MQI}

In this section, I further introduce the $\mathrm{MQI}^{2}$ as a construct, and then I describe how the MQI is measured with an observational instrument, beginning with a brief historical backdrop on classroom observational instruments. Lastly, I present a review of the literature pertaining to the relevance and importance of the MQI within a classroom mathematics lesson.

${ }^{2}$ See Chapter 1 for an introduction to the MQI in reference to a fictitious classroom example. 


\section{Understanding the MQI as a Construct}

The MQI specifically and exclusively refers to the nature of the mathematics available to students during instruction (LMT, 2011). The "I" of the MQI refers to classroom activity that is broader than just the teacher's actions; it refers instead to Cohen, Raudenbush, and Ball's (2003) conceptualization of mathematics instruction as any interaction between teacher, students, and/or mathematical content (see Figure 1). With this in mind, the " $M Q$ " of the MQI refers to the nature of mathematics that occurs during instruction. Table 1 gives examples of features of instruction that either influence, or do not influence, the MQI.

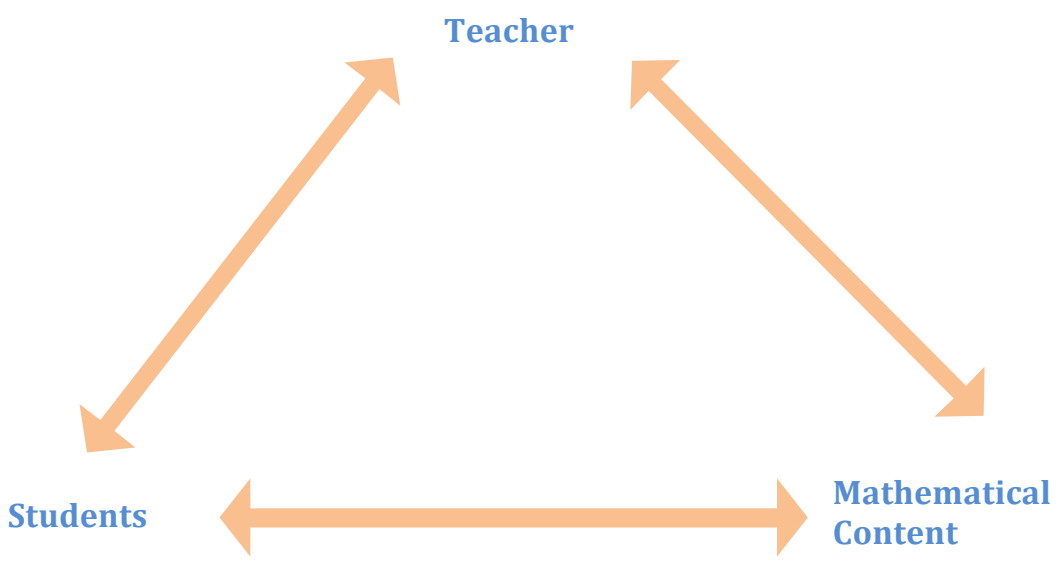

Figure 1. Instruction as Interaction (Cohen, Raudenbush, \& Ball, 2003)

Table 1.

Features of instruction that do and do not pertain to the MQI (LMT 2011)

\begin{tabular}{|l|l}
\hline Influences the MQI & Does Not Influence the MQI
\end{tabular}


Features of the instruction that influence the quality of mathematics available to students (e.g., richness of teachers' or students' mathematical explanations, presence or absence of uncorrected teachers' mathematical errors, teachers' accurate interpretation and uptake of students' mathematical contributions).
Pedagogical features of instruction (e.g., questioning techniques)

Features pertaining to how math, specifically, should be taught (e.g., via student discussion, with hands-on materials)

Classroom climate

General student engagement (e.g., whether students were "on-task")

Cross-lesson issues (e.g., unit pacing)

Written tasks or intended tasks (e.g., consideration of the intended cognitive demand of the lesson's activity)

\section{The MQI Classroom Observational Instrument}

I turn now to describing how the MQI is measured with an observational instrument and why such an instrument needed to be developed. First, however, I give a brief historical backdrop on classroom observational instruments to situate this discussion.

\section{A Brief History of Math Classroom Observation Instruments.}

Mathematics education researchers have a decades-long history of working to determine factors that comprise, and contribute to, effective mathematics teaching. The 1970's saw the birth of a collection of studies, now known as the processproduct research literature (Hill, Sleep, Lewis \& Ball, 2007). This period began with researchers focusing their efforts on capturing teacher characteristics that, in the 
researcher's opinions, made a teacher a good teacher of mathematics. Examples of characteristics of good teachers were: enthusiastic, helpful, and strict (as summarized in Ball, 1991). However, as researchers begin to define "effective teaching" in terms of student learning outcomes, these characteristics could not fully explain actual gains in student understanding or ability (Hill et al., 2007).

In the late 1970's, the process-product research turned to focus on what teachers did in the classroom, rather than on teacher characteristics. At this time, researchers focused on teacher actions, such as pacing of the lesson, or number of questions posed to students. While some of these teacher actions did, in fact, correlate with measures of student learning, critiques of this research are that: student learning was defined in terms of memorization and facility with procedures; the research was over-reliant on correlational relationships; and - perhaps most significantly - the research largely ignored the role of mathematical content (as summarized in Hill, Rowan, \& Ball, 2005).

In the 1980 's, researchers moved away from conducting process-product studies, towards: (1) looking at the knowledge needed to teach mathematics well (Shulman, 1986), and/or (2) exploring teaching techniques inspired by constructivist perspectives on learning. These two lines of research independently served as foundations for the development of new classroom observation instruments.

Modern Classroom Observation Instruments. Mathematics-specific classroom observation instruments vary widely in their theoretical groundings and 
intended foci (LMT, 2011). In Table 2, I summarize each available ${ }^{3}$ modern classroom observation instrument that is both research-affiliated and mathematicsspecific. What is important to notice about this collection of modern mathematicsspecific observational instruments, is that none explicitly measures the construct that Ball, Hill, and their colleagues defined as the $M Q I$ - that is, the nature of the mathematics available to students during instruction (LMT, 2011). While some instruments include aspects of MQI (e.g., the RTOP instrument attends to the accuracy of content presented by the teacher), most, instead, focus on particular pedagogical practices thought to encourage student learning. Further, none measure and quantify the MQI of a lesson as a separate feature of instruction, which is what motivated the development of the MQI instrument.

Table 2 Summaries of Modern Research-Based Mathematics-Specific Classroom Observation Instruments

Inside the Classroom Observation and Analytic Protocol. The Inside the Classroom Observation and Analytic Protocol (Horizon Research, 2000) is an extensive measure with both qualitative and quantitative components, designed to measure the quality of a K-12 science or math lesson by attending to the design, implementation, mathematics/science content, and classroom culture of a lesson. The term quality is conceptualized in reference to a reform-based or standards-based perspective, the protocol Examples of quantitative items on the protocol, which are rated on a five-point Likert scale, include: "the teacher's classroom management style/strategies enhanced the quality of the lesson," and "the teacher displayed an understanding of math/science concepts" (Horizon Research, 2000).

The Reformed Teaching Observation Protocol (RTOP). The RTOP is a well-validated quantitative observational tool designed to measure the degree to which mathematics or science instruction is reform-based. The RTOP consists of 25

${ }^{3}$ To find instruments, I conducted searches of published literature, database searches, internet searches, and I also asked for word-of-mouth recommendations. That said, it is still possible that there are more out there that I have missed. 
items, grouped into five categories: lesson design and implementation, content: propositional pedagogic knowledge, content: procedural pedagogic knowledge, classroom culture: communicative interactions, and classroom culture: student/teacher relationships. Classroom observers use a five-point Likert scale to code items such as, "connections with other content disciplines and/or real world phenomena were explored and valued," or, "students were actively engaged in thought-provoking activity that often involved the critical assessment of procedures" (Sawada \& Pilburn, 2000).

The Comprehensive Mathematics Instruction Framework (CMI). The CMI is a qualitative framework that is focused on reform-based pedagogical practices (Hendrickson, Hilton, \& Bahr, 2007). The framework conceptualizes mathematics instruction as consisting of three components: The teaching cycle, the learning cycle, and a continuum of mathematical understanding. A teacher or lesson observer can use the framework before, during, or after a lesson, with the goal of developing the teacher's skill with implementing particular instructional strategies that - according to the authors of the framework - promote the deepening of students' understanding. For example, the teaching cycle component promotes pedagogy that aligns with a launch-explore-discuss format. Iterations of the teaching cycle occur within a larger learning cycle. Concurrently, the continuum of mathematical understanding component of the framework encourages teachers to conceptualize students' mental images of concepts using a develop-solidify-practice model.

Instructional Quality Assessment for Academic Rigor in Mathematics Lessons and Assignments (IQA-AR). Drawing on research on levels of cognitive demand and cognitive processes, the IQR-AR (Boston \& Wolf, 2004) focuses on four dimensions - for either a given mathematics lesson or a mathematics assignment designed to evaluate students' opportunities to learn mathematics with understanding. The four dimensions are: potential of the task, implementation of the task, student discussion or students' written responses, and teachers' expectations. This quantitative instrument asks raters to assign each dimension a level of zero through four, with four corresponding to the highest cognitive demand.

The Classroom Observation Instrument (COI). The COI was developed as a way to capture the level of cognitive demand of a mathematical task as it is enacted in a classroom (Henningsen \& Stein, 1997). The COI includes nineteen categorical codes grouped into four main dimensions. The first dimension is descriptive, which includes codes about the mathematical features of the task and the number of in-class minutes spent on the task. The second dimension is set-up, which includes codes pertaining to the launch of the task and subsequent guidance the teacher provided to students regarding their approach to the task. The third dimension is implementation, which captures the level of cognitive engagement of students during the task. Finally, the fourth dimension of the COI captures factors that seemed to influence the level of cognitive demand of the task as it was enacted. 
Student Questioning Categories. Walter and Maher (2002) introduce a framework for categorizing the questions that students pose during in-class student-to-student discourse. Types of student questions in this framework are: interrogative, attunement, procedural, confirmative, speculative, and rhetorical.

\section{Oregon Mathematics Leadership Institute (OMLI) Classroom}

Observation Protocol. The OMLI Classroom Observation protocol (Weaver et al., 2002) is a tool for capturing the quality and quantities of discourse during a mathematics lesson. For the OMLI research study in particular, the tool was used to document evidence of mathematical discourse that indicated the level of students' engagement in thinking about mathematical concepts or procedures. The instrument asks observers to apply categorical codes to the following aspects of student mathematical discourse: episode type (large group, pairs/small group, or individual), and the mode, type, and tools of discourse. Observers also tally the number of incidences of mathematical discourse during an episode and write brief narrative descriptions of the episode. Additionally, observers complete a thorough observation summary, and optional pre- and post-lesson interviews with the teacher.

The MQI Instrument was developed by Heather Hill and her research group, to respond to the critical need for an observational instrument that measures the mathematical quality of instruction, specifically, as a separate and independent construct from pedagogical strategies or instructional styles (LMT, 2011). Hill and her LMT colleagues distinguish between the classroom interactions surrounding the mathematical content of instruction, and considerations of how mathematics should be taught, with the MQI exclusively measuring the former. The MQI Instrument does not, for example, attend to: teachers' questioning strategies, whether students are working together in groups, or the teacher's level of enthusiasm. Instead, the MQI focuses solely on the quality of the mathematical content available to students during instruction - such as the presence of sound mathematical reasoning and the 
absence of unmitigated mathematical errors - and is the first formal observational instrument to do so.

Moreover, the MQI has two additional features that distinguish it from similar observational instruments (e.g., Rowland, Huckstep, \& Twaites, 2005). First, the MQI is entirely quantitative. Second, the MQI focuses on the mathematical quality of instruction - which is broader than a focus on the mathematical quality of teaching or teachers. The items of the MQI capture various interactions between these, with the intent of capturing the mathematical quality of all aspects of classroom instruction. Each of the four dimensions of the MQI instrument pertain to a particular leg of Cohen, Raudenbush, and Ball's (2003) model of instruction as interaction (see Figure 2).

Dimensions of the MQI instrument. In order to develop the conceptual framework and corresponding dimensions of the MQI, Hill and her colleagues drew upon three sources: the researchers' personal experiences teaching mathematics, studying the teaching of mathematics, and mathematics teacher education; videotapes of 90 second through eighth grade mathematics lessons (nine lessons of from each of ten teachers); and existing research literature on MKT (The Mathematics for Teaching Project, 2011). Over a two-year, iterative process that cycled between broad and fine-grained analyses, the research group articulated, revised, and refined dimensions of the MQI and groupings of particular items within those dimensions. They used rigorous quantitative psychometric analyses to ensure that items and dimensions measured what they were intended to measure and measured it well. 
The MQI Instrument ${ }^{4}$ consists of four dimensions, each with multiple subdimensions (i.e., codes) that are scored as Not Present, Low, Mid, or High at the conclusion of every few (e.g., five) minutes of instruction. The four dimensions are: Richness of the Mathematics, Working with Students and Mathematics, Common Core Student Practices, and Precision and Focus on Mathematics. The codes that comprise each dimension are summarized in Table 3. Further, an excerpt of the MQI instrument appears in Appendix A.

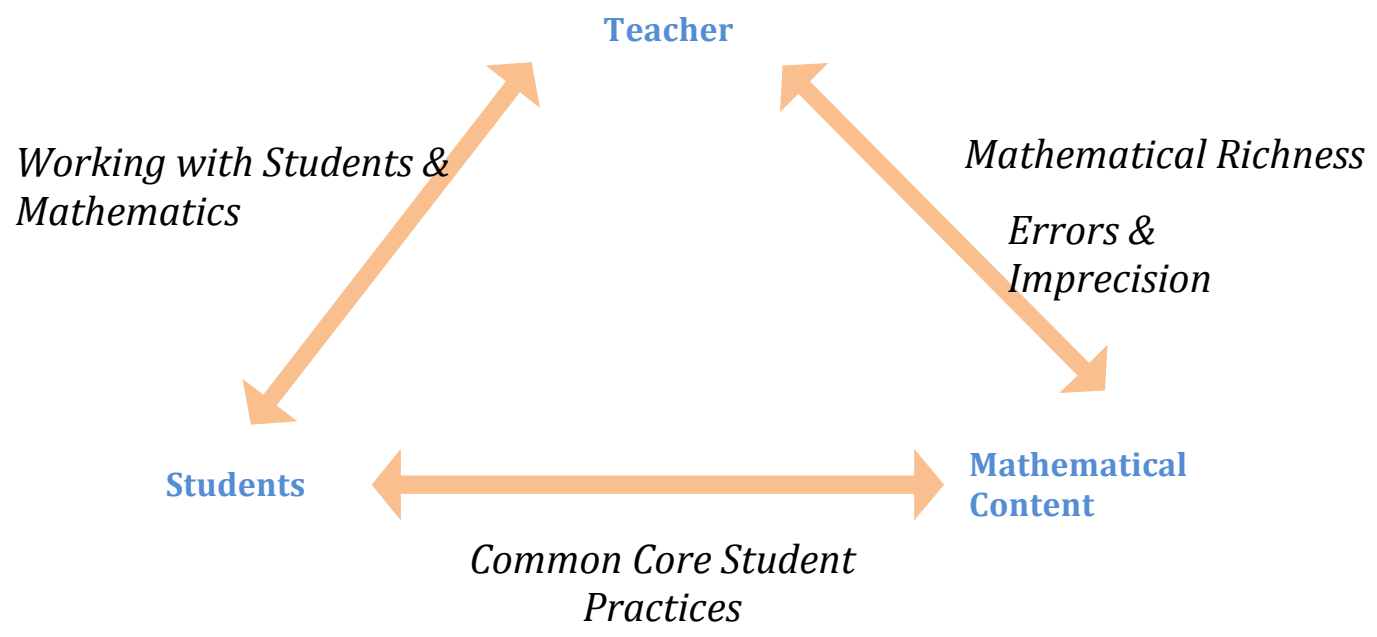

Figure 2. The four dimensions of the MQI instrument shown on Cohen, Raudenbush, and Ball's (2003) model of instruction as interaction

Table 3

Mathematical Quality of Instruction Dimensions and Items (MQI PD instrument 2014)

${ }^{4}$ There are multiple versions and iterations of the MQI instrument. For the purposes of this proposal, I am focusing specifically on the August 2014 version of the MQI for PD. The dimensions and codes of this version are a subset of the dimensions and codes of the full MQI instrument for research, and they were determined as a result of a pilot PD study with teachers in 2012-2013. 
Richness of the mathematics: This dimension attempts to capture the depth of the mathematics offered to students. This dimension consists of the following items:

- Linking and Connections: Linking and connecting mathematical representations, ideas, and procedures

- Explanations and Mathematical Sense-Making: Giving mathematical meaning to ideas, procedures, steps, or solution methods.

- Multiple Procedures or Solution Methods: Considering multiple solution methods or procedures for a single problem.

- Mathematical Language. Using dense and precise language fluently and consistently during the lesson.

Working with Students and Mathematics: This dimension captures whether teachers seem to understand and respond to students' mathematical contributions (utterances or written work) or mathematical errors. This dimension consists of the following items:

- Remediation of Student Errors and Difficulties: Instances of remediation in which student misconceptions and difficulties with the content are substantially addressed.

- Teacher Uses Student Mathematical Contributions: Instances where the teacher responds to students' mathematical contributions during instruction in mathematical appropriate ways, such as identifying mathematical insights in specific student questions, comments, or work; building instruction on student ideas or methods.

Common Core Student Practices: This dimension is intended to capture evidence of students' involvement in doing mathematics.

- Student Engagement in Mathematical Practices: Students' engagement in mathematical practices, including explaining their reasoning, conjecturing, asking a mathematical question, pattern noticing, commenting on another student's work, and/or expressing a mathematical thought.

- Enacted Task Cognitive Activation: The amount of mathematical invention, explanation, connection-forging, and so on, that students $d o$.

- Students Work with Contextualized Problems: The way in which students work with contextualized problems - in particular, how much independent student thinking versus teacher scaffolding occurs during this time.

Precision and Focus on Mathematics: This dimension is intended to address precision by capturing teachers' mathematical errors, lack of clarity, and imprecision when presenting mathematics and the degree to which classroom works focuses on mathematics.

- Error, Imprecision, and Lack of Clarity: The level of accuracy, precision, and clarity in the presentation of the mathematical content.

- Focus on Mathematics: The extent to which the focus of classroom activity is on mathematical content 


\section{MQI's Relevance and Importance}

Since the formal development of the MQI as a measurable construct, research has supported the notion that the MQI is associated with student learning outcomes. Although this relationship has yet to be empirically demonstrated with a large quantitative study, a substantial collection of studies suggest the relationship between the MQI and student achievement by demonstrating links between a teacher's MKT and the MQI of the teacher's instruction, and between the teacher's MKT and gains in the teacher's students' mathematical achievement (Charalambous et al., 2012; Hill et al., 2007; Hill \& Charalambous, 2012; Hill et al., 2008; Hill et al., 2005; Hill et al., 2012; Lewis \& Blunk, 2012). I review the research supporting each of these links, below.

First, there is strong empirical evidence suggesting that the MQI in a teacher's classroom is correlated with her MKT (Charalambous et al, 2012; Hill, et al., 2007; Hill \& Charalambous, 2012; Hill, et al, 2008; Hill et al., 2012; Lewis \& Blunk, 2012). Specifically, the higher a teacher's score on a paper-and-pencil measure of her MKT is, the more likely she is to implement instruction that scores higher on the overall MQI. Although mediating factors, such as access to supportive curricular materials (Charalambous et al., 2012; Hill \& Charalambous, 2012) or a teacher's beliefs about how mathematics should be taught (Hill et al., 2008), attenuate this relationship, the MKT-MQI correlation has been shown to be statistically significant in multiple studies across a diverse set of teachers and schools (Hill, Ball, Blunk, Goffney, \& Rowan, 2007; Hill, Charalambous, Lewis, Phelps, 
Sleep, \& Ball, 2008; Hill, Umland, Litke, \& Kapitula, 2012). Qualitative studies also support the MKT-MQI relationship, identifying instances in which teachers with stronger MKT implement lessons with greater mathematical richness, have better skill responding to students and using students' contributions to move a lesson towards a clear mathematical goal; and make fewer mathematical errors during instruction, as compared to their counterparts with weaker MKT (Hill et al., 2008; Charalambous et al., 2012; Lewis \& Blunk, 2012).

An equally compelling body of research suggests a correlation between MKT and gains in student achievement (Hill et al., 2005; Hill et al., 2012). In their study of 334 first grade teachers and 365 third grade teachers, Hill, Rowan, and Ball (2005) found a statistically significant correlation between a teacher's MKT score and her students' achievement gains on a standardized assessment. Hill and colleagues' (2012) study of 24 middle school teachers and ten elementary school teachers also found a correlation between a teacher's MKT and student achievement gains, as measured by students' performances on state assessments.

Given these associations, it is highly probable that the MQI students experience in the classroom is positively correlated with gains in their achievement. Indeed, Hill and her colleagues (2007) conclude that features captured by the MQI, such as the reduced number of errors, along with the increased number of instances of mathematical richness, justifications, reasoning, and meaning-making, which characterize the instruction in a high-MKT teacher's classroom, have a direct impact on student learning.

\section{Mathematics Teachers' Noticing}


In my research, I will be examining teachers' understanding of the MQI as a feature of instruction through the lens of their noticing. Thus, in this section, I introduce the field of study of teachers' noticing, and I present a review of research on mathematics teachers' noticing, in particular.

In order to make sense of any complex situation, humans naturally attend to certain features of the situation and filter out the rest (Simons, 2000). In the context of teaching a classroom of children, teachers engage in a form of professional noticing (Goodwin, 1994; Mason, 2002): the teaching-specific act of focusing on certain features of the complex classroom environment. Understanding teachers' noticing is important because what teachers notice is the basis for what they act on, and make adjustments for, both within a lesson and in subsequent lessons (Schoenfeld, 2011).

Focusing on mathematics teaching specifically, Sherin, Jacobs and Philipp (2011) introduce their book on mathematics teacher noticing by linking noticing to current reform efforts in mathematics education. In particular, they link teacher noticing to current efforts that call for adaptive and responsive teaching, which requires that teachers notice students' thinking, relate students' thinking to mathematical objectives of the lesson, and decide how to proceed based on this. Sherin, Jacobs, and Philipp also point out the role of teacher noticing in decomposing practice. Citing the current movement in mathematics education research that calls for decomposing mathematics teaching into core activities (e.g., Ball \& Cohen, 1999; Lampert, 2001; NCTM, 2014), the authors situate noticing as one such core activity 
of teaching mathematics. Thus, understanding mathematics teachers' noticing is a productive line of research inquiry.

In light of this, researchers have explored changes in mathematics teachers' noticing over time. Recent research suggests that teachers and prospective teachers can strengthen their noticing of particular aspects of instruction (e.g., Jacobs, Lamb, Philipp, \& Schappelle, 2011; Sherin \& van Es, 2005, 2009; Star \& Strickland, 2007; Star, Lynch, \& Perova., 2011; van Es \& Sherin, 2002, 2006, 2008). For example, Jacobs and her colleagues (2011) have studied the development of teachers' professional noticing of children's mathematical thinking. Using a cross-sectional design, they compared the noticing of a group of prospective teachers, and three groups of practicing teachers who had completed differing amounts of PD focused on children's mathematical thinking. Their study revealed patterns of change in teachers' attending to children's strategies, and deciding how to respond on the basis of children's understanding. Further, their results suggest that teachers' noticing can change with respect to noticing particular aspects of mathematics instruction through focused PD.

Likewise, van Es and Sherin, who have done extensive work using video as a setting for PD (Sherin \& van Es, 2005, 2009; van Es, 2011; van Es \& Sherin, 2002, $2006,2008)$, have documented shifts in teachers' noticing over the course of videobased PD. For example, van Es' (2011) study resulted in the development of a framework that reflects the trajectory of groups of teachers' noticing children's mathematical thinking. The framework includes two central components - What Teachers Notice and How Teachers Notice - each of which have two sub-components. 
What Teachers Notice includes to whom the teachers attend and the topic of their analysis. How Teachers Notice includes the teachers' analytic stance and their depth of analysis. The entirety of van Es' framework of teachers' noticing of children's mathematical thinking according to these components is shown in Figure 3.

\begin{tabular}{|c|c|c|c|c|}
\hline & $\begin{array}{l}\text { Level } 1 \\
\text { Baseline }\end{array}$ & $\begin{array}{l}\text { Level } 2 \\
\text { Mixed }\end{array}$ & $\begin{array}{l}\text { Level } 3 \\
\text { Focused }\end{array}$ & $\begin{array}{l}\text { Level } 4 \\
\text { Extended }\end{array}$ \\
\hline $\begin{array}{l}\text { What Teachers } \\
\text { Notice }\end{array}$ & $\begin{array}{l}\text { Attend to whole } \\
\text { class } \\
\text { environment, } \\
\text { behavior, and } \\
\text { learning, and to } \\
\text { teacher pedagogy. }\end{array}$ & $\begin{array}{l}\text { Primarily attend } \\
\text { to teacher } \\
\text { pedagogy. } \\
\text { Begin to attend to } \\
\text { particular } \\
\text { students' } \\
\text { mathematical } \\
\text { thinking and } \\
\text { behaviors. }\end{array}$ & $\begin{array}{l}\text { Attend to } \\
\text { particular } \\
\text { students' } \\
\text { mathematical } \\
\text { thinking. }\end{array}$ & $\begin{array}{l}\text { Attend to the } \\
\text { relationship } \\
\text { between } \\
\text { particular } \\
\text { students' } \\
\text { mathematical } \\
\text { thinking and } \\
\text { between teaching } \\
\text { strategies and } \\
\text { student } \\
\text { mathematical } \\
\text { thinking. }\end{array}$ \\
\hline $\begin{array}{l}\text { How Teachers } \\
\text { Notice }\end{array}$ & $\begin{array}{l}\text { Form general } \\
\text { impressions of } \\
\text { what occurred. } \\
\text { Provide } \\
\text { descriptive and } \\
\text { evaluative } \\
\text { comments. } \\
\text { Provide little or } \\
\text { no evidence to } \\
\text { support analyses. }\end{array}$ & $\begin{array}{l}\text { Form general } \\
\text { impressions and } \\
\text { highlight } \\
\text { noteworthy } \\
\text { events. } \\
\text { Provide primarily } \\
\text { evaluative with } \\
\text { some interpretive } \\
\text { comments. } \\
\text { Begin to refer to } \\
\text { specific events } \\
\text { and interactions } \\
\text { as evidence. }\end{array}$ & $\begin{array}{l}\text { Highlight } \\
\text { noteworthy } \\
\text { events. } \\
\text { Provide } \\
\text { interpretive } \\
\text { comments. } \\
\text { Refer to specific } \\
\text { events and } \\
\text { interactions as } \\
\text { evidence. } \\
\text { Elaborate on } \\
\text { events and } \\
\text { interactions. }\end{array}$ & $\begin{array}{l}\text { Highlight } \\
\text { noteworthy } \\
\text { events. } \\
\text { Provide } \\
\text { interpretive } \\
\text { comments. } \\
\text { Refer to specific } \\
\text { events and } \\
\text { interactions as } \\
\text { evidence. } \\
\text { Elaborate on } \\
\text { events and } \\
\text { interactions. } \\
\text { Make connections } \\
\text { between events } \\
\text { and principles of } \\
\text { teaching and } \\
\text { learning. } \\
\text { On the basis of } \\
\text { interpretations, } \\
\text { propose } \\
\text { alternative } \\
\text { pedagogical } \\
\text { strategies. }\end{array}$ \\
\hline
\end{tabular}


Figure 3. van Es' (2011) developmental framework for groups of teachers' learning to notice children's mathematical thinking

In light of these and other encouraging findings regarding mathematics teachers' noticing, it is reasonable to assume that teachers could also strengthen their noticing of MQI-specific features of mathematics instruction through focused, supportive PD. (Characteristics of such PD are discussed later in this section.) There is existing research on: shifts in secondary pre-service teachers' noticing of mathematics during a teaching methods course (Star \& Strickland, 2007; Star et al., 2011); development of practicing teachers' noticing of mathematical features of children's thinking (e.g., Jacobs et al., 2011; Goldsmith \& Seago, 2011; van Es, 2011); and children's noticing of mathematics during a mathematics lesson (Lobato, 2014). However, a study of intermediate and middle grades (three through eight) mathematics teachers' development of MQI-specific noticing skills has yet to be conducted, despite the well-established importance of the MQI. Accordingly, little is known about what different levels of MQI-specific noticing might look like, and what paths shifts in noticing might take, either for individual teachers or for groups of teachers participating together in an MQI-focused PD program.

\section{Mathematics PD}

In the above sections I discussed research in the fields of MQI and of mathematics teacher noticing in anticipation of introducing my research on teachers' noticing of MQI-related features of instruction. Before stating the first research questions of my study on MQI-related noticing, though, I will first present a 
discussion of research pertaining to mathematics in order to highlight the ways in which research supports the design of the MQI-based PD program my participants went through during my study.

In the past few decades, much of mathematics teacher PD has been characteristic of the traditional training model (Ball \& Cohen, 1999; Little, 1993; Smith, 2001). In this model, teachers are introduced to skills or instructional practices (e.g., methods for organizing group work, or use of manipulatives in instruction) that they are then expected to directly transfer into their classrooms (Little, 1993). Such training often approaches teaching as a routine and technical activity, with the content of the training designed to be a dissemination of information for teachers to add on to their existing repertoires for teaching (Ball \& Cohen, 1999; Smith, 2001).

Further, teachers' PD experiences in the traditional training model are often fragmented into a disconnected, decontextualized sequence of one-time workshops. Indeed, approximately $90 \%$ of teachers in the US report that their PD experiences consist primarily of short-term workshops (Wei, Darling-Hammond, Andree, Richardson, \& Orphanos, 2009). The result, some claim, is "the professional equivalent of yo-yo dieting," or "hit-and-run professional development," lacking a sustained, transformative curriculum for a teacher's continued professional learning (Ball \& Cohen, 1999, p. 4; Loucks-Horsley et al., 2009, p. 8; Smith, 2001).

Many in the PD and educational research communities have critiqued the status quo of mathematics PD, calling for major shifts in design and implementation 
(e.g., Ball \& Cohen, 1999; Hiebert \& Morris, 2012; Little, 1993; Loucks-Horsley et al., 2009; Smith, 2001). A key argument against the prevailing training model is that it is de-contextualized, disconnected, and un-sustained nature wholly fails to take into account at least three fundamentals of modern perspectives on K-12 education: (1) the complexity of facilitating the type of interactive, student-centered, social learning environments called for by recent reforms (Loucks-Horsley et al., 2009; Smith, 2001); (2) the need for teachers' in-depth examination of their core beliefs about teaching in order to truly improve their teaching (Philipp, 2007; Smith, 2001); and (3) the need for teachers to push the field forward, collectively, as groups of professionals (Hiebert \& Morris, 2012).

To address these shortcomings, there are calls for PD to be collaborative, teacher-centered, and inquiry-oriented (e,g,, Cohen \& Ball, 1999; Hiebert \& Morris, 2012; Little, 1993; Smith, 2001; Stigler \& Hiebert, 2004; Wei, Darling-Hammond, \& Adamson, 2010). In contrast to lecture-style information-dissemination-style PD, sessions should be modeled after the type of instruction that teachers are expected to enact (Loucks-Horsley et al., 2009). Little (1993) argued that "the most promising forms of professional development engage teachers in the pursuit of genuine questions, problems, and curiosities, over time in ways that leave a mark on perspectives, policy, and practice" (p. 133). Thus, mathematics PD should be rooted in the goal of developing teachers' perspectives of sustained inquiry into the practice of teaching. In this way, teaching is problematized as a complex social activity, embedded in specific contexts, and implications for changes in teachers' 
practice result from their collective and long-term examination into the details of practice - both their own and their colleagues' (Borko et al., 2008; Hiebert \& Morris, 2012; Smith, 2001; Stigler \& Hiebert, 2004).

A related recommendation is that mathematics PD should be practice-based and grounded in artifacts of practice, such as classroom video recordings or student work samples (Borko et al., 2008; Cohen \& Ball, 1999; Loucks-Horsley et al., 2009; Stigler \& Hiebert, 2004). In 1999, Cohen and Ball made a powerful argument that "practice cannot be wholly equipped by some well-considered body of knowledge," and instead, "teaching occurs in particulars...learned in and from practice" (p. 10). As such, artifacts from real practice should be the focus of teachers' analyses during PD. And there is evidence to suggest that PD grounded in artifacts of practice improves teacher learning (e.g., Borko et al., 2008; Kazemi \& Franke, 2004). For example, results from Borko and colleagues' (2008) study of a two-year video-based mathematics PD program were that teachers' discussions became more productive over the course of the PD. Accordingly, the authors suggest that classroom video can be an effective tool for increasing the focus and depth of teachers' discussions pertaining to the teaching and learning of mathematics. Further, research on the well-known Cognitively Guided Instruction (CGI) PD program, in which early grades teachers are engaged in analyzing artifacts of children's mathematical thinking and its development, lends further support to the idea that teachers' collective inquiry into artifacts of practice is an effective approach to PD. In particular, Kazemi and Franke (2004) found that the teachers in their study exhibited changing roles and 
identities, and explored new ways of teaching, as they went through a CGI PD program. A long-term follow-up with a different cohort of CGI teachers provide evidence to suggest that there was lasting impact on the teachers' practices, partially because the program had trained teachers to continually study their own students' thinking and then make changes and improvements to their teaching, accordingly (Franke, Carpenter, Levi \& Fennema, 2001).

Quantitative research results offer further support for the above recommendations that mathematics PD be collaborative, inquiry-oriented, practicebased, and grounded in artifacts of practice, in addition to the recommendations that it should be centered on specific content, intensive and sustained over a significant period of time, and coherent with existing school and district policies (Bell, Wilson, Higgins \& McCoach 2010; Birman, Desimone, Porter \& Garet, 2000; Desimone, Porter, Garet, Yoon \& Birman, 2002; Garet, Porter, Desimone, Birman, \& Yoon 2001; Wei et al., 2010). Results from Desimone and colleagues' studies of hundreds' of teachers' experiences in PD lend statistically-based support to the reform movement in mathematics PD - away from one-stop, add-on informative workshops, and towards models that engage teachers in a meaningful, long-term, inquiry-oriented curriculum of collectively exploring and improving their practice as professionals. Further, Bell and Colleagues' (2010) results from the quantitative study of the nationally disseminated Developing Mathematical Ideas (DMI) PD program found that the practice-based, long-term DMI program produced 
statistically significant gains in teachers' MKT and other measures of teacher knowledge, as compared with a control group.

With the goal of improving teachers' perceptions and noticing of mathematically significant features of instruction, researchers Hill, Beisiegel, and Mitchell have designed an MQI-centered PD program for intermediate and middle grades teachers. Past research suggests that alignment and coherence between the PD that teachers receive and other improvement efforts in teachers' schools and districts (e.g., formal feedback from classroom observers, policy initiatives) boosts the likelihood of stronger results from these improvement efforts (Cohen \& Hill, 2001; Garet et al., 2001). The MQI PD program is in line with this research in that it is a mathematics-specific PD program that is directly aligned with a particular classroom observation tool (Hill, Beisiegel, \& Mitchell, 2012).

Additional features of the MQI PD program are well-aligned with abovementioned research results and corresponding recommendations. For example, in the sessions of the program, teachers are first trained to code classroom video clips with the MQI in an intensive two-day-long training session. From there, teachers meet (along with a PD facilitator) for a total of 20 hours over the course of ten weeks, coding and discussing classroom video clips, as well as exploring implications for their own practice. During the sessions, teachers are not told what the "right" scores are for each clip; instead, the discussions and coding are teachercentered and rooted in their developing ideas and understandings of the MQI and the video clips. In this way, the MQI PD program is inquiry-oriented, practice-based, 
grounded in video artifacts of practice, collaborative, moderately sustained (with nearly 30 hours of engagement). Thus, the MQI PD is well-aligned with modern recommendations and research on effective mathematics PD.

Hill, Beisiegel, and Mitchell's current investigations into the effectiveness of their MQI PD program also include program design variations, such as teacher-led versus facilitator-led sessions and the source of videos analyzed during the sessions (stock footage versus videos from teachers' own classrooms), which will provide further insight into effective elements of PD. Hill and colleagues (2013) have previously made a convincing argument that rigorous comparisons of PD program design features are urgently needed in the field of PD research, even when the PD is being implemented on a relatively small scale.

All variations of the MQI PD program are video-based, combining elements of video club PD and lesson analysis PD. The lesson analysis design for PD entails teachers watching lessons - or parts of lessons - from a video library and analyzing those lessons using a particular analytic lens. Research supports the notion that a lesson analysis design for PD can promote teacher learning (Santagata \& Angelici, 2010; Santagata, Zannoni, \& Stigler, 2007). For example, teachers in Santagata Zannoni, and Stigler's (2007) lesson analysis PD developed in their abilities to understand children's mathematical thinking and reflect critically on the mathematical content being taught. Santagata and Angelici (2010) also found that lesson analysis was effective in facilitating preservice teachers' learning to elaborate on what they observe during video clips of mathematics teaching; to propose 
alternative teaching strategies; and provide evidence from the video clip to support their evaluations of the instruction.

Video club PD programs, in which the teachers' watch videos of their own instruction, have also been shown to promote teachers' professional learning. Specifically, Borko and her colleagues (2008) found that when teachers in a video club setting had conversations focused on carefully selected video clips, and with a specific analytic focus, the teachers learned about new pedagogical strategies, gained a deeper appreciation for students' capacities for mathematical reasoning, and realized that all teachers in the group struggled with similar issues. Sherin and van Es' research on teachers' learning in a video club PD setting has focused on teachers' learning to notice, interpret, and base instruction on children's mathematical thinking. For example, findings of van Es and Sherin's (2008) study of teachers' noticing of students' mathematical thinking in a year-long video club PD suggest that the video club can help teachers increase in their capacity to attend to students' mathematical thinking - progressing from initial dismissal of students' thinking toward focused in-depth analyses of students' thinking - over the course of the year of PD. Sherin and van Es (2009) observed similar developments in teachers' in-the-moment noticing and use of students' mathematical thinking, during their instruction.

Because the MQI observational instrument is specifically designed for capturing features of video recordings of instruction, it is a natural fit with videobased PD designs. The research described above lends support to the notion that teachers could learn to incorporate the MQI into their conceptualizations of high- 
quality mathematics instruction and learn to notice MQI-related features of instruction, via a video-based PD program. However, because Hill, Beisiegel and Mitchell's PD is the first to be based on the MQI - and the first mathematics-specific PD program to be based on a classroom observation instrument - teachers' learning has yet to be explored in this context. Specifically, the paths characterize the shape of individual teachers' learning about MQI-related features of instruction remains wholly unstudied.

\section{Call for the First Research Question}

In this chapter, I have reviewed the existing body of research on: the MQI and its corresponding classroom observation instrument, mathematics teacher noticing, and mathematics teacher PD. Taken together, my review of these branches of research lend support for the ideas that: the MQI is an important feature of classroom mathematics instruction, particularly in light the research supporting the relationships between the MQI, MKT, and student learning outcomes; if we want teachers to improve aspects of their teaching related to the MQI, though, they first need to notice MQI-related features of instruction, and there is evidence to suggest that such noticing could be strengthened through focused PD; and lastly, given what is known about characteristics of successful PD programs, shifts in teachers' MQIrelated noticing might be supported via the MQI PD program.

Whether teachers' noticing of MQI-related features actually shifts during the course of a video-based MQI PD program has remained unstudied prior to my research. More foundationally, it was previously unknown whether and how different levels of teachers' MQI-related noticing could be defined and characterized 
in order to identify such shifts. My study begins to address these gaps, specifically by examining the following question: (1) How do individual teachers' noticing of MQIrelated features of instruction shift as they go through an MQI-focused professional development program?

\section{Teachers' Noticing of Students' Mathematical Practices}

My second research question addresses an aspect of MQI Noticing that is more narrow than for the first question: teachers' noticing of students' mathematical practices. Below, I present a review of literature that points to the importance of investigating teachers' noticing of students' mathematical practices during instruction. The review below focuses on students' mathematical practices in the context of the eight Common Core Math Practices (CC Math Practices, NGA \& CCSSO, 2010), which overlap with the student mathematical practices captured by the MQI. This overlap is detailed at the conclusion of this section.

The eight CC Math Practices (shown in Figure 4) are reflective of widely agreed-upon ways in which students need to engage with mathematics in order to learn. Developed based on the National Council for Teachers of Mathematics' (NCTM's) process standards (NCTM, 2000) and the National Research Council's strands of mathematical proficiency (Kilpatrick, Swafford, \& Findell, 2001), the CC Math Practices reflect well-supported notions of the ways in which students should be working with mathematics in the classroom in order to have the opportunity to learn mathematics well (e.g., NCTM, NCSM, ASSM, \& AMTE, 2010). 
Thus, K-12 teachers in the U.S. are tasked with facilitating classroom lessons that promote students' engagement in the CC Math Practices. Accordingly, they also need to gauge their level of success in doing so, and then make adjustments to instruction, both in-the-moment and in future lessons, based on their observations and conclusions about the degree to which their students actually engaged in CC Math Practices within the lesson. In this way, a teacher's ability to notice students' engagement in CC Math Practices is a critical skill.

There is emerging evidence to suggest that teachers struggle to interpret and unpack the meaning of the eight CC Math Practices themselves. For example, the elementary teachers in Stephens and Barlow's (2015) Summer PD institute wrestled with unpacking the meaning of Math Practice \#4: Modeling with Mathematics. Only after weeks of intentional work in the PD did teachers seem to be able to consistently understand the meaning of the phrase, "modeling with mathematics."

Apart from teachers' understandings of specific CC Math Practices, though, is the issue of what perspectives - that is, to what (or to whom) they attend, and how they interpret what they attend to - teachers bring to the task of identifying potential instances of students engaging in mathematical practices and gauging the success of a lesson with respect to students' engagement in these - and closely related - practices. My second research question, introduced in the next section, addresses this aspect of teachers' noticing.

\section{Common Core Standards for Mathematical Practice}




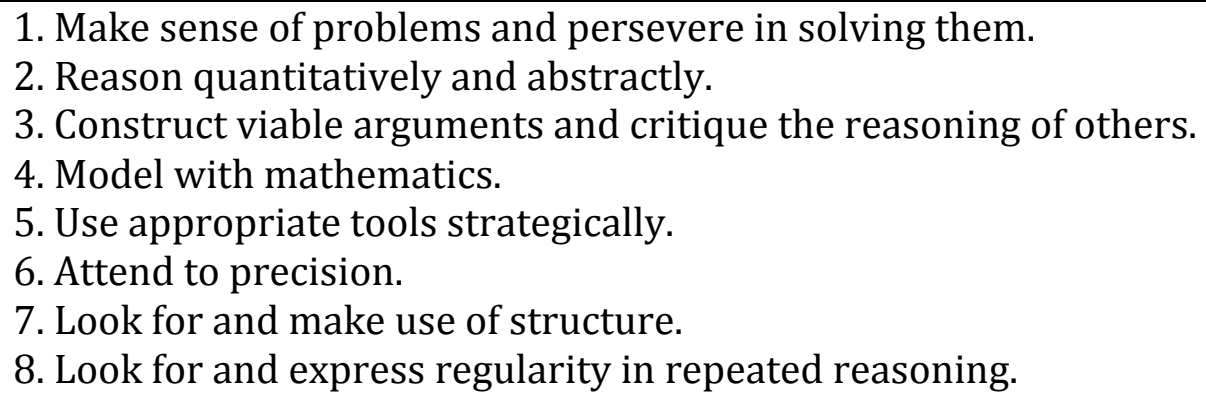

Figure 4. The eight Common Core Standards for Mathematical Practice (NGA \& CCSSO, 2010)

\section{Call for the Second Research Question}

In the section above, I highlighted the importance of teachers' noticing of CC Math Practices. These practices overlap with the student mathematical practices captured in the Student Engagement in Mathematical Practices (SEMP) and Enacted Task Cognitive Activation (ETCA) codes within the Common Core Student Practices dimension of the MQI instrument. The Venn diagram in Figure 5 shows the relationship between the CC Math Practices and the mathematical practices captured in these codes of the MQI instrument (MQI Math Practices) - specifically that MQI Math Practices and CC Math Practices both include CC Math Practices \#2, 3, $6,7, \& 8$, and part of \#1. The MQI Math Practices do not include CC Math Practices \#5 ("use appropriate tools strategically"), and part of \#1("persevere in [problem solving]") because students' engagement in these particular practices could arguably be enacted by students without reasoning about mathematical content. (And CC Math Practice \#4 is addressed in a different part of the MQI - not within the SEMP or ETCA codes.) 
My research analyzes the perspectives that teachers exhibit during discussions of students' MQI Math Practices, inclusive of the overlapping CC Math Practices. Thus, the above literature supporting the importance of studying teachers' noticing of CC Math Practices and the literature I reviewed supporting the importance of studying teachers' MQI-related noticing in general, together supports my study of teachers' noticing of students' math practices in the context of the scoring video clips with the MQI. 


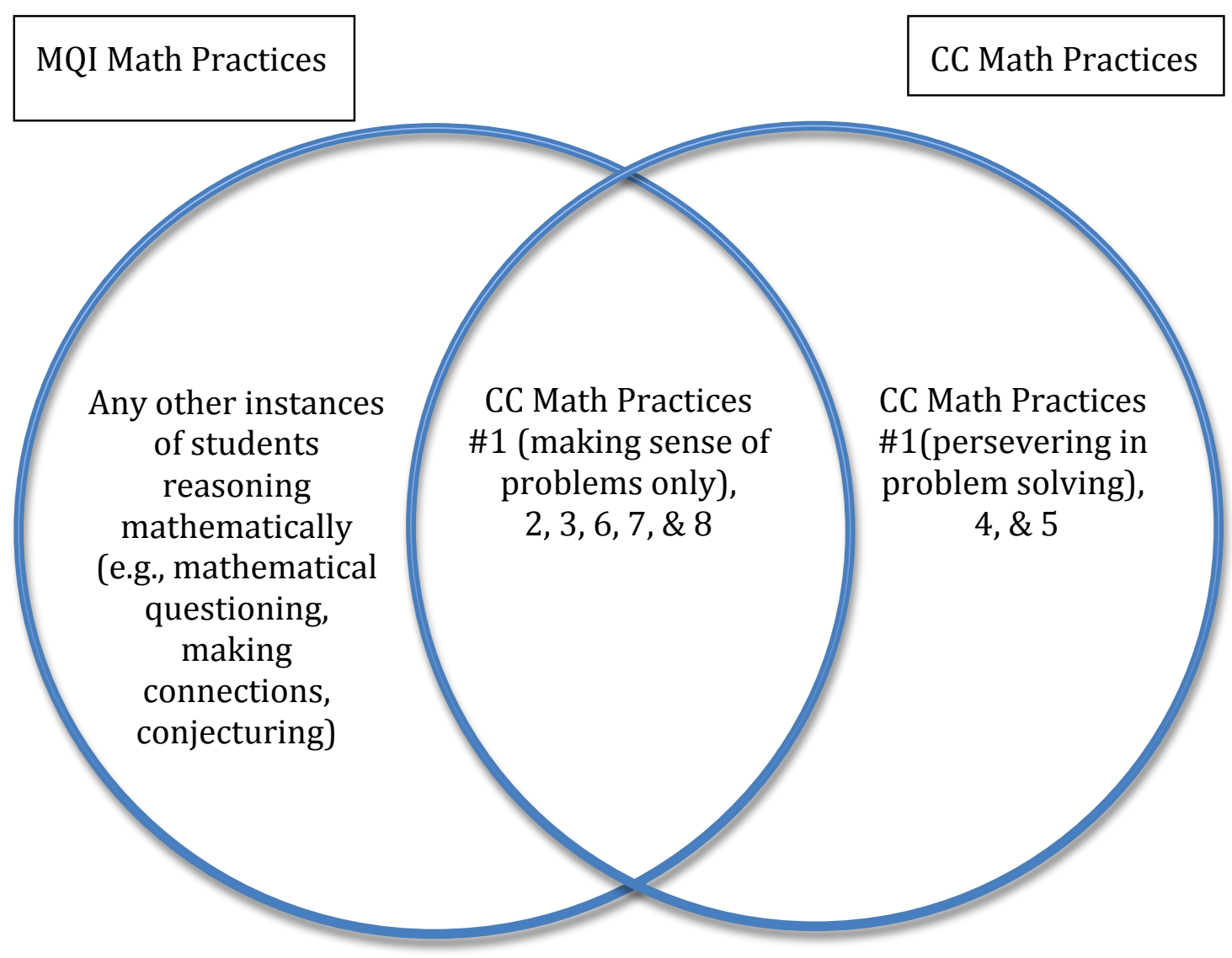

Figure 5. Venn diagram of the relationship between Common Core Mathematical Practices and the Math Practices in the MQI

Accordingly, I focus in on teachers' noticing of students' MQI Math Practices, specifically, by identifying and explication the approaches used by one group of MQI PD teachers as they discuss potential instances of students' engagement in any of the MQI Math Practices within video clips of instruction during the MQI PD sessions. Accordingly, my second research question is: How do teachers approach the task of noticing students' engagement in mathematical practices? 


\section{Summary of Research Questions}

The specific goals of my study are to build on recent teacher noticing literature to develop an MQI-based noticing framework that can be used to identify differences and changes in teachers' MQI Noticing; and to zoom in on one particular aspect of the MQI, instances of students' engagement in mathematical practices, uncovering the approaches of MQI PD teachers as they discuss potential instances of such practices. Correspondingly, the specific questions for my research are:

(1) How do individual teachers' noticing of MQI-related features of instruction shift as they go through an MQI-focused professional development program?

(2) How do teachers approach the task of noticing students' engagement in mathematical practices? 


\section{CHAPTER 3: RESEARCH METHODS I}

In this chapter, I describe the methodology I used to study teachers' noticing of MQI-related features of instruction. I begin this chapter by giving an overview of the larger setting in which my research took place. Then, I describe the theoretical perspectives that informed my study. I conclude this chapter with descriptions of the specific dataset, participants, and analyses performed in relation to my first research question. (Descriptions of the dataset, participants, and analyses for my second research question are given in a supplemental methods chapter: Chapter 5.)

\section{Overview of the Research Setting}

\section{Parent Study}

My research takes place in the context of a larger, ongoing study (referred to as "the parent study" from here on). Specifically, my research is situated within the parent study in the following ways: (1) all of the participants included in my analyses are simultaneously participants in the parent study, (2) accordingly, the PD implemented during the parent study is simultaneously the PD the participants in my study experienced, and (3) in my research, I analyzed some of the data collected as part of the parent study. Thus, it will aid the reader in fully understanding my methodology to first have a basic understanding of this overarching context.

The parent study is a multiyear NSF-funded project conducted by researchers Heather Hill at the Harvard Graduate School of Education, Mary Beisiegel at Oregon State University, and Rebecca Mitchell at Boston College. Their study aims to develop and test multiple versions (described below) of a PD program aligned with the MQI instrument (the MQI PD). 


\section{Description of the MQI PD}

Over the two-year course of data collection for the parent study, twelve groups of four-to-ten teachers each (with one exception - a group of seventeen teachers), of grades three through eight, engaged in an MQI-based professional development (MQI PD) program. As part of this PD, each group of teachers attended an intensive sixteen-hour Summer training seminar, during which they received focused training on how to code videos using the MQI instrument. Then, each group of teachers met, together with a facilitator, once per week for ten weeks in the Fall. Each Fall session was two hours in duration.

The developers of the MQI PD were careful to design the program such that its core features align with the findings and recommendations of research in PD. (Refer to Chapter 2 of this dissertation for a review.) Specifically, the PD is (1) designed to be an interactive and social experience for teachers; (2) focused on the core work of teaching mathematics through video case lesson analysis (introduced in Chapter 2 of this dissertation); and (3) it is anchored in a framework for analyzing instruction.

The content of the MQI PD is grounded in the dimensions and codes of the MQI Instrument (also introduced in Chapter 2 of this dissertation). Each activity within the PD sessions centers on one or two dimensions of the MQI Instrument. For example, sometimes MQI PD teachers watch a video clip together and then deliberate on scores for the clip on two dimensions of the MQI Instrument, with a think, pair, share discussion protocol. As another example, sometimes MQI PD 
teachers collaborate in pairs to plan a lesson that would be likely to score "high" on a particular code or dimension.

Description of Fall Sessions. All ten Fall sessions shared a consistent format: first, teachers worked on either a reflective question about the PD or a math warm-up question related to a classroom video clip to-be-coded that day; then they watched a video clip as a group; this was immediately followed by individual think time during which the teachers coded the video clip on two specified MQI dimensions, then pair-sharing time during which teachers discussed their codes with a partner, and lastly, whole group sharing time during which all teachers discussed their codes with each other. This sequence of activities usually then repeated with a second video clip and two MQI dimensions. The sessions typically concluded with a connection-to-practice activity. As a prototypical example of the contents of a Fall session, Figure 6 shows a detailed outline of the agenda for Week 4's session.

Fall sessions 1 and 2 differed from the other eight sessions, but only in that they were framed as review/refresher sessions since some weeks had elapsed since the initial Summer training. Following the same overall session format as above, Week 1 focused on reviewing the first two dimensions of the MQI Instrument (Mathematical Richness, and Working with Students and Mathematics), and Week 2 focused on reviewing the other two dimensions (Common Core Student Practices, and Precision and Focus on Mathematics). 


\begin{tabular}{|c|c|c|}
\hline Time & Activity & Preparation Notes \\
\hline $5 \mathrm{~min}$ & Welcome, Agenda & $\begin{array}{l}\text { Slides 1-2 } \\
\text { Facilitator welcomes everyone and shows agenda. }\end{array}$ \\
\hline $15 \mathrm{~min}$ & Warm up activity & $\begin{array}{l}\text { Slide } 3 \\
\text { Think-Pair-Share } \\
\text { How is the process of watching and coding lesson clips, influencing } \\
\text { how you think about your own instruction? Please give at least one } \\
\text { specific example. }\end{array}$ \\
\hline $3 \mathrm{~min}$ & Housekeeping & Slide 4 (if needed, use the norms slide (5-7) ) \\
\hline $22 \min$ & $\begin{array}{l}\text { Code and Discuss - } \\
\text { Elena: Series of } \\
\text { Books }\end{array}$ & $\begin{array}{l}\text { Slides 7-11 } \\
\begin{array}{l}\text { (1 min) Set up lesson } \\
\text { (4 min) Play clip. Encourage participants to text mark transcript } \\
\text { for utterances relevant to both codes. } \\
\text { (4 min) Think: Ask participants to use transcript and code } \\
\text { descriptions to justify score points for each code silently by } \\
\text { themselves. } \\
\text { (3 min) Pair: Ask participant to share justifications for each code } \\
\text { with partner. } \\
\text { (10 min) Share: See High/Low Facilitation notes in the power } \\
\text { point }\end{array}\end{array}$ \\
\hline $22 \min$ & $\begin{array}{l}\text { Code and Discuss - } \\
\text { Pamela: School } \\
\text { Fundraiser }\end{array}$ & 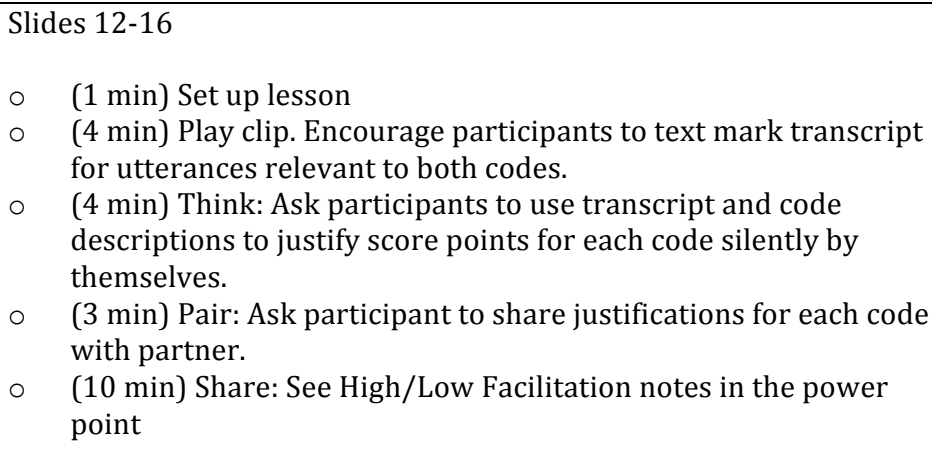 \\
\hline
\end{tabular}




\begin{tabular}{|c|c|c|}
\hline Time & Activity & Preparation Notes \\
\hline $50 \mathrm{~min}$ & $\begin{array}{l}\text { Connections to } \\
\text { Practice }\end{array}$ & $\begin{array}{l}\text { Slides } 18 \text { - } 20 \\
\text { Show Slide } 18 \text { ( } 2 \text { min) } \\
\text { Slide } 19 \text { ( } 20 \text { min) } \\
\text { In pairs or groups of three work on the task present. Create posters } \\
\text { How can you show that the commutative property holds } \\
\text { true for multiplication, but does not hold true for division? } \\
\text { (Consider this through the lens of Linking Between } \\
\text { Representations and Explanations \& Mathematical } \\
\text { Sense-Making) } \\
\text { If time allows, create multiple representations for the } \\
\text { distributive property. (Again, consider linking and sense- } \\
\text { making between representations.) } \\
\text { Slide } 20 \text { (18 min) } \\
\text { Pair-Share } \\
\text { What is the value of using multiple representations to } \\
\text { discuss the commutative property and distributive } \\
\text { property? } \\
\text { What other concepts would benefit from the use multiple } \\
\text { representations? }\end{array}$ \\
\hline $1 \mathrm{~min}$ & $\begin{array}{l}\text { Wrap Up and Exit } \\
\text { Card }\end{array}$ & $\begin{array}{l}\text { Slide } \\
\begin{array}{l}\text { (1 min) Participants complete the exit card --Regarding } \\
\text { connections to your own practice, what moment during } \\
\text { today's session most resonated with you? What made this } \\
\text { moment notable? } \\
\circ \quad \text { Any questions or thoughts? } \\
\\
\quad \text { Hand in as participants walk out }\end{array}\end{array}$ \\
\hline$\sim 120 \mathrm{~min}$ & & \\
\hline
\end{tabular}

Figure 6. Agenda for Fall session \#4 of the MQI PD

\section{PD Group Conditions}

Because the primary aim of the parent study is to look at the impact of PD delivery conditions, each PD group was randomly assigned a particular delivery condition (while still experiencing the same core features and format of the PD sessions described above). Specifically, out of twelve PD groups, six had facilitator- 
led discussions during the weekly Fall meetings, whereas six had teacher-led discussions. In the teacher-led groups, one of the teachers (a volunteer that differed from session-to-session) facilitated the group scoring discussions; in the facilitatorled groups, the PD facilitator took on this role instead, at every session.

In addition to the facilitation condition of the study, there was a project-vs.own videotape condition, so that half of the twelve groups used project footage during their weekly meetings, and the other half of the groups used project footage for the first four meetings and then clips from their own classrooms for the last six meetings, depending on participants' willingness to share videos from their classrooms. If there weren't two own video clips for the session, then the session would be supplemented with clip(s) from the video library (the same clips that the project-videotape groups would be watching). The own video groups were highly variable in how many own video clips were shared. For example, in one group, there were two own video clips for each of the session, yet in another group, only four clips were shared for the entirety of the PD.

In addition to these twelve groups, one group of thirteen teachers served as a comparison group. They received no MQI-based training, yet they completed the same data collection activities that the PD teachers did outside the PD sessions (e.g., online surveys). The conditions for all thirteen groups of the parent study are summarized in Table 4.

Table 4

Summary of parent study conditions

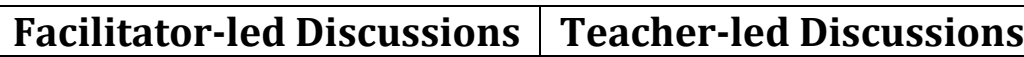




\begin{tabular}{|l|l|l|}
\hline $\begin{array}{l}\text { Project video } \\
\text { throughout }\end{array}$ & Condition 1: Three groups & Condition 2: Three groups \\
\hline $\begin{array}{l}\text { Project video } \\
\text { meetings 1-4; own } \\
\text { tape meetings 5-10 }\end{array}$ & Condition 3: Three groups & Condition 4: Three groups ${ }^{5}$ \\
\hline \multicolumn{2}{|c|}{ [Control condition: One group of thirteen teachers] } \\
\hline
\end{tabular}

\section{Participants and Recruitment}

Figure 7 is a visual representation of all second-year participants ${ }^{6}$ and comparison participants in the parent study. These participants are 60 teachers within five district-based MQI PD groups (five small groups of five-to-ten teachers, and one larger group of seventeen teachers), as well as thirteen comparison teachers who did not go through the MQI PD program. All teachers in the study were third- through eighth-grade math teachers from six urban school districts located either in the Pacific Northwest or in the Northeastern United States. The districts were chosen based on geographic convenience and on district interest and consent.

MQI PD teachers were recruited in the Spring of 2014. All teachers who volunteered for the study were then contacted to schedule first data collection activities. Comparison teachers were recruited in the Spring of 2013. They were originally part of a larger pool of teachers for the first year of the study, but these

${ }^{5}$ I facilitated a group that was randomly assigned to Condition 4.

${ }^{6}$ Note: there was a prior year of MQI PD participants that were not included in my study. From this point forward, when I say "all participants," I am referring to the participants included in my study: second-year PD participants and comparison participants (but not first-year PD participants). 
were the teachers that could not make it to the PD sessions. (In other words, the control teachers were not randomly assigned to condition.)

Within my local school district in the Pacific Northwest, I recruited teachers from five elementary and middle schools by giving a short presentation about the PD and associated research, at each school. These schools were selected based on personal contacts, word-of-mouth recommendations from the district administration, and principal consent. Originally, I recruited fourteen volunteers for my local group of which I would be the facilitator; five teachers from three schools remained in the study (and hence, in the group) by the time the Summer training began. 


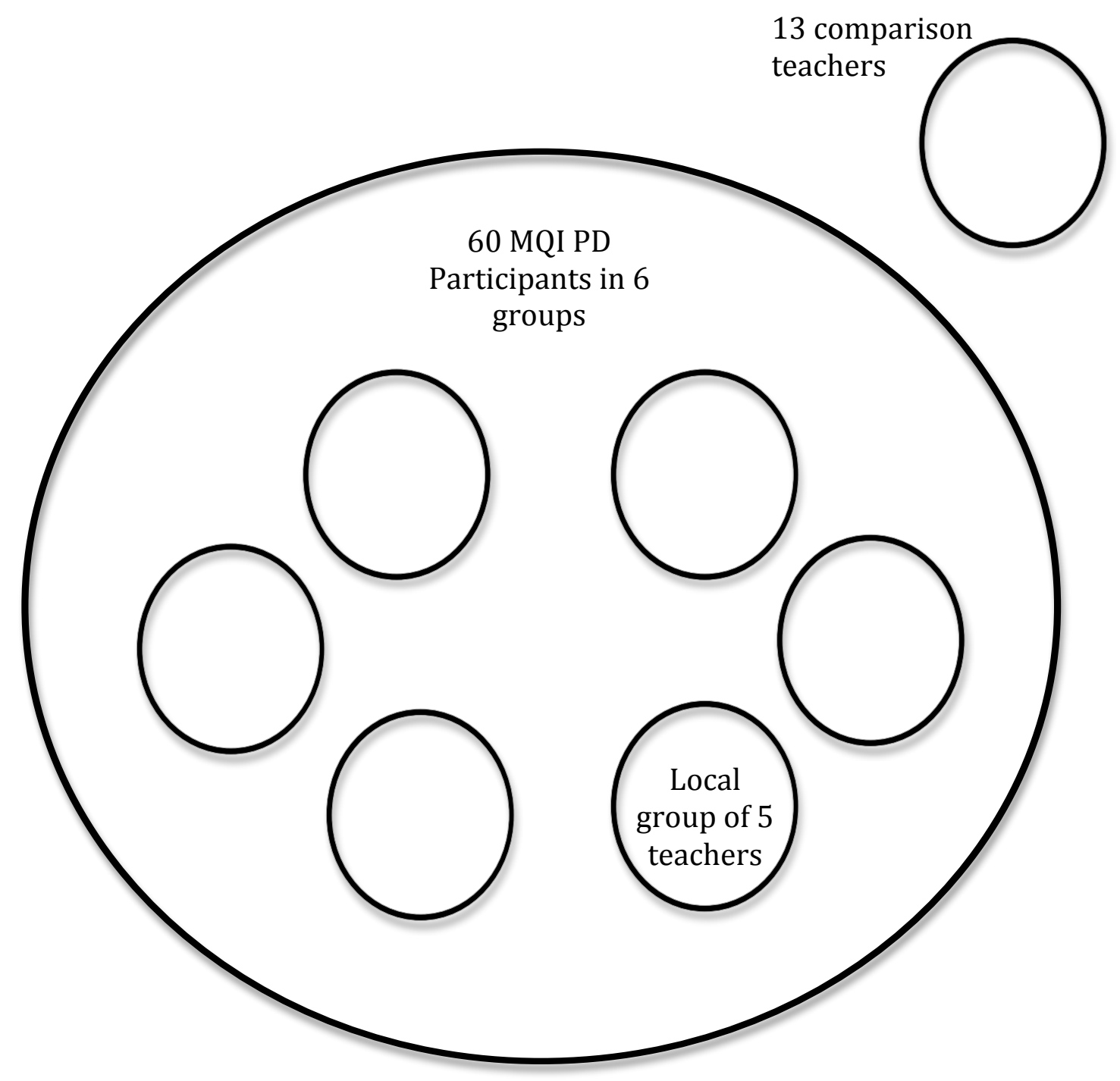

Figure 7. Visual representation of all participants in the parent study.

\section{Parent Study Data Collection Activities}

Data collection activities for the parent study included the audio-recordings of all PD sessions and for each teacher: a measure of the teacher's MKT before the PD (Hill, Schilling, \& Ball, 2004) three typed reflections on their own lessons (pre, 
mid, and post-PD); three typed responses to project classroom video clips (pre, mid, and post-PD); weekly MQI scoring exercises completed during every PD meeting; and an MQI certification assessment after the PD. A complete list of question prompts for the typed responses and links to the video clips appear in Appendix B. A summary of the timeline on which each data collection activity occurred as part of the parent study, is shown below in Table $5^{7}$.

Table 5

Timeline of data collection activities for the parent study

\begin{tabular}{|l|c|c|c|c|c|c|}
\hline & Pre-PD & $\begin{array}{c}\text { Summer } \\
\text { Training }\end{array}$ & $\begin{array}{c}\text { During } \\
\text { each of } \\
\text { Fall } \\
\text { meetings } \\
\mathbf{1 - 4}\end{array}$ & $\begin{array}{c}\text { Mid- } \\
\text { PD }\end{array}$ & $\begin{array}{c}\text { During } \\
\text { each of } \\
\text { Fall } \\
\text { meetings } \\
\mathbf{5 - 1 0}\end{array}$ & $\begin{array}{c}\text { Post- } \\
\text { PD }\end{array}$ \\
\hline $\begin{array}{l}\text { Session } \\
\text { audio- } \\
\text { recordings }\end{array}$ & & $\mathrm{X}$ & $\mathrm{X}$ & & $\mathrm{X}$ & \\
\hline $\begin{array}{l}\text { MKT } \\
\text { assessment }\end{array}$ & $\mathrm{X}$ & & $\mathrm{X}$ & & & \\
\hline $\begin{array}{l}\text { Online } \\
\text { lesson } \\
\text { reflections }\end{array}$ & $\mathrm{X}$ & $\mathrm{X}$ & $\mathrm{X}$ & & $\mathrm{X}$ \\
\hline $\begin{array}{l}\text { Online } \\
\text { video clip } \\
\text { responses }\end{array}$ & $\mathrm{X}$ & & $\mathrm{X}$ & & $\mathrm{X}$ & \\
\hline $\begin{array}{l}\text { Weekly MQI } \\
\text { scoring } \\
\text { sheets }\end{array}$ & & & & & $\mathrm{X}$ & \\
\hline $\begin{array}{l}\text { Weekly Exit } \\
\text { Cards }\end{array}$ & & & & & & \\
\hline MQI & & & & & & \\
\hline
\end{tabular}

${ }^{7}$ In addition to parent study data collection activities, I developed and conducted one-on-one interviews with the teachers in the group that I facilitated, at pre-PD, mid-PD, and post-PD. However, I did not end up using that data in this dissertation. Therefore, the interview development and questions are in Appendix $\mathrm{C}$ rather than in the main body of this dissertation. 


\begin{tabular}{|l|l|l|l|l|l|l|}
\hline $\begin{array}{l}\text { certification } \\
\text { assessment }\end{array}$ & & & & & & $\mathrm{X}$ \\
\hline
\end{tabular}

\section{Perspectives Informing My Research}

In this section, I identify and describe two perspectives that informed all of my analyses: situated cognition and a conceptualization of the construct of teacher noticing.

\section{Situated Cognition}

I conducted my analyses from the perspective that knowledge is situated (Greeno, 1991). In general, situated cognition refers to the idea that all knowledge is contextual and is interconnected with an environment. This is in contrast to a cognitive perspective, for example, because from a cognitive perspective, knowledge can be abstracted from its context or associated environment. For example, Rhoads and Weber (2014) explicate their shift in perspectives from a cognitive perspective to a situated perspective, in their analyses of the knowledge of expert mathematics teachers. Noticing that the expert teachers in their study struggled to abstractly describe the mathematical knowledge they used while teaching, Rhoads and Weber re-analyzed their interview data using a situated perspective, instead seeking to understand the teachers' use of mathematical knowledge in teaching through the teachers' descriptions of their practice, which was a more fruitful and practicecentered approach to addressing their research questions.

My use of the situated perspective is similar to that of Rhoads and Weber (2014). Overall, I sought to understand my participants' MQI-related noticing as I 
saw it evidenced in their descriptions of, reflections on, and analyses of, instances of teaching (whether those instances be in memory, on video, or imagined).

\section{A Conceptualization of Teacher Noticing}

van Es and Sherin's (2008) three-part conceptualization of noticing in the context of mathematics teaching guided my own understanding and use of noticing in my research. According to their conceptualization, noticing goes beyond capturing to what and to whom a teacher is attending, to more comprehensively include: (1) attending to events, (2) reasoning about those events, and then (3) deciding how to respond to them based on broader principles of instruction. The analyses within this dissertation focused exclusively on components (1) and (2), attending and reasoning because my research questions pertained to these components, but not the third component - deciding how to respond. Thus, I conceptualized noticing as incorporating both of the first two components so that I was looking at what teachers noticed (attending) and how they noticed it (reasoning).

\section{Participants, Dataset and Analyses for Research Question 1}

\section{Brief Overview}

My first research goal was to develop a framework to capture teachers' noticing of MQI-related features in classroom video clips. Specifically, I aimed to articulate dimensions of such noticing, with each dimension consisting of multiple levels. To accomplish this, I examined both comparison and PD teachers' individual 
typed responses to two classroom video clips midway through the MQI PD, given the prompt "What stood out to you about the math in this clip?" In particular, this dataset consisted of the responses of 73 teachers, 60 within the MQI PD program (all of the second-year MQI PD participants) and thirteen comparison teachers not in the MQI PD program. I carried out analyses using a combination of a priori and data-driven coding (described in more detail later in this chapter).

Then, to test the use of the framework, and to explore whether statistically significant shifts could be identified in the data, I coded all 60 second-year MQI PD teachers' pre-PD (Clips 1 and 2), mid-PD (Clips 3 and 4) and post-PD (Clips 5 and 6) video responses and used statistical analyses to illuminate trends in the data as the PD progressed.

Then, to exemplify possible patterns of change as teachers progressed through the MQI PD, I zoomed in on two teachers' noticing journeys as detailed examples of shifting MQI-related Noticing. I reported each teacher's six individual typed video clip responses that they gave as they progressed through the PD (two pre-PD, two mid-PD, two post-PD), which I then characterized in relation to the quantitative analyses on the larger dataset.

\section{Dataset for Research Question 1}

The dataset I analyzed for exploring teachers' MQI Noticing consisted of teachers' responses to six short video clips. After watching each clip, teachers typed responses to the open-ended question, "What stood out to you about the 
mathematics in this clip?" Responses to the first two clips were collected at pre-PD, responses to the second two clips were collected at mid-PD (between Fall sessions \#5 and \#6), and the final two responses were collected at post-PD.

Teachers were asked to complete their responses within an approximately one week window. Table 6 below shows the actual timing of the PD sessions and online video response submissions for two example participants (Michael and Hope), as they happened in the Summer and Fall of 2014. It is important to notice that Michael and Hope, submitted their post-PD video responses in January, after the 2014 winter break and well after the final Fall PD session. This timing is representative of approximately half of participants. The other half of the MQI PD participants submitted their post-PD video responses closer the end of the last session of the Fall PD in December. I take this fact into account in my discussion of results in Chapter 4.

Table 6

Examples of actual dates of data collection activity completion

\begin{tabular}{|c|c|c|c|c|c|c|}
\hline & $\begin{array}{l}\text { Pre-PD video } \\
\text { responses } \\
\text { (clips } 1 \& 2 \text { ) }\end{array}$ & $\begin{array}{l}\text { Summer } \\
\text { Training } \\
\text { Session }\end{array}$ & $\begin{array}{l}\text { Fall } \\
\text { Sessions 1- } \\
5\end{array}$ & $\begin{array}{l}\text { Mid-PD } \\
\text { video } \\
\text { responses } \\
\text { (clips } 3 \text { \& 4) }\end{array}$ & $\begin{array}{l}\text { Fall } \\
\text { Sessions } \\
6-10\end{array}$ & $\begin{array}{l}\text { Post-PD } \\
\text { video } \\
\text { responses }\end{array}$ \\
\hline Michael & June $4^{\text {th }}$ & \multirow{2}{*}{$\begin{array}{l}\text { Aug } 21^{\text {st }} \& \\
22 \text { nd }\end{array}$} & \multirow{2}{*}{$\begin{array}{c}\text { Sept } 25^{\text {th }}, \\
\text { Oct } 2^{\text {nd }} \\
16^{\text {th }}, 23^{\text {rd }} \\
30^{\text {th }}\end{array}$} & Oct 30 th & \multirow{2}{*}{$\begin{array}{c}\text { Nov } 13^{\text {th }} \\
20^{\text {th }}, \text { Dec } \\
4^{\text {th }}, 11^{\text {th }} \\
18^{\text {th }}\end{array}$} & Jan 26th \\
\hline Hope & & & & & & \\
\hline
\end{tabular}

By design, each video clip was unique, meaning that teachers never completed a video response to the same video clip twice. The methodological 
advantage of this approach lies in the fact that it eliminates a potential concern about "practice effects." Namely, if the teachers had responded to the same two video clips at pre-, mid-, and post-PD, then improvements in their MQI-related noticing might be due to their familiarity with the video clips. It would be impossible to untangle whether teachers were becoming more adept at noticing MQI-related features of the video clips, or if they were simply able to notice "more" because they had seen and responded to the clips before. Thus, having teachers respond to novel video clips at every data collection occasion is an approach with this distinct strength.

However, the fact that video clips at each data collection occasion were unique from the video clips at other data collection occasions introduces the possibility that there might be "more" or "less" to notice at each data collection occasion, and that this might skew results. Indeed, it is unavoidable that the selection of video clips had an impact on the teachers' video clip responses, thus an analysis of the video clips was necessary in order to interpret my later findings in light of "how much there was for teachers to notice" at each data collection occasion.

According to a group of expert MQI raters, the video clips that were most saturated with MQI-related instances were the first two clips that the teachers responded to at pre-PD. Table 7 shows the MQI score for each dimension of the full MQI Instrument (which is even more comprehensive than the MQI Instrument for PD) according to the group of five expert MQI raters. The pre-PD clips both have "high" scores on one dimension, two dimensions with "Mid" scores, and one 
dimension with a "Low" or "Not Present". The clips at Mid-PD are less saturated with MQI-related instances, yet there are still some instances for teachers to notice. One clip has "Mid" scores across the dimensions, while the other clip has one "Mid" and one "Low" score and two "Not Present" scores. The post-PD clips are similarly less-saturated with MQI-related features than the pre-PD clips, yet one clip does have a "High" score in one dimension, and neither of the clips have any dimensions with a score of "Not Present".

With the intention of mitigating the effects of these fluctuating saturations of MQI-related features of instruction across data collection timepoints, my large-scale quantitative analyses were conducted at the level of the timepoint, rather than at the level of the clip. In other words, for each timepoint, I analyzed teachers' responses to both clips together, so that I knew teachers had the opportunity to find MQI-related instances across the two clips.

Even still, the clips that the teachers responded to at each timepoint do indeed have different levels of saturation of MQI-related instances within them. According to the expert scores in Table 7, I expected that a teacher attending to MQI-related instances would notice more MQI-related instances at pre-PD, a lot fewer at Mid-PD, and then a medium amount at Post-PD. Thus I interpret all of my findings in light of these unequal "opportunities to notice," and as I discuss in the next chapter, the particular MQI-related saturations of the clips actually ended up supporting the strength of my findings. 
Table 7

Expert MQI scores for the six video response clips

\begin{tabular}{|c|c|c|c|c|c|}
\hline & & $\begin{array}{l}\text { Richness of the } \\
\text { Mathematics }\end{array}$ & $\begin{array}{l}\text { Working with } \\
\text { Students and } \\
\text { Mathematics }\end{array}$ & $\begin{array}{l}\text { Errors and } \\
\text { Imprecision }\end{array}$ & $\begin{array}{c}\text { Common } \\
\text { Core Student } \\
\text { Practices } \\
\end{array}$ \\
\hline \multirow{2}{*}{ के } & $\begin{array}{l}\text { Clip } 1 \\
\text { Lauren: Likelihood } \\
\text { line }\end{array}$ & Mid & High & Not Present & Mid \\
\hline & $\begin{array}{l}\text { Clip } 2 \\
\text { Ms. Dawes: Cows \& } \\
\text { Calves }\end{array}$ & Mid & High & Low & Mid \\
\hline \multirow{2}{*}{ : } & $\begin{array}{l}\text { Clip } 3 \\
\text { Daria: One Problem, } \\
\text { Four Operations }\end{array}$ & Mid & Mid & Mid & Mid \\
\hline & $\begin{array}{l}\text { Clip } 4 \\
\text { Dale: Folded Paper, } \\
\text { Equivalent Fractions }\end{array}$ & Mid & Not Present & Low & Not Present \\
\hline \multirow{2}{*}{ مि } & $\begin{array}{l}\text { Clip } 5 \\
\text { Daniella: Equivalent } \\
\text { Fractions }\end{array}$ & High & Mid & Low & Low \\
\hline & $\begin{array}{l}\text { Clip } 6 \\
\text { Anastasia: Area and } \\
\text { Perimeter }\end{array}$ & Low & Mid & Mid & Mid \\
\hline
\end{tabular}

\section{Analyses for Research Question 1}

Framework Development. The process that I used to develop an MQI

Noticing framework was inspired by the process van Es (2011) used to develop her framework that captures groups of teachers' noticing of children's mathematical thinking. Specifically, I closely followed the first two steps of her frameworkbuilding process, described on pages 137 and 138 of her chapter, which can be summarized as follows:

Step 1: Examine the literature to identify areas central to teachers' noticing. 
Step 2: Turn to the data in order to examine the noticing exhibited therein and attempt to categorize the data into the pre-existing categories. Reflexively modify the categories so that they capture all the data and also maintain their theoretical roots.

A description of how I applied each step to my specific dataset is below.

Step 1: Examining the Literature. Having searched through the wealth of research on mathematics teacher noticing, I identified a priori categories within previously-established noticing frameworks (namely, Goldsmith and Seago, 2011, and van Es, 2011) that seemed relevant to noticing MQI-related features of instruction. The resulting a priori categories for What Teachers Notice were General Mathematics, Specific Mathematics, and Non-mathematics (grouped into a Mathematics dimension), and Enacted Instruction, Non-Instruction, and Other (grouped into an Instruction dimension). The a priori categories for How Teachers Notice were Evaluative, Interpretive, and Descriptive (grouped into a Tone dimension), and With Correct Evidence and Without Correct Evidence (grouped into an Evidence dimension). Some of these categories would be collapsed and/or modified in Step 2 (details below).

Step 2: Incorporating the Data and Finalizing the Framework. As part of Step 2 of my process of developing an MQI Noticing framework, I examined all PD teachers' $(\mathrm{N}=60)$ and all comparison teachers' $(\mathrm{N}=13)$ individually-typed responses midway through the PD, to two video clips (Clip 3 and Clip 4). Thus the dataset consisted of two sets (one for Clip 3 and one for Clip 4) of 73 teachers' 
individually-typed responses to the open-ended question, "What stood out to you about the mathematics in this clip?" I included the responses of both the groups of MQI PD teachers (who had over 20 hours of experience with the MQI by the time of the responses) and comparison teachers (who had no known formal exposure to the MQI) because I wanted to build an MQI Noticing framework that captured a wide range of responses.

My rationale for choosing to build the framework based on the teachers' responses at mid-PD, as opposed to pre- and/or post-PD, is based on particular features of the mid-PD video clips, Clip 3 and Clip 4. Specifically, both clips included strong elements of general mathematics pedagogy (e.g., eliciting students' mathematical thinking), but Clip 3 contained various mathematical errors on the part of the teacher, and Clip 4 contained the use of multiple representations that were not used in a mathematically meaningful way. Therefore, both of these clips lend themselves nicely to the task of differentiating between teachers' noticing of the quality of mathematical features of instruction, versus noticing of more surfacelevel pedagogical features and/or the clip-teachers' attempts that did not quite come to fruition.

Because some teachers' typed responses addressed multiple aspects of the clip, I decided to break each of the 146 responses (two video clip responses for each of 73 teachers) into statements (see Figure 8 below for an example). By statements, I am referring to a meaning unit - "words, sentences or paragraphs containing aspects related to each other through their content and context" - within the 
collection of teachers' typed responses to the two mid-PD video clips (Graneheim \& Lundman, 2004, p. 106). An example of a multi-statement response appears in

Figure 8 , and the number of statements within each of the 146 video clip responses that I used to develop the framework are shown in Table 8.

[Statement 1] The question lended (sic) itself to open-ended answers and divergent discussion, addressing the question of how you could use different operations to solve a story problem. [Statement 2] While the students suggested reasonable approaches to solving the story problem, their calculations needed more explanation (like the student who described using addition) or were perhaps incorrect, like the student who suggested repeated subtraction with 25c. [Statement 3] When the teacher remediated, it sometimes muddied the math like "subtract by $\$ 1.25$," and multiplying one half a candy bar by one half a candy bar to get a whole candy bar.

Figure 8. A teacher's video clip response broken up into statements (i.e., meaning units)

Table 8

The number of statements within each of 146 video clip responses used to develop the MQI Noticing Framework

\begin{tabular}{|c|c|c|c|c|c|c|c|}
\hline & $\begin{array}{c}\mathbf{1} \\
\text { Statemt. }\end{array}$ & $\begin{array}{c}\mathbf{2} \\
\text { Statemts. }\end{array}$ & $\begin{array}{c}\mathbf{3} \\
\text { Statemts. }\end{array}$ & $\begin{array}{c}\mathbf{4} \\
\text { Statemts. }\end{array}$ & $\begin{array}{c}\mathbf{5} \\
\text { Statemt. }\end{array}$ & $\begin{array}{c}\mathbf{6} \\
\text { Statemts. }\end{array}$ & $\begin{array}{c}\text { Total \# of } \\
\text { Statements }\end{array}$ \\
\hline $\begin{array}{c}\text { Clip 3 } \\
(\mathrm{N}=73)\end{array}$ & 40 & 23 & 7 & 2 & 0 & 1 & 121 \\
\hline $\begin{array}{c}\text { Clip 4 } \\
(\mathrm{N}=73)\end{array}$ & 49 & 16 & 3 & 1 & 0 & 0 & 94 \\
\hline $\begin{array}{c}\text { Both Clips } \\
\text { Combined } \\
(\mathrm{N}=146)\end{array}$ & 89 & 39 & 10 & 3 & 0 & 1 & $\mathbf{2 1 5}$ \\
\hline
\end{tabular}

Next, I worked to establish framework categories that were grounded in the a priori categories determined in Step 1, and that also captured all 215 of the 73 teachers' statements. I first attempted to sort 215 statements into the a priori categories described in Step 1, with the expectation that the categories would need to be revised and refined to represent these data. I wrote each statement on a small piece of paper, disassociated from the teachers' identification number and 
treatment condition, and then sorted and re-sorted the data into categories, beginning with the a priori categories described in Step 1, which were revised many times over the course of many rounds of sorting so that each statement fit into exactly one category.

Through this process, it happened more than once that multiple categories needed to be collapsed into one category. For example, the distinction between "Descriptive" and "Interpretive" statements was often indistinguishable in a typed video response context (as opposed to a conversational context). As an example of this, the statement "the clip included rich mathematics" is arguably both descriptive and/or interpretive. This proved to be repeatedly problematic, so the distinction was dropped. Further, any statements that were not "descriptive/interpretive" were ultimately put into a "Non-Noticing" category so that it then became unnecessary to explicitly label all the other categories as "descriptive/interpretive". The categories that resulted from this process are shown in Table 9.

Table 9

The MQI Noticing Framework

\begin{tabular}{|c|c|c|c|}
\hline & \multicolumn{2}{|c|}{ How Teachers Notice } \\
\hline & & $\begin{array}{l}\text { With Reference to } \\
\text { Specific Evidence }\end{array}$ & $\begin{array}{l}\text { Without Reference to } \\
\text { Specific Evidence }\end{array}$ \\
\hline \multirow{2}{*}{ 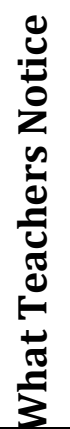 } & $\begin{array}{l}\text { Mathematical } \\
\text { Features of } \\
\text { Instruction }\end{array}$ & $\begin{array}{l}\text { Noticing Mathematical } \\
\text { Features of Instruction }\end{array}$ & $\begin{array}{l}\text { Noticing Mathematical } \\
\text { Features of Instruction } \\
\text { without Evidence }\end{array}$ \\
\hline & $\begin{array}{l}\text { Other Features of } \\
\text { Instruction }\end{array}$ & $\begin{array}{l}\text { Noticing Other Features of } \\
\text { Instruction }\end{array}$ & $\begin{array}{l}\text { Noticing Other Features of } \\
\text { Instruction without } \\
\text { Evidence }\end{array}$ \\
\hline
\end{tabular}




\begin{tabular}{|l|l|c|}
\hline & & \\
\hline Mathematics & Noticing Mathematics \\
\hline & \\
\multicolumn{2}{|l|}{ Non-Noticing: Inferences, Evaluations, Commentary, Wonderings, etc. } \\
\hline
\end{tabular}

\section{Exploring Shifts Using the MQI Noticing Framework}

Having developed an MQI Noticing Framework, I tested its use and explored whether statistically significant shifts could be identified in the data. At this point, I chose to mathematize the framework by assigning numerical values ("levels") to each category, which effectively collapsed the two-dimensional framework into a single, ordinal dimension. Table 10 below shows how the categories of the framework corresponded to the mathematized levels, which were used for statistical analyses to determine if participants' noticing was "increasing".

The choice to mathematize the MQI Noticing Framework in this way resulted in minor challenges to validity because some categories that are conceptually distinct were treated as "the same" in statistical analyses (e.g., Noticing Mathematical Features of Instruction without Evidence and Nothing Other Features of Instruction with Evidence). And indeed, the particular way in which I mathematized the framework affected the results of my analyses; had I mathematized the framework differently, the results might have been different. At the time analyses were carried out for this dissertation, though, these challenges seemed to be outweighed by the affordance of being able to compare trends in MQI Noticing 
across time and across participants with a single value for each participant. In future analyses of this dataset, I chose to explore the participants' video response data without collapsing the MQI Noticing framework into a single dimension.

Table 10

The MQI Noticing Framework mathematized into one dimension of levels

\begin{tabular}{|c|c|c|c|}
\hline & \multicolumn{2}{|c|}{ How Teachers Notice } \\
\hline & & $\begin{array}{l}\text { With Reference to } \\
\text { Specific Evidence }\end{array}$ & \begin{tabular}{|l|} 
Without Reference to \\
Specific Evidence
\end{tabular} \\
\hline \multirow{3}{*}{ 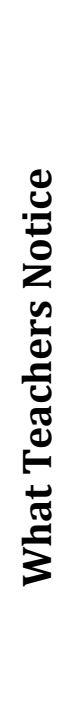 } & $\begin{array}{l}\text { Mathematical } \\
\text { Features of } \\
\text { Instruction }\end{array}$ & $\begin{array}{l}\text { Noticing Mathematical } \\
\text { Features of Instruction } \\
\text { (Level 4) }\end{array}$ & $\begin{array}{l}\text { Noticing Mathematical } \\
\text { Features of Instruction } \\
\text { without Evidence } \\
\text { (Level 3) }\end{array}$ \\
\hline & $\begin{array}{l}\text { Other Features of } \\
\text { Instruction }\end{array}$ & $\begin{array}{l}\text { Noticing Other Features of } \\
\text { Instruction with Evidence } \\
\text { (Level 3) }\end{array}$ & $\begin{array}{l}\text { Noticing Other Features of } \\
\text { Instruction without } \\
\text { Evidence } \\
\text { (Level 2) }\end{array}$ \\
\hline & Mathematics & \multicolumn{2}{|c|}{$\begin{array}{l}\text { Noticing Mathematics } \\
\text { (Level 1) }\end{array}$} \\
\hline \multicolumn{4}{|c|}{$\begin{array}{l}\text { Non-Noticing: Inferences, Evaluations, Commentary, Wonderings, etc. } \\
\text { (Level 0) }\end{array}$} \\
\hline
\end{tabular}

With the mathematized version of the framework, I coded all 60 second-year MQI PD teachers' pre-PD (Clips 1 and 2), mid-PD (Clips 3 and 4) and post-PD (Clips 5 and 6) video responses and used Page's Trend Test (Hollander \& Wolfe, 1999) 
using the open-source software called " $\mathrm{R}$ " to determine whether there was a statistically significant change in teachers' MQI Noticing as the PD progressed.

Page's Trend Test (Hollander \& Wolfe, 1999) is an appropriate statistical tool to employ in these analyses because of three key considerations: First, the dependent variable data are ordinal - as opposed to continuous interval or ratio data. This means a non-parametric test is appropriate because non-parametric tests do not carry the assumption of normally-distributed data. Secondly, there is one independent variable that is measured for the same participants (repeated measures) at three "levels" (pre, mid, and post-PD). If these were the only two considerations, then Friedman's test would be appropriate - and indeed I could have chosen to use Friedman's test for my analyses. (See Figure 9 below.) The test that I chose to run, Page's Trend Test, is an extension of Friedman's test, and is applicable here because of this third consideration: it can be hypothesized that the "levels" have a particular order with respect to the dependent variable - that is, it can be hypothesized that scores at mid-PD will be higher than scores at pre-PD, and scores at post-PD will be higher than scores at mid-PD (pre $<$ mid $<$ post). Page's Trend Test has the same null hypothesis as Friedman's test $($ pre $=$ mid $=$ post $)$, but the alternative hypothesis with Page's Trend Test is ordered (pre $<$ mid $<$ post) while Friedman's alternative hypothesis is non-ordered (pre $\neq$ mid $\neq$ post). Page's Trend Test is therefore the best statistical test to apply in this situation. 


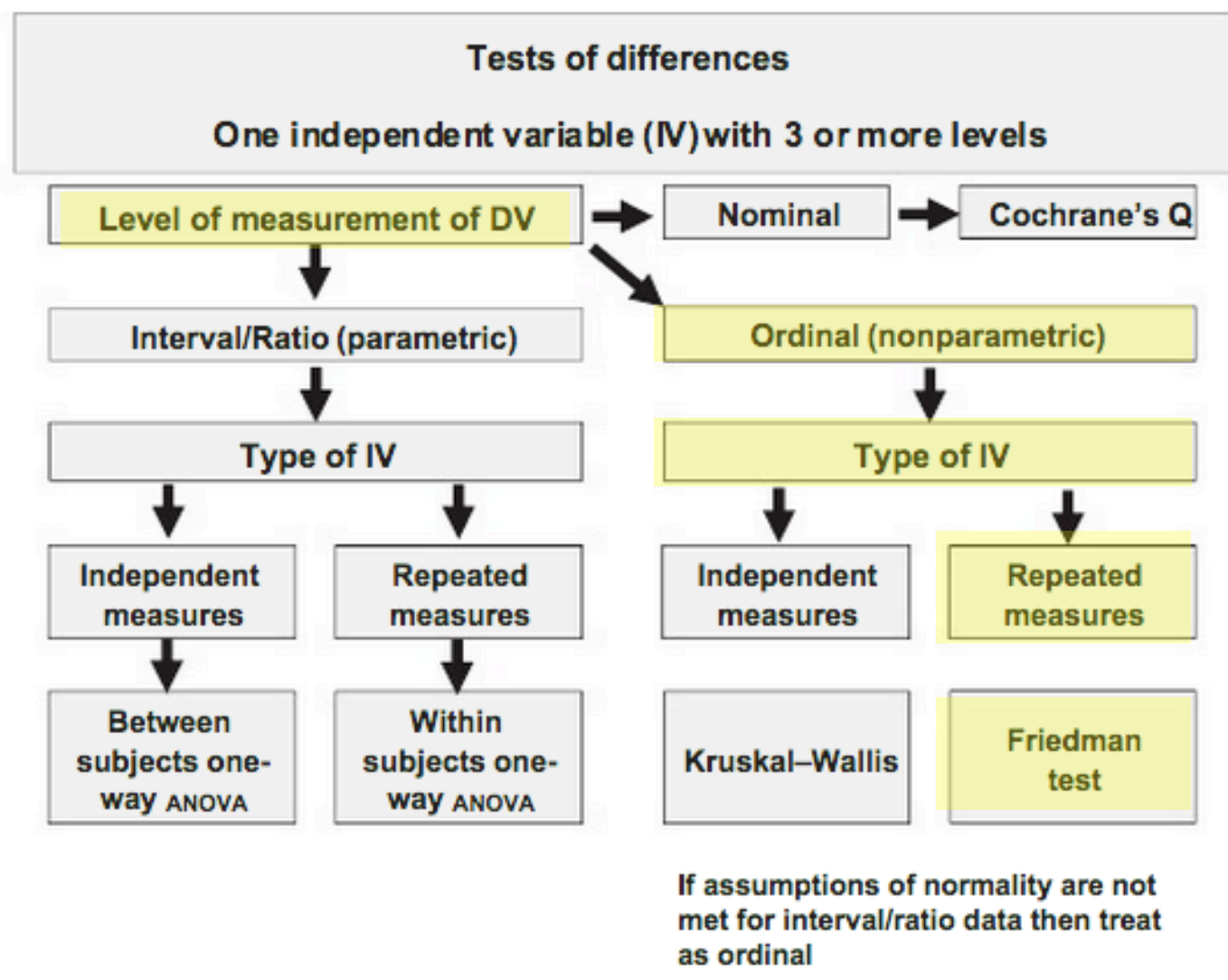

Figure 9. Flow chart for statistical tests of differences for one independent variable with three or more levels (Bettany-Soltakov \& Whittaker, 2014)

I also employed a different non-parametric statistical test, the Mann-Whitney U-Test (Hollander \& Wolfe, 1999) as part of a preliminary exploration of the validity of the MQI Noticing Framework. In this case, the independent variable was not repeated measures on the same participants; instead, it was whether the participant was in the PD condition or in the comparison condition. For these analyses, I used the data from mid-PD for both PD and comparison participants to explore whether the scores for these two groups were significantly different. Figure 10 shows why the Mann-Whitney U-Test was the appropriate test for these explorations. 


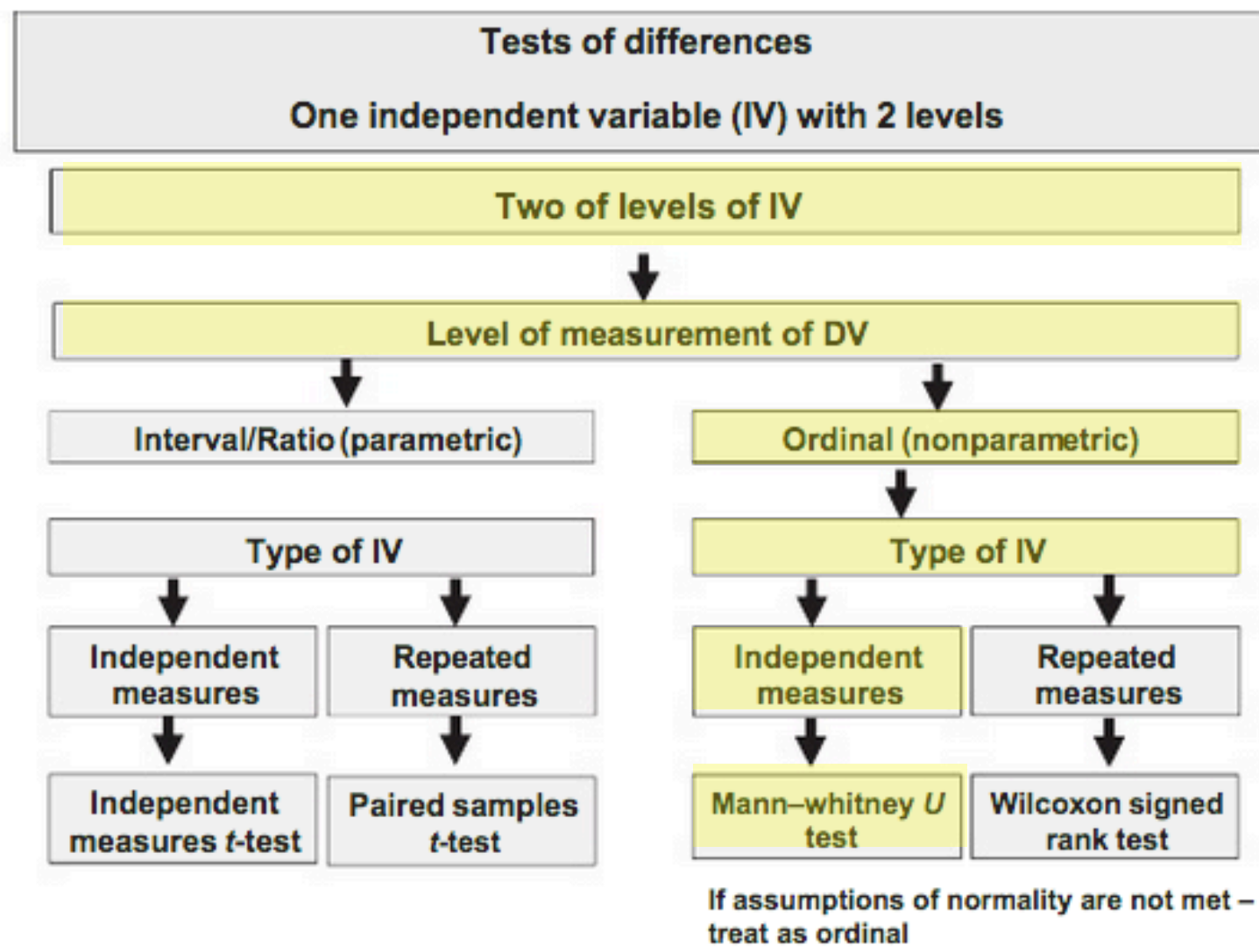

Figure 10. Flow chart for statistical tests of differences for one independent variable with two levels (Bettany-Soltakov \& Whittaker, 2014)

\section{Two Teachers Journeys as Illuminating Examples}

Having completing these statistical analyses, I chose to dig deeper into the nature of the changes in MQI Noticing by exploring the shifts in two teachers' video responses to serve as illuminating examples. The participants I chose for this were Michael and Hope, who were participants from the group I facilitated. I chose to study Michael and Hope in particular because they represent examples of classroom teachers with "exemplary" participation; Michael and Hope both attended 100\% of the MQI PD sessions, and - according to my personal memory - both of their 
participation throughout the PD could be characterized as engaged and interested in the sessions' activities. Because of this, any lack of change in their MQI Noticing cannot be attributed to poor attendance or participation during the PD. Of the three other PD participants that were in the group, two had somewhat spotty attendance and so I chose not to use them as examples for these analyses. The third was a math intervention specialist, rather than a classroom teacher. While understanding her journey would be interesting research, it is not the focus of my study, which is on classroom teachers. In this way, Michael and Hope are examples of "what is possible" or "what might happen" with respect to a classroom teacher's MQI Noticing as they go through the MQI PD under conditions of exemplary attendance and participation. As such, Michael and Hope are not representative of "typical" participation in the MQI PD, nor are they intended to be.

The focal data I analyzed in order to characterize Michael and Hope's MQI Noticing journeys were their individually-typed video clip responses. For both Michael and Hope, I used the MQI Noticing framework to code the MQI Noticing levels of every statement within each of his or her six (two pre-PD, two mid-PD, and two post-PD) individual typed responses to classroom video clips. Having done this, I reported the number and proportions of statements for each participant at each level within their responses at each time point, and I situated these within the results of my previous analyses on the larger group of participants. I also summarized qualitative features of the teachers' responses using the MQI Noticing framework as an interpretive lens, and I looked across time points within each participant to describe any observable quantitative or qualitative shifts in their MQI 
Noticing development. For each participant, my overarching goal was to characterize his or her MQI Noticing journey more broadly (i.e., explaining that this is an example of).

The results of these analyses are presented in the next chapter. 


\section{CHAPTER 4: SHIFTS IN INDIVIDUAL TEACHERS' MQI NOTICING}

In Chapter 2 of this dissertation, I explained that we know the MQI is positively correlated with a teacher's MKT and is also associated with students' learning outcomes (Charalambous et al., 2012; Hill et al., 2007; Hill \& Charalambous, 2012; Hill et al., 2008; Hill et al., 2005; Hill et al., , 2012; Lewis \& Blunk, 2012). In other words, we know that strong MQI can provide students with rich and plentiful opportunities to experience and explore mathematics. On the other hand, we also know that what teachers notice about mathematics instruction, and how they notice it, are of critical importance with respect to the enactment and growth of their own practice (Sherin et al., 2011). A teacher cannot make informed decisions about, or deliberate improvements to, an aspect of her practice of which she does not notice (Erickson, 2011). Nevertheless, there was heretofore no systematic way to characterize or differentiate levels of teachers' MQI Noticing.

I argue that distinct degrees of MQI Noticing can indeed be identified within and between teachers' responses. In this chapter, I use an operationalized modification of the MQI Noticing Framework. This modified framework is unidimensional, multiple-level, and ordinal, such that it represents the degree to which a teacher's typed video response statement reflects MQI Noticing with a single value (a level). As I discussed in the previous chapter, this modification affords the use of specific statistical tests that can illuminate trends in PD participants' MQI Noticing across time as the PD progressed. Limitations are discussed at the end of this chapter. 
The remainder of this chapter consists of four main sections. I begin with an introduction to, and presentation of, the modified, uni-dimensional version of the MQI Noticing Framework. Following this, I test the use of the framework to examine whether there were statistically significant shifts in teachers' MQI Noticing within their video responses as the PD progressed. Then, with these statistical results in hand, I zoom in on two participants' MQI Noticing "journeys" throughout the PD, according to the MQI Noticing levels of their video response statements. I conclude this chapter with a discussion of the results, along with limitations, and implications of the findings.

\section{Uni-Dimensional, Mathematized Version of the MQI Noticing Framework}

Table 14 shows the levels that I used to capture degrees of MQI Noticing in teachers' responses. In the remainder of this section, I explicate definitions of terms used in the mathematized framework, and then I explain and give examples for each level.

Table 11

Example statements for each level of the uni-dimensional version of the MQI Noticing Framework

\begin{tabular}{|l|l|l|}
\hline Level & Name & Examples \\
\hline 4 & $\begin{array}{l}\text { Noticing } \\
\text { Mathematical } \\
\text { Features of } \\
\text { Instruction with } \\
\text { Evidence }\end{array}$ & $\begin{array}{l}\text { "There were many math errors here on the part } \\
\text { of the teacher. For example, a half of a candy } \\
\text { bar times a half of a candy bar does not equal a } \\
\text { whole candy bar." } \\
\text { "Rich math vocabulary was used: Addition, } \\
\text { subtraction, multiplication, division, part, whole, } \\
\text { number, divide, multiply, subtract, equal, minus, }\end{array}$ \\
\hline
\end{tabular}




\begin{tabular}{|c|c|c|}
\hline & & $\begin{array}{l}\text { add." } \\
\text { They were engaging in sense making when they } \\
\text { evaluated the reasonableness of finding a } \\
\text { number to multiply by the } \$ 1.25 \text {. }\end{array}$ \\
\hline 3 & $\begin{array}{l}\text { Noticing } \\
\text { Mathematical } \\
\text { Features of } \\
\text { Instruction without } \\
\text { Evidence } \\
\\
\text {-OR- } \\
\text { Features of } \\
\text { Evidence } \\
\text { Noticing Other }\end{array}$ & $\begin{array}{l}\text { "I noticed a lot of imprecision in mathematical } \\
\text { language." [no evidence] } \\
\text { "He did not show why his 'trick' works by } \\
\text { showing how } 4 / 8 \text { is the same as } 1 / 2 . " \text { [noticing } \\
\text { that a mathematical feature of instruction did } \\
\text { not happen were included in level 3] } \\
\\
\text { "The teacher asked students to share their } \\
\text { thinking with each other, like when she used the } \\
\text { 'turn and talk' prompt after posing the candy } \\
\text { bar question." }\end{array}$ \\
\hline 2 & $\begin{array}{l}\text { Noticing Other } \\
\text { Features of } \\
\text { Instruction without } \\
\text { Evidence }\end{array}$ & $\begin{array}{l}\text { "This was a discussion-based lesson." } \\
\text { "Students shared their thinking." } \\
\text { "It was teacher-centered. For example, she } \\
\text { struggled to stop herself from inserting her own } \\
\text { ideas into the conversation when she asked the } \\
\text { student to explain her strategy." }\end{array}$ \\
\hline
\end{tabular}




\begin{tabular}{|c|c|c|}
\hline & & "There was a lot of mathematics involved." \\
\hline 1 & $\begin{array}{l}\text { Noticing } \\
\text { Mathematics }\end{array}$ & "This lesson was about probability." \\
\hline 0 & $\begin{array}{l}\text { Non-Noticing: } \\
\text { Inferences, } \\
\text { Evaluations, } \\
\text { Assumptions, } \\
\text { Suggestions, or } \\
\text { Commentary }\end{array}$ & $\begin{array}{l}\text { Inference: "The teacher linked a visual model of } \\
4 / 8=1 / 2 \text { to the procedure." [inaccurate - this } \\
\text { did not occur in the clip and is therefore } \\
\text { categorized as an inference] } \\
\text { Evaluation: "I loved this teaching!" } \\
\text { Assumptions: "I assume she had talked about } \\
\text { this beforehand." } \\
\text { Suggestion for improvement: "It would have } \\
\text { been better if she had discussed what the } 4 \text { in } \\
\text { the solution strategy represented." } \\
\text { Commentary on the importance of the topic: } \\
\text { "Equivalent fractions are an important } \\
\text { foundation for later study of decimals." } \\
\text { Commentary on one's own classroom: "I will use } \\
\text { this activity in my own classroom." }\end{array}$ \\
\hline
\end{tabular}

\section{Framework Definitions and Points of Clarification}

A Feature of Instruction. By a feature of instruction, I (along with the developers of the construct of the MQI itself) am referring to a teacher's noticing of any part of instructional interaction according to Cohen, Raudenbush, and Ball's (2003) instruction as interaction model. From there, the feature of instruction is mathematical if it pertains to content, and it is considered other if it does not. 
Examples of other features of instruction from the LMT's (2011) article introducing the MQI are: format of the lesson (e.g., lecture-style), approaches to teaching mathematics (e.g., with hands-on manipulatives), and pedagogical features of instruction (e.g., students sharing their thinking).

Mathematical Feature of Instruction vs. the Mathematics. When I refer to a mathematical feature of instruction, the noun (i.e., the what) is a feature of instruction (Cohen, Raudenbush, \& Ball, 2003), and the adjective mathematical means that the feature of instruction pertains to the mathematics available to students during that instruction (LMT, 2011). By contrast, when referring to mathematics, the noun (the what) is the math. In the teachers' statements, it was apparent that some statements referred to the mathematics, which was distinctly different than a mathematical feature of instruction. For example, in the teacher's the statement, "This was a lesson about probability," the what is the mathematics, but no features of instructional interaction - mathematical or otherwise - are mentioned.

With and Without Evidence. It is important that teachers, when making statements in response to observing mathematics instruction, ground their statements in evidence from within that instruction (Borko et al., 2008, Goldsmith \& Seago, 2011; Jacobs et al., 2011; van Es, 2011). As such, the ideas of "with evidence" and "without evidence" appear throughout the MQI Noticing Framework. A statement was considered to be "with evidence" if the teacher referenced a specific event (or events) from within the video clip to support what they noticed about the 
instruction. Otherwise, the statement was considered to be "without evidence." Further, if the specific event(s) that the teacher referenced in his or her statement was inaccurate (i.e., it did not actually happen in the clip), then it was categorized as an inference (Level 0).

\section{Levels of the Framework}

In this section, I introduce each level of the framework and explain example statements that would be categorized into each level of the framework.

\section{Level 4: Noticing Mathematical Features of Instruction}

At the highest level, teachers' statements lend evidence to suggest that they are engaging in the act of MQI Noticing, according to the definition described earlier in this paper. That is, a teacher at Level 4 attends to mathematical features of instruction and uses accurate evidence to support their statement about the mathematical feature of instruction.

Level 4 Example. The following statement that one teacher made about Clip 3 falls into Level 4: "There were many math errors here on the part of the teacher. For example, a half of a candy bar times a half of candy bar does not equal a whole candy bar." This statement is Level 4 MQI Noticing because it includes: a description of a mathematical feature of the instructional interaction that occurred within the lesson - in this case, a teacher's mathematical error; and accurate, evidence to support the claim, pointing to a specific error that the teacher made during the clip 
(the teacher's statement that half a candy bar times half a candy bar is a whole candy bar).

\section{Level 3: Noticing Mathematical Features of Instruction Without Evidence}

At Level 3 of the framework, teachers' statements lend evidence to suggest that they are essentially engaging in one of the two parts of MQI Noticing, but not both. Either they are noticing a mathematical feature of instruction but without evidence, or they are noticing another (non-mathematical) feature of instruction with correct evidence. In other words, statements at Level 3 either align with MQI Noticing on "What Teachers Notice" but not "How Teachers Notice," or vice versa.

Level 3, Example 1. The following statement that one teacher made about Clip 3 falls into Level 3, as opposed to Level 4, for its lack of evidence: "I noticed a lot of imprecision in the mathematical language." This statement it includes: a description of a mathematical feature - in this case, imprecise mathematical language; yet it lacks evidence to support the claim of imprecise mathematical language.

Level 3, Example 2. A second example of Level 3 MQI Noticing is the following statement that one teacher made about Clip 4: "He did not show why his 'trick' works by showing how $4 / 8$ is the same as $1 / 2$. .' This is an example of a teacher pointing to a mathematical feature of instruction was absent from the clip (the lack of connections between the paper model and the procedure for equivalent fractions). It was decided that all instances in which teachers correctly point out 
mathematical features of instruction that were absent from the clip would be categorized into Level 3.

Level 3, Example 3. As third example, the following statement is categorized into Level 3, because the teacher is noticing an other (non-mathematical) feature of instruction, and he or she identifies a specific instance from within the clip to support the statement: "The teacher asked students to share their thinking with each, like when she used the "turn and talk" prompt after posing the candy bar question." This is an example of a statement that aligns with "How Teachers Notice" on MQI Noticing, but not "What Teachers Notice".

\section{Level 2: Noticing Other Features of Instruction Without Evidence}

At Level 2 of the framework teachers' statements suggest that they are noticing features of instruction that are not mathematical (for example: pedagogical features of instruction or non-mathematical interactions between teacher and students), and they do not provide evidence with their statement.

Level 2 Example. The following statement that one teacher made about Clip 3 is coded into Level 2: "It was teacher-centered." This statement is Level 2 because it includes: a description of another (non-mathematical) feature of instruction and it was not supported by evidence. If this statement had been supported by specific evidence from within the clip, then it would be categorized into Level 3 instead.

\section{Level 1: Noticing Mathematics}


At Level 1 of the framework, teachers' statements reflect a description of the mathematics covered within the lesson. The salient feature of statements at this level is that they do not refer to any features (whether mathematical or not) of the interactions that happened during instruction (Cohen, Raudenbush, \& Ball, 2003). For example, "The lesson was about probability" is a statement about the mathematics in the clip that does not refer to any instructional interaction, and is therefore categorized at Level 1.

\section{Level 0: Inferences, Evaluations, Assumptions, Suggestions, or Commentary}

Level 0 of the framework is a catch-all category for any type of statement that was not a noticing statement. This is not to say that the teachers themselves did not engage in the act of noticing in order to produce the statement; and it is also not to say that the teachers did not engage in noticing in a different statement within the same multi-statement response. It simply means that the content of the statement does not reflect noticing. Examples of the nature of responses in this category include, but are not limited to: teachers' reflections on how the math problem could be used in his or her own classroom; a commentary on the importance of the mathematics addressed in the problem, unsupported evaluative comments about the clip ("I thought it was all great"), suggestions for how the instruction could have been better, and inferences about the goal of the lesson or students' level of understanding. Also included in this category are incorrect statements about features of instruction, meaning that the feature of instruction did not actually occur in the clip. Such statements were seen as inferences. 


\section{Using the Framework to Analyze Shifts in MQI Noticing}

To test the use of the framework, and to explore if there were measurable shifts in teachers' MQI Noticing as they progressed through the PD, I applied a statistical test to determine whether teachers' MQI Noticing levels increased from pre-PD to mid-PD to post-PD.

Coding Procedure. For all pre-PD, mid-PD and post-PD responses for all 60 MQI PD teachers, I coded each statement within the response using the MQI Noticing framework. Following this, each teacher was assigned the highest-level statement within his or her response. For example, if a teacher's response included 3 statements, two coded at Level 1 and one coded at Level 3, then the teacher would be given the code for the highest Level, which is Level 3. The rationale for using the maximum statement level was two-fold: (1) to use a statistical test of significance, I needed to assign each participant a single number at each time point, and (2) using maximums for each participant at each time point - as opposed to modes, means, medians, etc. - seemed to be the most appropriate number for testing if there truly was an increase in MQI Noticing because it assigned each participant to his or her highest level at every time point, regardless of the number of lower-level statements within the response at that time point.

Results. A table reflecting percentages of each level at each timepoint appears in Table 12. (Raw quantitative data appears in Appendix D.) To test the hypothesis that the levels of MQI Noticing for participants increased over time, I 
conducted a quantitative analysis of these data using Page's Trend Test. The results of the test suggested the rejection of the null hypothesis that no increase in the MQI Noticing levels of MQI PD teachers' responses over time (alpha $=.05, L=919, p<$ .001). These results support the claim that the MQI Noticing levels of participants' responses increased over time. That is, there is statistically significant support to suggest that the maximum-level statement within teachers' responses at each time point, increased as the PD progressed (max pre $<\max \operatorname{mid}<\max$ post).

Table 12

Percentage of participants by maximum MQI Noticing statement scores at pre, mid, and post- $P D$

\begin{tabular}{|l|l|l|l|l|l|}
\hline & Level 0 & Level 1 & Level 2 & Level 3 & Level 4 \\
\hline Pre & $17 \%$ & $38 \%$ & $22 \%$ & $14 \%$ & $7 \%$ \\
\hline Mid & $0 \%$ & $3 \%$ & $26 \%$ & $36 \%$ & $33 \%$ \\
\hline Post & $0 \%$ & $17 \%$ & $12 \%$ & $36 \%$ & $33 \%$ \\
\hline
\end{tabular}

An additional way to look at the same max-level data is to focus on change from one time-point to another. Table 13 shows three different time-point change comparisons in max-level scores: pre-to-mid, mid-to-post, and pre-to-post. For each of these three intervals, it displays the percentage of participants whose max-level scores decreased, the percentage of participants whose max-level scores were maintained, and the percentage of participants whose max-level scores increased across the interval.

Table 13

Percentage of participants according to change (decrease, maintenance, or increase) in maximum MQI Noticing statement scores across PD time intervals.

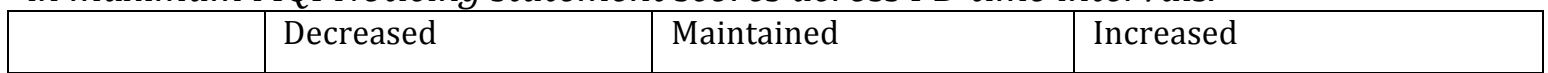




\begin{tabular}{|l|l|l|l|}
\hline Pre-to-Mid & $0 \%$ & $7 \%$ & $93 \%$ \\
\hline Mid-to-Post & $22 \%$ & $50 \%$ & $28 \%$ \\
\hline Pre-to-Post & $12 \%$ & $20 \%$ & $68 \%$ \\
\hline
\end{tabular}

Looking across the top row of Table 13, which pertains to comparisons between pre-PD to mid-PD, two things are immediately apparent. First, there were not any participants whose max-level scores decreased. Second, the vast majority of participants demonstrated max-level scores that increased over this time interval. These observations support the notion that attending the first half of the PD (during which the teachers went from absolutely no formal MQI training, to 5 weeks of MQI training), results in teachers improved MQI Noticing.

Looking across the middle row of Table 13, which pertains to comparisons between mid-PD to post-PD, the picture is more muddied. Exactly half of the participants maintained their max-level scores between mid-PD and post-PD, while $22 \%$ showed a decrease and $28 \%$ showed an increase. On the surface, this would seem to suggest that the later part of the PD did not further strengthen teachers' MQI Noticing. However, I argue that this is not necessarily the case for two reasons. (1) For approximately half the participants, there was a delay in the timing of their "post" responses. Some participants completed their responses more than a month after the PD ended, thus possibly dampening the apparent effect of the PD. (2) There is a ceiling effect in play in these data. Namely, $1 / 3$ of participants reached the highest level by mid-PD (see Table 12). Of those $1 / 3$ of participants, more than half (11 of 20) were still at the highest level at post-PD. So, while these participants 
might have demonstrated strengthened MQI Noticing from mid-PD to post-PD, that could not be captured by my framework. Four more of the $1 / 3$ of participants who demonstrated a max-level score of 4 at mid-PD decreased in max-level scores from mid-to-post PD, but they only dropped to level 3. In other words, because there was such a strong shift towards the max-level of MQI Noticing between pre-to-mid-PD, any impact of the later half of the PD is difficult to capture from an MQI Noticing perspective.

Nonetheless, looking at the final row of Table 13, which shows pre-PD to post-PD scores, we see that most participants (68\%) demonstrated an overall increase in max-level MQI Noticing scores, 20\% maintained their level, and only $12 \%$ showed a decrease. Coupled with the results of Page's Trend Test, it is unambiguous that the impact of the MQI PD can be seen through the trend of teachers' generally increased MQI Noticing. And further, the increase resulted in teachers' max-level scores being on the higher end of the scale by the conclusion of the PD, with $69 \%$ of participants at Level 3 or 4 at post-PD. By contrast, only $21 \%$ of participants were giving responses Level 3 or 4 at pre-PD.

\section{Statistical Tests of Validity}

After completing the MQI Noticing Framework, I conducted tests to determine whether there is preliminary support for the validity of the framework with respect to: (1) inter-rater agreement, and (2) the framework's ability to differentiate between groups that theoretically differ on MQI Noticing - MQI PD 
teachers and the group of comparison teachers. In this section, I describe the procedures and results for both types of validity, and I conclude with a discussion of other types of validity that would be relevant to explore in the future.

\section{Inter-Rater Reliability}

I calculated an intra-class correlation coefficient (ICC) to assess inter-rater reliability between two independent coders. According to Halgren (2012), ICC is an appropriate reliability statistic for use with ordinal data. The specific coding procedures used are described below, followed by a report of the results of our coding.

Coding Procedure. Myself and the other researcher independently coded twenty randomly-chosen statements for Clip 3 using the MQI Noticing Framework. There is no absolute rule about how many statements should be chosen to calculate inter-rater agreement, and the ICC takes into account the number of statements coded, with a higher score being more difficult to achieve with fewer ratings (Halgren, 2012). During our coding, both of us were blind to condition, and we categorized each statement into exactly one level of the framework.

Results. Commonly accepted cut-offs for ICC values are "poor" IRR for ICC values less than .40, "fair" for values between .40 and .59 , "good" for values between .60 and .74, and "excellent" for values between .75 and 1.0 (Cicchetti, 1994). The ICC coefficient for our coding was .72, which indicates "good" agreement between raters. 


\section{Differentiating Between Groups}

The ability of a coding rubric to differentiate between groups that theoretically differ on the construct that the rubric intends to code, is referred to as concurrent validity. In order to assess whether there is preliminary support for the concurrent validity of the MQI Noticing statement, I used a statistical test for ordinal data, called the Mann-Whitney U-test to compare the codes of responses to Clip 3 for the group of teachers in the MQI PD (mid-way through the program) versus the teachers' responses in the comparison group.

Before I continue, it is important that I highlight two things about this test of validity. First, since the intention here is to see if the framework distinguishes between the two groups of teachers, I wanted to eliminate any unbalancing effects of responses that include multiple statements. I was most interested in comparing the highest-level statement within each teacher's responses, across groups, regardless of whether the teacher also made lower-level statements within their response. So, I ran the statistical test on teachers' entire responses, rather than their individual statements. In order to do this, the MQI Noticing Framework was used to code individual statements, and then each teacher's response was given a code according to his or her highest-level statement within the response.

Second, this inquiry is based on the assumption that, if the result of the statistical test suggests that the MQI PD teachers (after more than 20 hours of training on the MQI instrument) differ from the comparison teachers according to 
the MQI Noticing framework, then this difference is on the construct of MQI

Noticing. Although the groups theoretically differ on this construct, this assumption could indeed be false. If the result of the statistical test is significant, perhaps the groups differ on some other construct that is not MQI Noticing. Significant results below imply that the framework differentiates between the two groups of teachers not necessarily that it differentiates the groups on the construct of MQI Noticing. Future work on construct validity will be needed in order to determine the later.

Coding Procedure. Continuing where the inter-rater agreement coding left off, myself and the other researcher met to resolve discrepancies between coded statements and agreed, through discussion, on a final code for these statements. Following this, each teacher was assigned the highest-level statement within his or her response. For example, if a teacher's response included 3 statements, two coded at Level 1 and one coded at Level 3, then the teacher would be given the code for the highest Level, which is Level 3.

Results. Table 14 displays the results of the coding of PD and comparison teachers' individual, typed responses to Clip 3. To test the hypothesis that the framework differentiates between groups that theoretically differ on MQI Noticing specifically, that the MQI PD teachers score higher on the MQI Noticing framework than comparison teachers do- I performed a Mann-Whitney $U$ Test. The results of the test suggested the rejection of the null hypothesis that the difference between the mean ranks of MQI PD teachers' and comparison teachers' responses were the result of a random sample of MQI Noticing Levels (alpha $=.05, U=529.0, p=.023$, 
one-tailed). This result lends early, preliminary support for the claim that the framework differentiates between groups that theoretically differ on the construct of MQI Noticing.

\section{Table 14}

Frequencies and percentages of MQI PD teachers' and comparison teachers' individual responses to Clip 3 (midway through the PD), according to their MQI Noticing level.

\begin{tabular}{|l|l|l|l|l|l|}
\hline & Level 4 & Level 3 & Level 2 & Level 1 & Level O \\
\hline $\begin{array}{l}\text { MQI PD } \\
\text { Teachers } \\
\mathrm{n}=60)\end{array}$ & & & & & \\
\hline Frequency & 19 & 22 & 18 & 1 & 0 \\
\hline Percentage & $32 \%$ & $37 \%$ & $30 \%$ & $2 \%$ & $0 \%$ \\
\hline $\begin{array}{l}\text { Comparison } \\
\text { Teachers } \\
(\mathrm{n}=13)\end{array}$ & & & & & \\
\hline Frequency & 2 & 3 & 6 & 0 & 2 \\
\hline Percentage & $15 \%$ & $23 \%$ & $46 \%$ & $0 \%$ & $15 \%$ \\
\hline
\end{tabular}

Note: Percentages total to 101\% (MQI PD teachers) and 99\% (comparison teachers) due to rounding to the nearest whole number percentages.

\section{Other Types of Validity}

The framework remains to be validated in important ways. For example, I have not explored its construct validity, which refers to whether or not the framework is measuring MQI Noticing, or if it is actually measuring something else. Nor have I explored its discriminant validity, which refers to whether or not the framework diverges from measuring constructs that it should not theoretically be related to. Finally, the results presented above are only preliminary and by no means complete the work on reliability or concurrent validity that should be done but is beyond the scope of this dissertation. 


\section{Discussion of Statistical Results}

The quantitative results presented up to this point in the chapter suggest that the modified version of the MQI Noticing Framework was indeed able to detect a statistically significant increasing shift in teachers' responses as they progressed through the PD. Below, I discuss limitations of these findings and argue for their importance nonetheless.

One potential concern with these findings pertains to whether participants' MQI Noticing was actually shifting or whether, instead, they were simply saying what they thought they were supposed to, knowing that they were responding to a data collection instrument associated with the MQI PD. Indeed, both are possible explanations for the shifts I found, and I argue that both explanations imply important developments on the part of the participants. Specifically, in the case where a participant is simply saying what they think the MQI PD project "wants to hear," it is highly unlikely that the participant would be able to produce a higherlevel MQI Noticing video response without noticing MQI-related features in that video clip. In other words, even if some participants' responses were artificially shifted towards reporting MQI-related features within a video clip, this still implies two important things: 1) They increasingly responded to the prompt "What stood out to you about the mathematics in this clip" by actually discussing mathematical features of instruction, regardless of their reasons for doing so; and 2) In order to be able to discuss these mathematical features of instruction in their responses, they would have needed to pick out these features from within the clip on their own. 
Thus, the statistically significant shifts identified within teachers' MQI Noticing are important, regardless of the teachers' motivations behind responding how they did.

That said, my statistical findings that show an increasing trend in MQI Noticing are undeniably constrained by the "snapshot" nature of the data collection. The fact that the teachers completed their video responses in three discrete moments in the timeline of the PD (pre, mid, and post) means that there are holes in the portrait of teachers' change in MQI Noticing between these data collection time points. Future exploration into teachers' session-to-session discussions and video coding during the PD would help fill in the gaps between the video response time points and help paint a more complete picture of teachers' MQI Noticing development.

On a similar note, the actual dates that the teachers completed their online video responses might have impacted the results I found. In particular, as I noted in the Methods Chapter, approximately half of the participants were as much as six weeks late in completing their post-PD video responses. In fact, some participants did not complete their final responses for more than eight weeks, meaning that their response could be characterized more accurately as "slightly delayed post-PD" rather than "immediately post-PD". If anything, though, this fact speaks to the power of the statistical findings I did find. Although the mid-to-post changes in MQI Noticing scores are not as strong as the pre-to-mid changes, the mid-to-post changes still reflect increasing MQI Noticing, even though about half of the participants waited about a month after the PD ended to fill out their post-PD video responses. 
Had all participants completed the post-PD response immediately after the conclusion of the PD program, the mid-to-post changes might have been even stronger. And as it stands, the mid-to-post changes that did show up suggests that the MQI PD might have lasting impact on teachers' noticing. This could be explored in future research via the collection and analysis of delayed post-PD responses (e.g., one year later).

Another limitation of my findings is that I only analyzed teachers' single maxlevel scores from their responses to two video clips at each time point. The changes in max-level scores I identified speak to a powerful shift in teachers' noticing, yet the levels of the all the other statements within teachers' responses were not reflected in these results. An analysis of the distribution of all the statements within teachers' responses would add to the interpretation of the statistical shifts in max-level scores. Thus, in the section below, I explore this idea by looking at two teachers' video clip responses in much more detail.

\section{Shifts in Two Teachers' Noticing as They Progressed Through the PD}

In this section, I dig deeper into the shifts in teachers' MQI Noticing that I identified above through statistical analyses by taking a close look at the journeys of two teachers from the MQI PD group that I facilitated, Michael and Hope, as they progressed through the MQI PD program. In Chapter 3, I explained why I chose Michael and Hope as focal participants, yet I will restate here that Michael and Hope are examples of "what is possible" or "what might happen" with respect to a classroom teacher's MQI Noticing journey as he or she goes through the MQI PD 
with ideal attendance and participation. As such, Michael and Hope are not representative of "typical" participation in the MQI PD, nor are they intended to be.

To understand Michael's and Hope's journeys, I present the MQI Noticing levels (see Table 11) of every statement within his or her individual typed responses to two short video clips. I do this for each video response time point throughout the PD (pre-PD, mid-PD, and post-PD; links to each video clip are in Appendix B, and MQI scores for each clip are in Chapter 3). In particular, I focus on the proportion of statements at each level within the responses at each time point, paying particular attention to the proportion of Level 3 and 4 statements, in which the teacher is attending to the mathematical features of instruction in the clips either with evidence (Level 4) or without (Level 3). I chose to look at proportions, rather than raw counts because it makes comparisons across time points more clear (factoring out the "number of total statements" variable across time points).

After articulating each participant's MQI Noticing levels at each time point, I then describe salient qualitative features of the teacher's responses at each time point. Next, I look across time points within each participant to describe both quantitative and qualitative shifts that I observe in his or her MQI Noticing development. I conclude the section on each participant by arguing that his or her journey can be characterized more broadly (i.e., explaining that this is an example of...) within the larger dataset of all participants.

Prior to presenting these analyses, however, I introduce the teachers via basic demographic information and their scores on the LMT survey (which assesses MKT) completed on the first day of the Summer training session of the PD. 


\section{Michael's MQI Noticing Journey}

\section{Background: Before the PD}

Demographic Information. In the Summer of 2014, immediately prior to the beginning of the PD, Michael was preparing to enter his $16^{\text {th }}$ year teaching mathematics to children. In the 2014-15 school year, he was a fulltime multi-subject fifth grade teacher at a K-5 elementary school in a midsized urban school district in the Northwestern U.S.

MKT. According to his responses on the LMT Survey for Elementary Teachers, Michael's MKT was strong coming into the PD. Of the seventeen questions on the survey, Michael answered fifteen correct (88\%), which is in the top quintile of elementary teachers' scores nationally (H. Hill, personal communication, June $10^{\text {th }}, 2015$ ) and is well above the average of $70 \%$ for all MQI PD teachers (including treatment and control teachers).

\section{Michael's Video Responses}

Overview. Michael's pre-, mid-, and post-PD video clip responses and their levels according to the MQI Noticing framework appear in Table 15 below. In the paragraphs below, I show that Michael's statements become increasingly dense with Levels 3 and 4 MQI Noticing statements as he focuses in on mathematical features of 
instruction more frequently as the PD progresses. Further, he more frequently references specific instances to support his statements. 


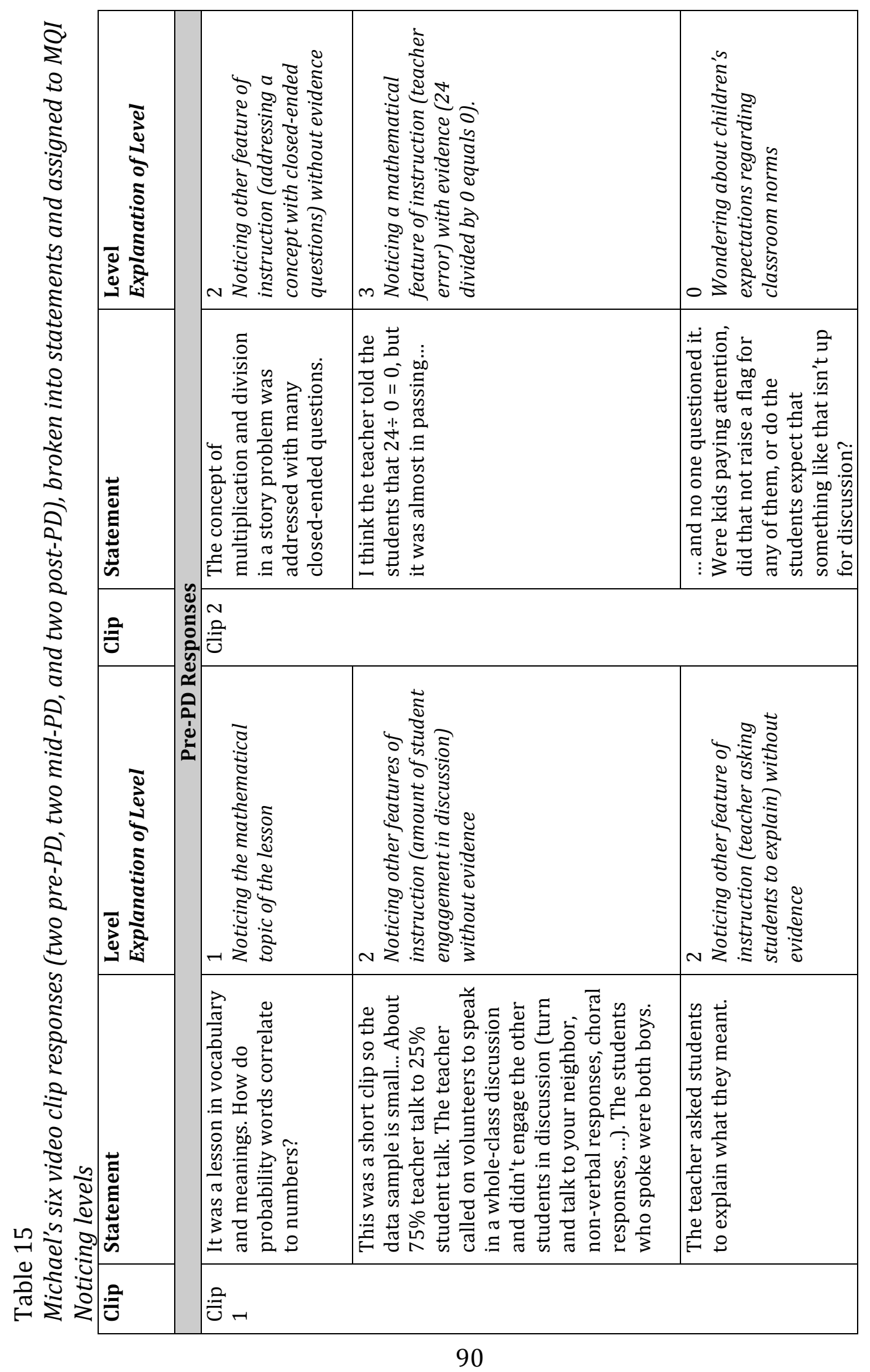




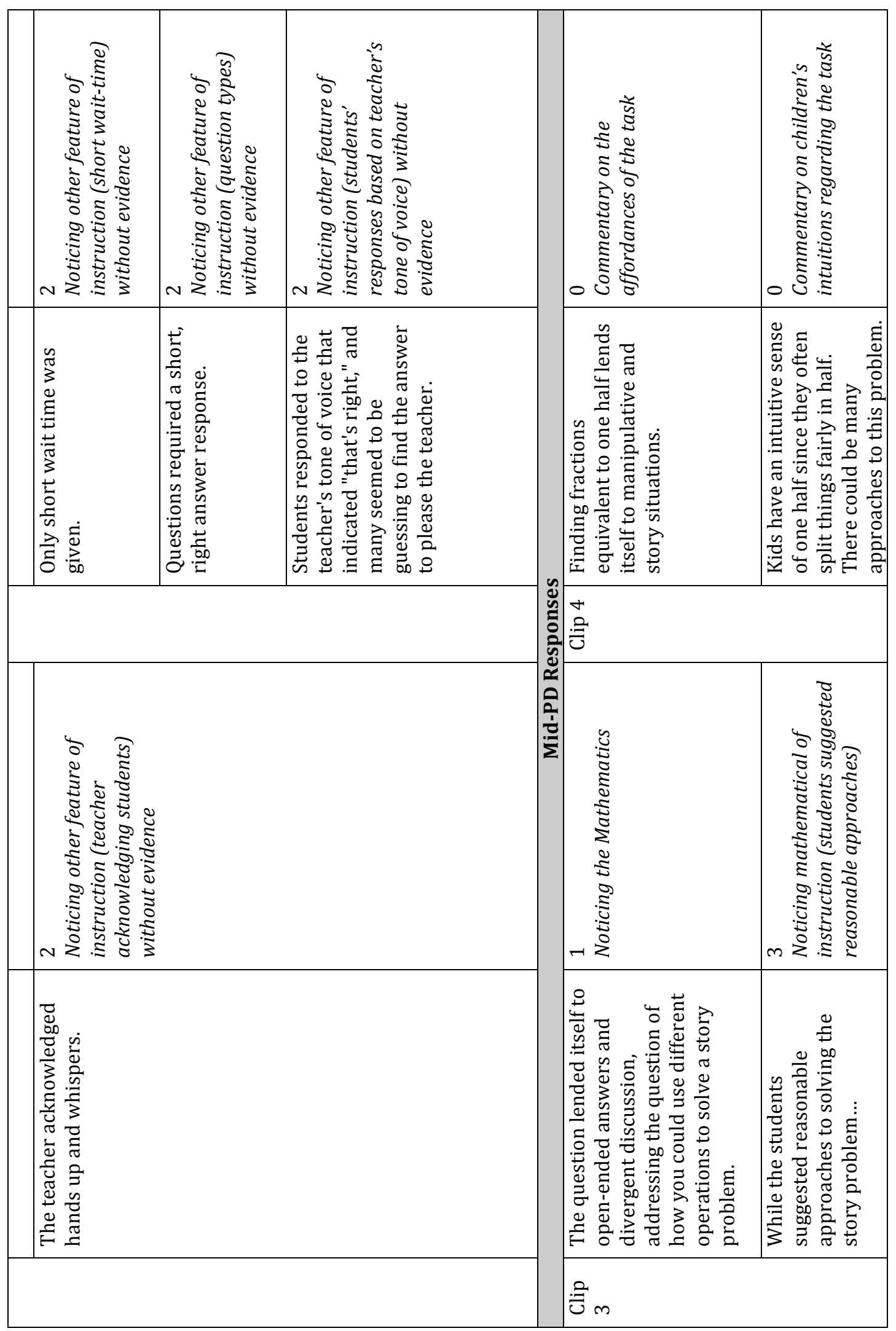




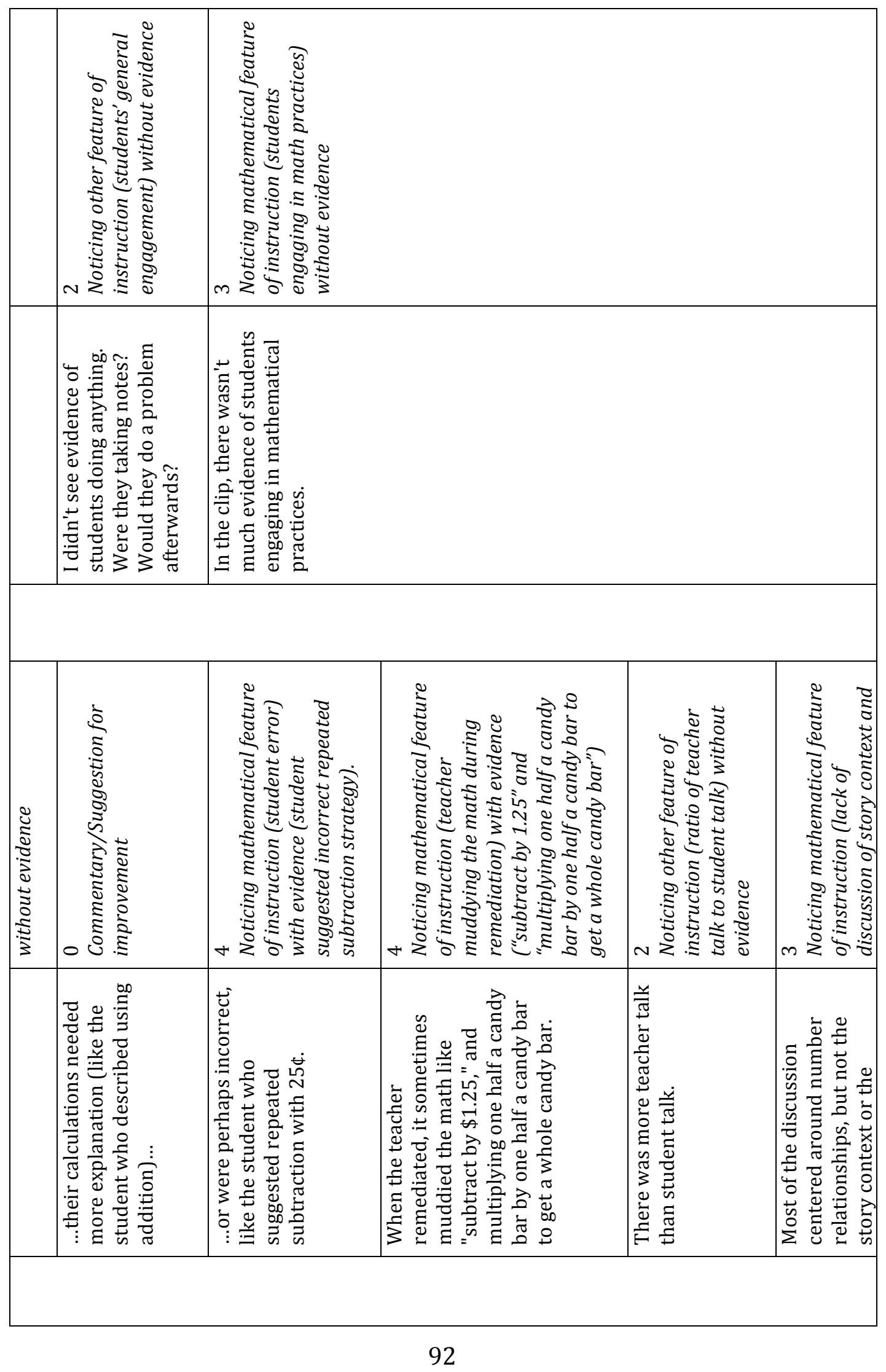




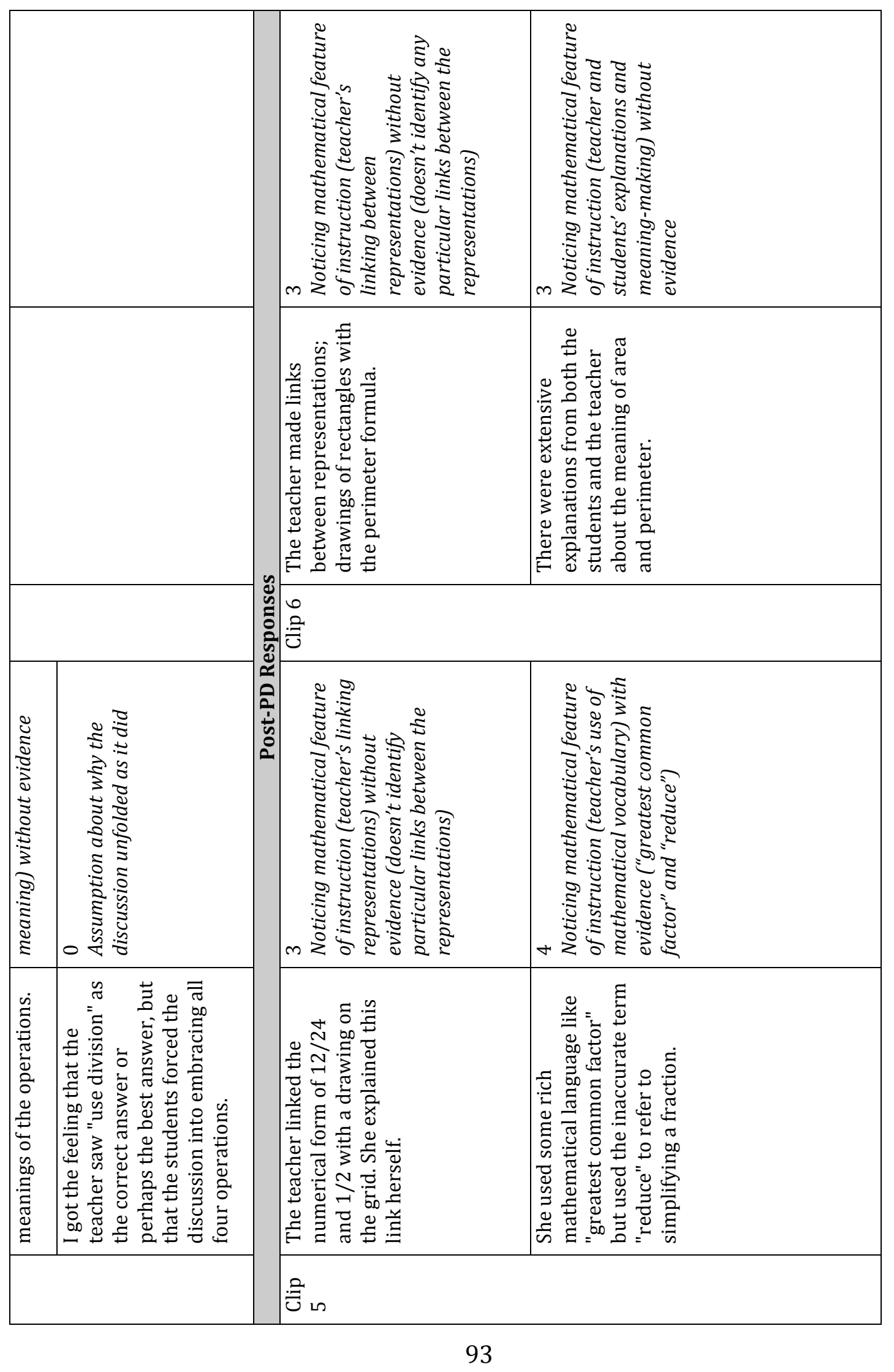




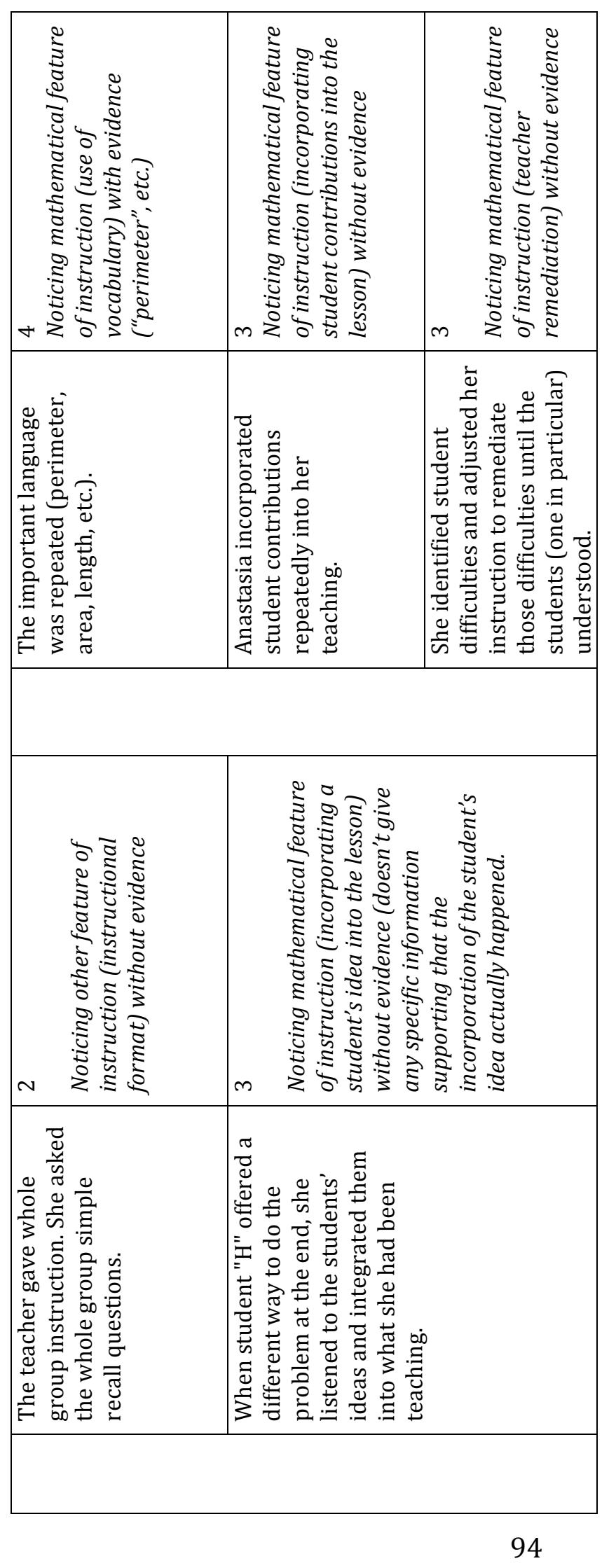


Michael's pre-PD video responses. Most (7 out of 10, or 70\%) of Michael's pre-PD video response statements reflected Level 2 MQI Noticing - Noticing other features of instruction without evidence. His Level 2 statements primarily center on the structure of the discourse and questioning that took place within the clips (e.g., "75\% teacher talk to $25 \%$ student talk" and "questions required a short rightanswer response"). Only one of his statements (10\%) is categorized at Level 3 because it is about the quality of the mathematical content within the instruction, and none of his statements are categorized as Level 4 .

Michael's mid-PD responses. Michael's mid-PD video response statements spanned from Level 0 through Level 4. In his thirteen mid-PD statements, five of them (38\%) are at Level 0, which included Michael's commentary on the task or why the lesson unfolded as it did. Apart from these Level 0 comments, though, the distribution of his mid-PD statements are similar to that of his pre-PD statements, except he had a higher percentage of statements at Level 4. Five of his statements were at Level 3 or 4 (38\%), and two were at Level 2 (15\%). His Level 3 and 4 MQI Noticing statements pertained to mathematical features of instruction, such as: the accuracy of teachers' and students' mathematical contributions, and also with the level of engagement in the mathematics that students were demonstrating within the clip. The Level 2 statements were similar in nature to his Pre-PD statements; commenting on the overall task ("the question lended (sic) itself to open-ended 
answers and divergent discussion...") and the structure of the classroom discourse ("There was more teacher talk than student talk.")

Michael's post-PD video responses. In contrast to the previous two response time points, most ( 8 out of 9, or 89\%) of Michael's post-PD video responses reflected Level 3 or Level 4 MQI Noticing. For both clips, he pointed out a wide range of mathematical features of instruction. For example, Michael notes that, in Clip 6, "there were extensive explanations from both the students and the teacher about the meaning of area and perimeter." Some of Michael's post-PD statements (2 out of 9, or 22\%) were categorized into Level 4 because he referenced specific instances from within the clip to support his claims. For example, Michael stated, "she [the teacher] used some rich mathematical language like 'greatest common factor' but used the inaccurate term 'reduce' to refer to simplifying a fraction."

\section{Shifts in Michael's video responses across time points. Looking} quantitatively across data collection time points, Michael's video responses included a marked increase in the proportion of statements that reflected either Level $4 \mathrm{MQI}$ Noticing (Noticing a mathematical feature of instruction with evidence) or Level 3 MQI Noticing (Noticing a mathematical feature of instruction without evidence). In particular: one out of ten $(10 \%)$ of his pre-PD statements were Level 3 or 4 ; five out of thirteen (438\%) of his mid-PD statements were at Level 3 or 4; and eight out of nine (89\%) of his post-PD statements were Level 3 or 4 MQI Noticing. Put another way, at pre-PD, only one of Michael's statements was at Level 3 or 4, yet by post-PD only one of Michael's statements was not at Level 3 or 4 . This reflects a substantial 
and steady shift in the amount of strong MQI Noticing statements within his responses as the PD progressed. Michael's percentages for each MQI Noticing level at each time point are shown in Table 16.

Qualitatively, the overall focus of Michael's responses shifted from comments about general features of instruction ("about 75\% teacher talk, 25\% student talk"), towards mathematical features of instruction (e.g., "there were extensive explanations from both the teacher and the students about the meaning of area and perimeter") Additionally, at mid-PD and at post-PD, some of Michael's statements about mathematical features of instruction were supported by references to specific instances from within the clip, which were not included in his pre-PD responses.

Table 16

Percentages of MQI Noticing Levels of Michael's video response statements at Pre-PD, Mid-PD, and Post-PD

\begin{tabular}{|l|l|l|l|l|l|}
\hline & Level 4 & Level 3 & Level 2 & Level 1 & Level 0 \\
\hline Pre & $0 \%$ & $10 \%$ & $70 \%$ & $10 \%$ & $10 \%$ \\
\hline Mid & $15 \%$ & $23 \%$ & $15 \%$ & $8 \%$ & $38 \%$ \\
\hline Post & $22 \%$ & $67 \%$ & $11 \%$ & $0 \%$ & $0 \%$ \\
\hline
\end{tabular}

Note: Percentages are approximate and might not sum to exactly $100 \%$.

\section{Hope's MQI Noticing Journey}

\section{Before the PD}

Demographic Information. In the Summer of 2014, immediately prior to the beginning of the PD, Hope was preparing to enter her $25^{\text {th }}$ year teaching 
mathematics to children. In the 2014-2015 school year, she was a fulltime multisubject third grade teacher at the same K-5 midsized elementary school as Michael.

MKT. According to her responses on the LMT Survey for Elementary Teachers, Hope's MKT was strong coming into the PD. Of the seventeen questions on the survey, she answered sixteen correct (94\%), which is in the top quintile of elementary teachers' scores nationally $\left(\mathrm{H}\right.$. Hill, personal communication, June $10^{\text {th }}$, 2015) and is well above the average of 70\% for all MQI PD teachers (including treatment and control teachers).

\section{Hope's Video Responses}

Overview. In this section, I argue that Hope's responses (see Table 17) become denser with Level 3 statements when comparing her pre-PD to mid-PD responses, and that her mid-PD and post-PD responses consist of similarlydistributed levels as one another. Further I will point to her shift towards a checklist-type approach to responding to video clips. 


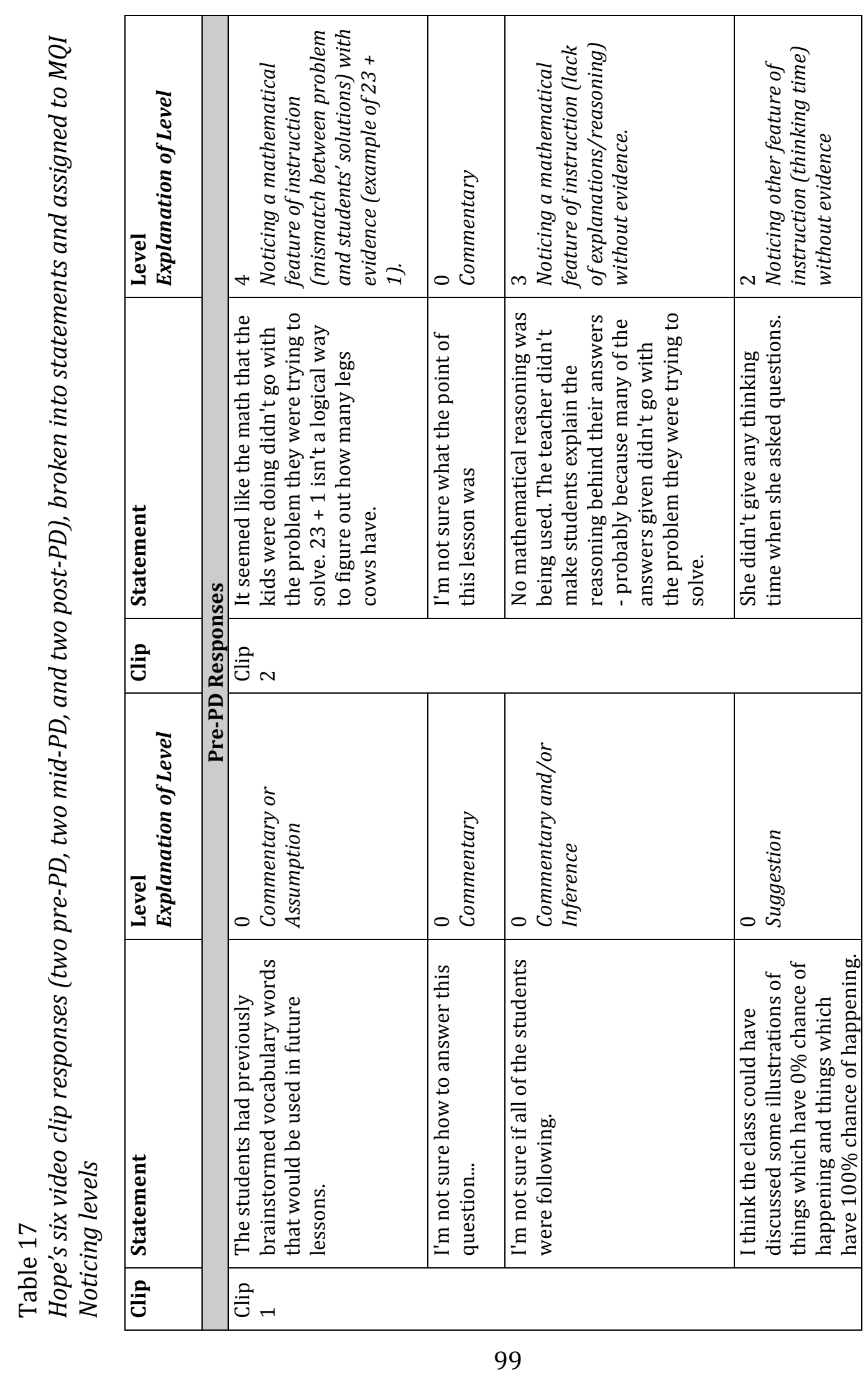




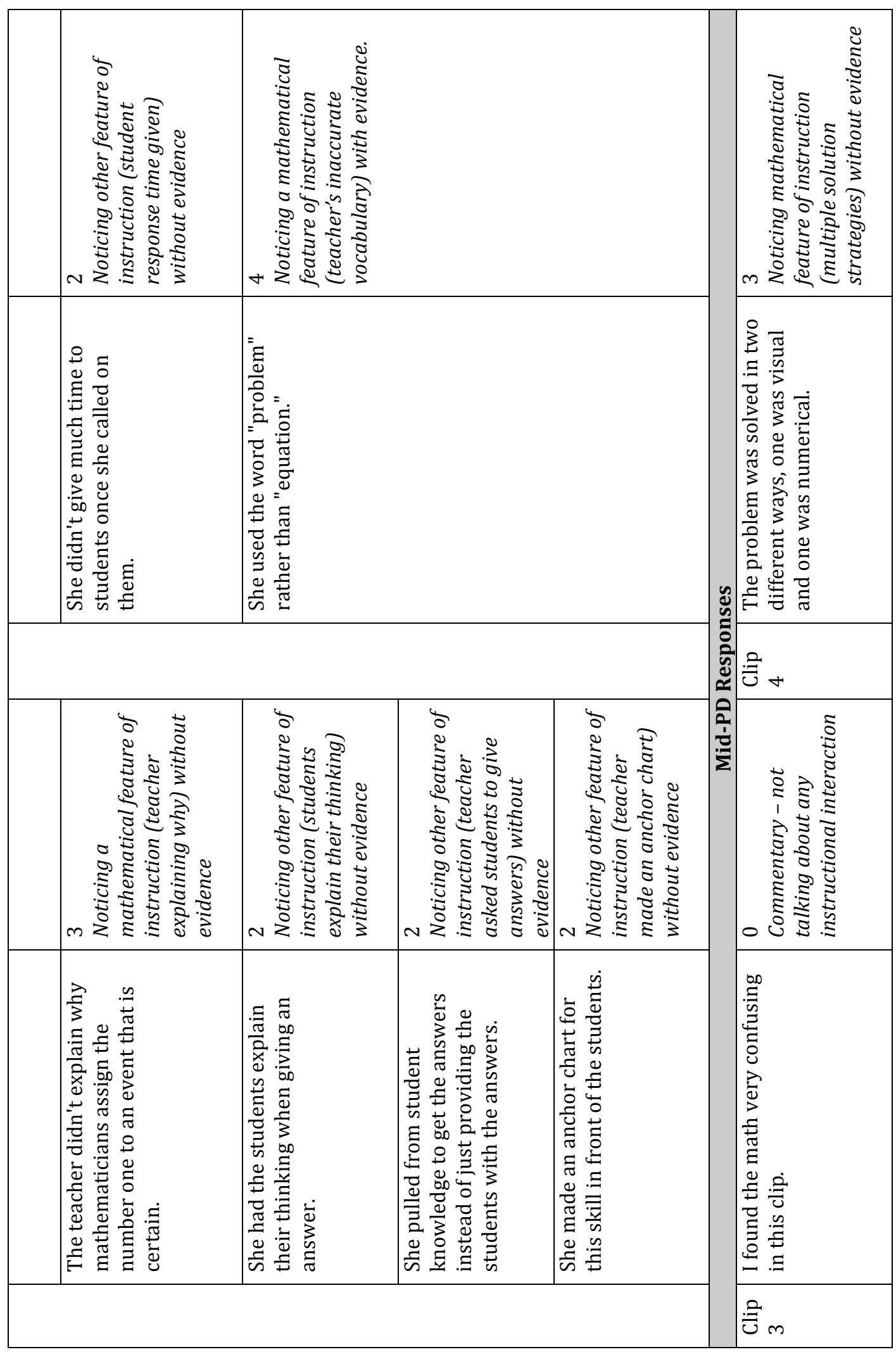




\begin{tabular}{|c|c|c|c|c|c|}
\hline 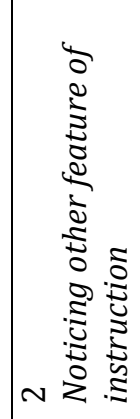 & $m$ & 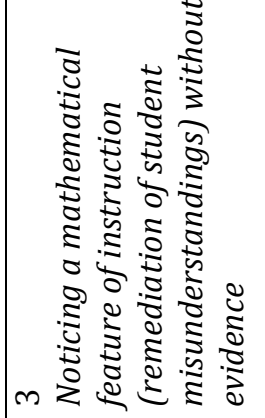 & 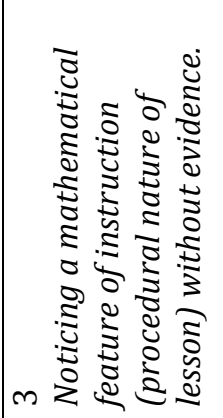 & 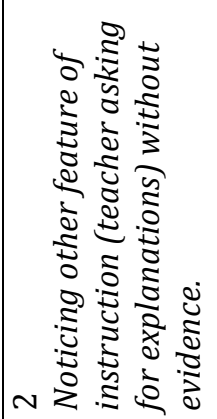 & $m$ \\
\hline 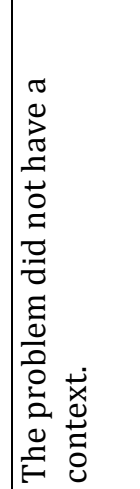 & 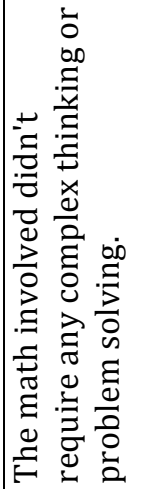 & 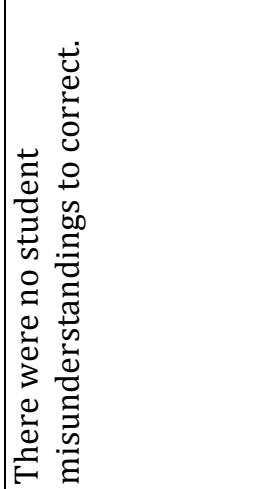 & 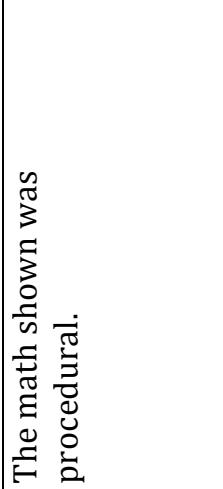 & 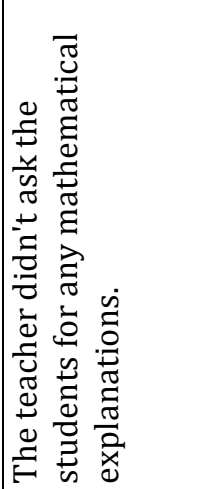 & 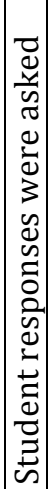 \\
\hline
\end{tabular}

\begin{tabular}{|c|c|c|c|}
\hline 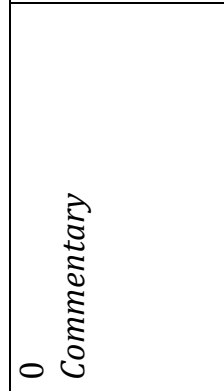 & 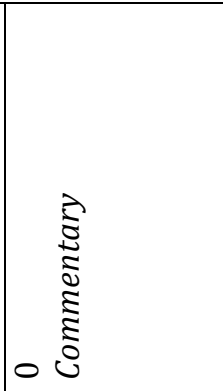 & 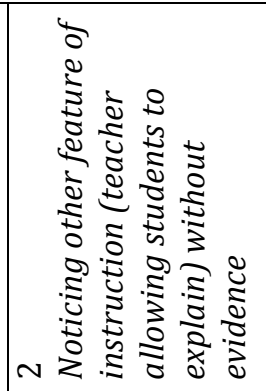 & 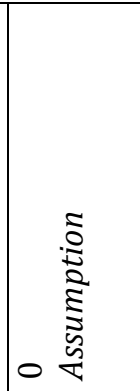 \\
\hline 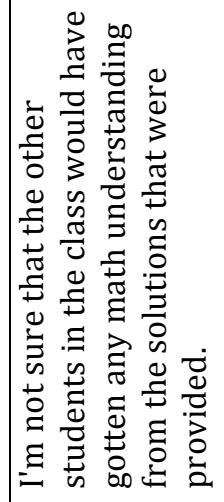 & 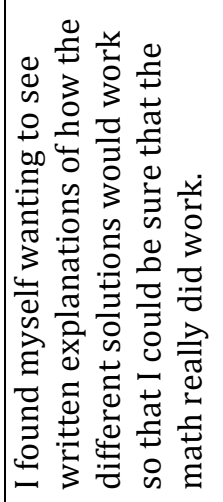 & 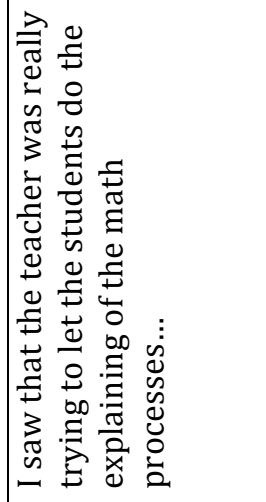 & 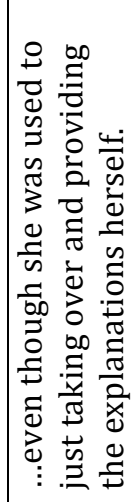 \\
\hline
\end{tabular}




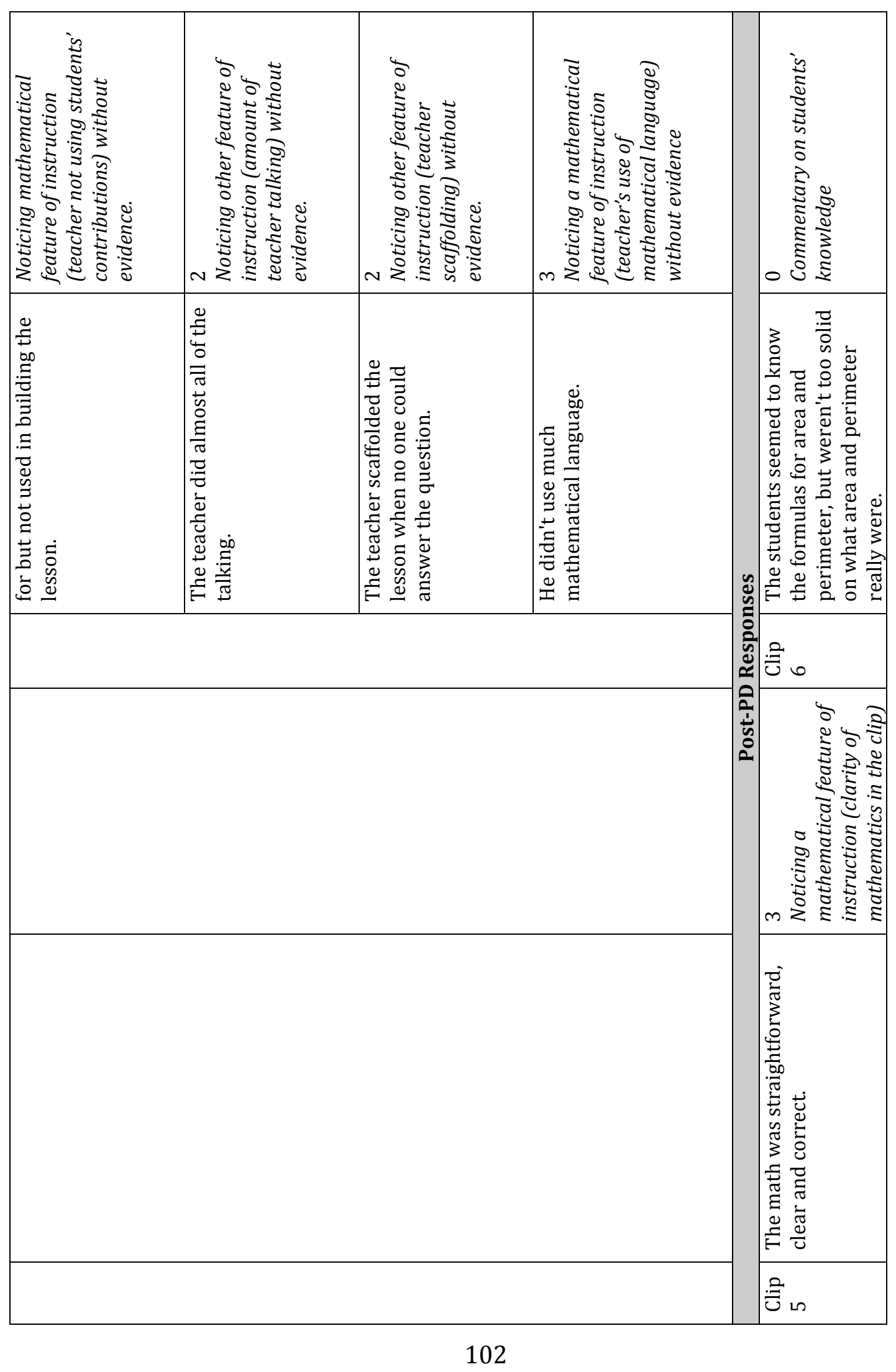




\begin{tabular}{|c|c|c|c|c|c|}
\hline & 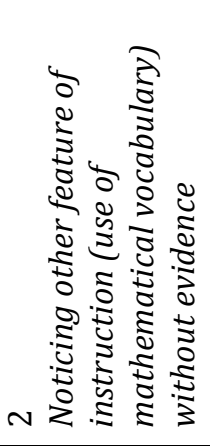 & 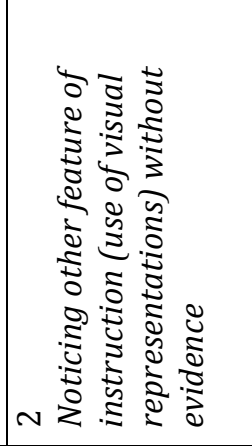 & 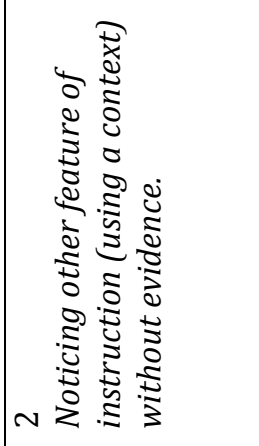 & 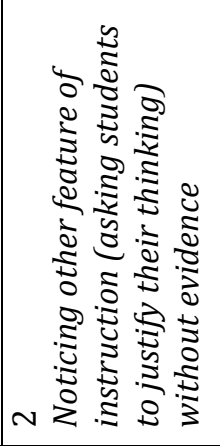 & 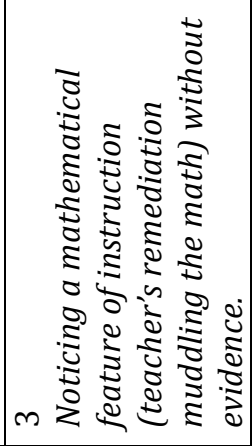 \\
\hline & 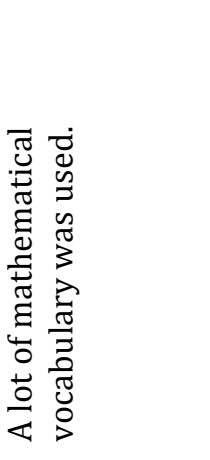 & 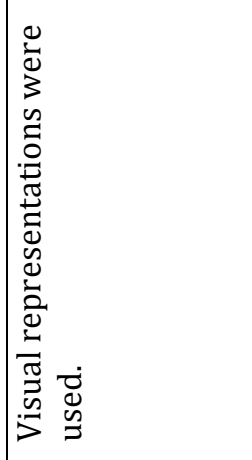 & 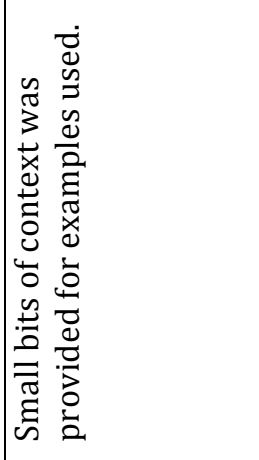 & 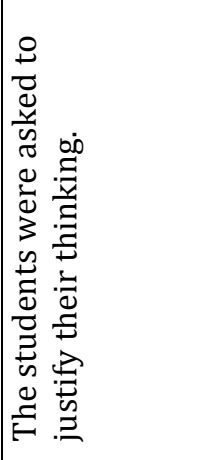 & 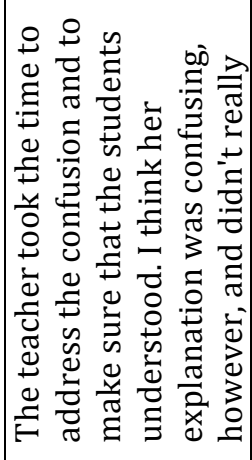 \\
\hline 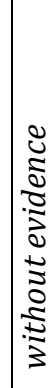 & 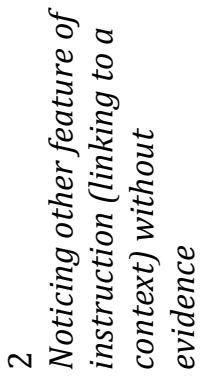 & 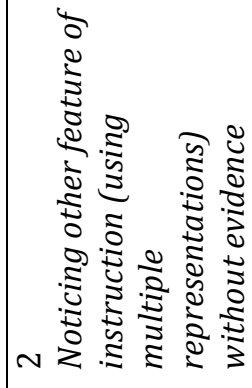 & 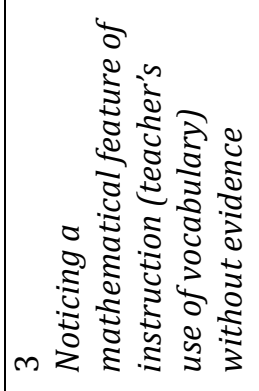 & 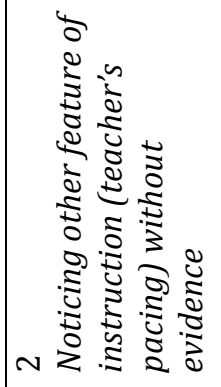 & 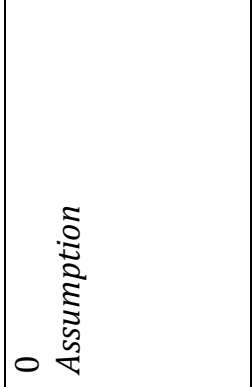 \\
\hline & 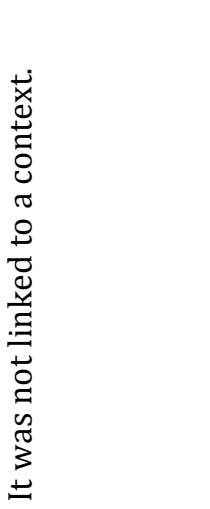 & 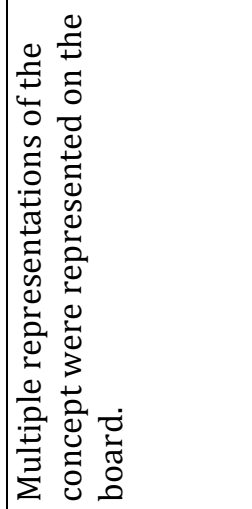 & 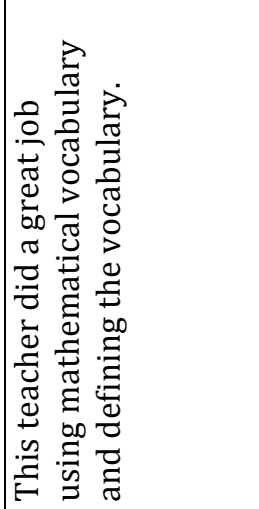 & 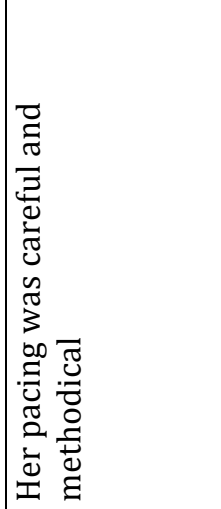 & 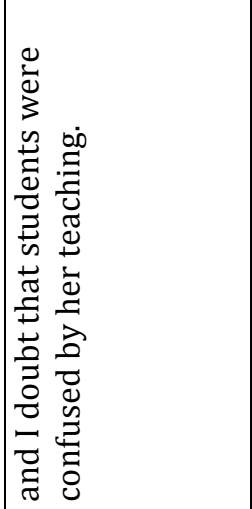 \\
\hline
\end{tabular}




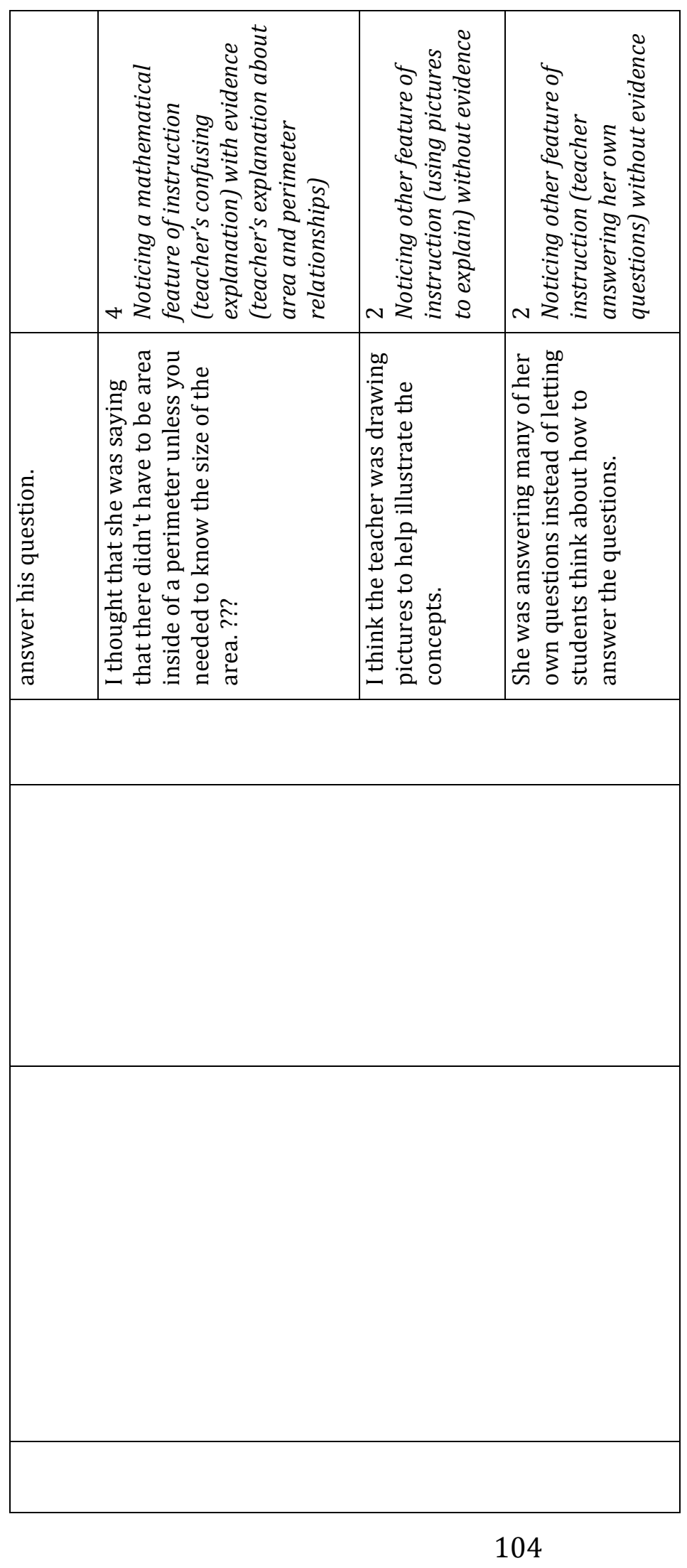


Hope's pre-PD video responses. Hope's pre-PD responses can be almost equally split between "Low", “Mid”, and "High” MQI Noticing. Her pre-PD statements were assigned at the following levels: Level 0 ( 5 out of 14, or 36\%), Level 2 (5 out of 14, or $36 \%$ ), and Level 3 or 4 ( 4 out of 14 , or $28 \%$ ). Some of her statements pointed to her noticing of MQI-related features of instruction, particularly regarding her noticing the absence of some MQI-related features (e.g., "the teacher didn't explain why mathematicians assign the number one to an event that is certain" and "no mathematical reasoning was being used"). Other statements in her pre-PD responses reflected Hope's noticing of more general pedagogical features of the enacted instruction - for example, her attention to the teacher's wait time or the use of an anchor chart during the lesson. A third group of statements, her Level 0 statements, included her more broad reflections and commentary: for example, her confusion about how to answer the response prompt ("I'm not sure how to answer this question"), and her uncertainty about the purpose of the lesson ("I'm not sure what the point of this lesson was"). In this way, Hope's pre-PD responses reflect a wide range of MQI Noticing levels.

Hope's mid-PD and post-PD video responses. Hope's mid-PD and post-PD video responses had nearly identical distributions, and so they are discussed together here. Her mid-PD and post-PD statements included statements at Level 0, level 2, and Level 3 or 4, with almost half of her statements ( 6 out of 15 , or $40 \%$ at mid-PD; 7 out of 16, or $47 \%$ at post-PD) at Level 3 . Her other statements were split between Level 2 and Level 0 , with the exception that one of her post-PD statements was at Level 4. The nature of her most frequent-level statements, Level 3 
statements, reflected her attention to both the presence (e.g., "the math shown was procedural") and the absence (e.g., "he didn't use much mathematical language") of mathematical features of instruction. Further, her Level 3 responses seem to suggest that Hope was running down a mental or physical list of features of instruction, making present/absent remarks (without specific evidence) on each of these features. This approach to responding to video clips makes sense in light of the way the MQI instrument partitions instruction into discrete sections, which could be thought of as a list of MQI-related features of instruction.

Apart from her Level 3 statements, Hope's mid-PD and post-PD statements at Level 2 were reminiscent of her Level 2 statements at pre-PD. Specifically, her Level 2 statements reflected attention to general pedagogical features of instruction (e.g., scaffolding the lesson).

Hope's video responses across time points. Looking quantitatively across data collection time points, Hope's video responses included a noticeable increase in the proportion of statements that reflected either MQI Noticing with Evidence (Level 4) or MQI Noticing without Evidence (Level 3) from pre-PD to mid-PD, and the proportions remained steady from mid-PD to post-PD. Hope's percentages for each MQI Noticing level at each time point are shown in Table 18.

Qualitatively, as the PD progressed, the nature of Hope's responses seem to take on a checklist-like quality with respect to MQI-related features of instruction, commenting on MQI-related features without many references to specific examples from within the video clip. At pre-PD, she comments that she is not quite sure how 
to answer the question of "What stood out to you about the mathematics in this clip?" By mid-PD, she seems to have a clear idea of how to answer the question: by going through items she has learned about from the MQI PD.

Table 18

MQI Noticing Levels of Hope's video response statements at pre-PD, mid-PD, and post$P D$

\begin{tabular}{|l|l|l|l|l|l|}
\hline & Level 4 & Level 3 & Level 2 & Level 1 & Level 0 \\
\hline Pre & $14 \%$ & $14 \%$ & $36 \%$ & $0 \%$ & $36 \%$ \\
\hline Mid & $0 \%$ & $40 \%$ & $33 \%$ & $0 \%$ & $27 \%$ \\
\hline Post & $6 \%$ & $47 \%$ & $31 \%$ & $0 \%$ & $19 \%$ \\
\hline
\end{tabular}

${ }^{1}$ Note: Percentages are approximate and might not sum to exactly $100 \%$.

\section{Discussion \& Conclusion}

Earlier in this chapter, I presented a multiple-level ordinal framework of MQI Noticing, and I demonstrated its use by finding statistically significant shifts in teachers' responses as they progressed through the MQI PD. As this is the first instance of an empirical inquiry into teachers' MQI Noticing, this is an important result in and of itself because it lends support to the notion that the MQI PD helped teachers develop their MQI-specific noticing skills.

To complement these quantitative results, I then took a closer look at the nature of Michael's and Hope's shifts in MQI Noticing by detailing the MQI Noticing journeys of two teachers in the MQI PD. These two teachers' MQI Noticing journeys are two examples of what a strong experience in the PD might entail, with respect to the development of MQI Noticing. Specifically, Michael's MQI Noticing strengthens in such a way that it becomes more focused on salient aspects from within a specific episode of instruction (e.g., a video clip), supporting statements with evidence. 
Hope's MQI Noticing strengthens in a different way. The nature of her MQI Noticing by the end of the PD includes scanning for many MQI-related features and remarking about their presence or absence.

Limitations of these results are similar in nature to the limitations of the statistical analyses and findings discussed earlier in this chapter. Most notably, these are "snapshot" looks at MQI Noticing - not developmental "movie" pictures of teachers' learning. And secondly, the delay in teachers' post responses should be taken into account, meaning that the "post-PD" responses for Michael and Hope are more accurately "delayed post-PD" responses.

With these limitations in mind, though, the findings presented in this chapter are an important advancement into the study of teachers' MQI Noticing. I have shown that degrees of teachers' MQI Noticing can be conceptualized via a multi-level framework, and that a mathematized version of that framework can be used to identify statistically significant shifts in teachers' MQI Noticing as the MQI PD progressed. Moreover, my findings illuminated the nature of such shifts for two teachers whose MQI Noticing strengthened as the PD progressed. Clearly, further research into these ideas is warranted - particularly: investigations into the development of teachers' MQI Noticing (not just "snapshot" shifts), explorations of more individual examples of MQI Noticing throughout the PD, identification of factors that might support strong and/or sustained learning of MQI Noticing in a PD setting, and application of the MQI Noticing framework to other data collected throughout the PD. 


\section{CHAPTER 5: RESEARCH METHODS II}

In this short chapter, I introduce the methods I used to explore my second research question:

(2) How do teachers approach the task of noticing students' engagement in mathematical practices?

The research setting and theoretical perspectives are unchanged from those introduced in the first methods chapter of this dissertation (Chapter 3), so I will not repeat them here. What is distinct in this chapter from the first methods chapter, though, are the particular set of participants, data analyzed, and procedures for analysis. Below, I describe each of these as they pertain to the second research question.

\section{Participants, Dataset, and Analyses for Research Question 2}

\section{Brief Overview}

The goal of this investigation was to identify and explicate the ways in which teachers approached the task of noticing students' engagement in mathematical practices. To accomplish this, I used thematic analyses (Braun \& Clarke, 2006) on transcripts of the MQI PD teachers' group conversations. In particular, the conversations consisted of teachers' discussions of possible instances of students' mathematical practices (as identified by the teachers themselves), after having watched short video clips of instruction together during the Fall PD sessions. All 
such conversations that occurred within the first six weeks ${ }^{8}$ of the PD were included in these analyses.

\section{PD Activities Pertaining to Students' Mathematical Practices}

The participants' efforts to identify and discuss students' mathematical practices occurred in the specific context of a video-coding task that occurred on multiple occasions throughout the MQI PD. The PD teachers were specifically tasked with scoring video clips on the Common Core Student Practices (CCSP) dimension of the MQI instrument. Two of the three sub-dimensions (called "codes" in the MQI PD) within the CCSP dimension are defined in explicit reference to instances of students' engagement in mathematical practices. The first of these codes, Student Engagement in Mathematical Practices (SEMP), is intended to capture the quantity of instances of students' explaining reasoning, conjecturing, asking mathematical questions, pattern noticing, commenting on another student's work, and/or engaging in reasoning about mathematics, etc. The four score points for this code (the criteria for which are shown in Figure 15) depend explicitly on the degree to which the classroom clip is dense with instances of students' engagement in these mathematical practices.

8 There were ten Fall PD sessions in total. However, sessions 7 through 10 are omitted from the present analysis due to the fact that teachers were scoring video clips from their own classrooms during these later weeks. The nature of these later weeks' scoring discussions was uniquely sensitive and included social considerations that call for different analyses in future research. 
The second code, Enacted Task Cognitive Activation (ETCA) aims to capture the demand of the task as it was enacted within the clip, in terms of the amount of mathematical invention, explanation, connection-forging, and so on, that the majority of students in the class were doing. This code has a different emphasis than the code above; in particular, it pertains to the overall level of cognitive engagement of the lesson, as opposed to pertaining solely to instances of students engaging in math practices. Nonetheless, it is important to note that two of the four score points for the ETCA code ("Low" and "Mid") include an explicit reference to "students engagement in mathematical practices" (see Figure 11). Thus, when scoring with the ETCA code, teachers were still tasked with looking for and deliberating on instances of students engaging in the math practices.

\begin{tabular}{|c|c|c|c|}
\hline \multicolumn{4}{|c|}{$\begin{array}{l}\text { Student Engagement in Mathematical Practice Students engage in Mathematical Practices, } \\
\text { including explaining their reasoning, conjecturing, asking a mathematical question, pattern } \\
\text { noticing, commenting on another student's work, and/or engaging in reasoning about } \\
\text { mathematics. }\end{array}$} \\
\hline $\begin{array}{l}\text { Not Present } \\
\text { No student } \\
\text { engagement in } \\
\text { mathematical } \\
\text { practices. There are } \\
\text { no instances of } \\
\text { student explanations, } \\
\text { conjecturing, or } \\
\text { reasoning. }\end{array}$ & $\begin{array}{l}\text { Low } \\
\text { There are one or two } \\
\text { instances of student } \\
\text { engagement in } \\
\text { mathematical } \\
\text { practices. }\end{array}$ & $\begin{array}{l}\text { Mid } \\
\text { Student engagement } \\
\text { in mathematical } \\
\text { practices is more } \\
\text { sustained or more } \\
\text { often, but not } \\
\text { characteristic of the } \\
\text { clip. }\end{array}$ & $\begin{array}{l}\text { High } \\
\text { Student } \\
\text { engagement in } \\
\text { mathematical } \\
\text { practices } \\
\text { characterizes the } \\
\text { clip. }\end{array}$ \\
\hline \multicolumn{4}{|c|}{$\begin{array}{l}\text { Enacted Task Cognitive Activation The amount of mathematical invention, explanation, } \\
\text { connection-forging, and so on, that students do in the context of engaging in the task. }\end{array}$} \\
\hline $\begin{array}{l}\text { Not Present } \\
\text { Students are not } \\
\text { engaged in the } \\
\text { mathematics. The } \\
\text { instruction is teacher- } \\
\text { led with no interaction } \\
\text { with students. }\end{array}$ & $\begin{array}{l}\text { Low } \\
\text { Students engage with } \\
\text { the content at a low } \\
\text { cognitive level, such as: } \\
\text { - } \quad \text { Recalling/applying } \\
\text { well-established } \\
\text { procedures, facts, } \\
\text { rules, or formulas; }\end{array}$ & $\begin{array}{l}\text { Mid } \\
\text { Students engage with } \\
\text { content at a middling } \\
\text { or mixed level of } \\
\text { cognitive activation. } \\
\text { May include: } \\
\text { - Task starts high, } \\
\text { then cognitive }\end{array}$ & $\begin{array}{l}\text { High } \\
\text { Students engage } \\
\text { with content at a } \\
\text { high level of } \\
\text { cognitive } \\
\text { activation. For } \\
\text { example, students: } \\
\text { - Determine the }\end{array}$ \\
\hline
\end{tabular}




\begin{tabular}{|c|c|c|c|}
\hline & $\begin{array}{l}\text { - Applying } \\
\text { procedures without } \\
\text { attention to } \\
\text { meaning; OR } \\
\text { Direct Instruction } \\
\text { with one or two } \\
\text { examples of } \\
\text { student } \\
\text { engagement in } \\
\text { mathematical } \\
\text { practices } \\
\text { Listening to a } \\
\text { teacher with } \\
\text { limited student } \\
\text { input } \\
\text { Unsystematic } \\
\text { exploration }\end{array}$ & $\begin{array}{l}\text { demand devolves } \\
\text { - Change in task } \\
\text { level mid- } \\
\text { segment } \\
\text { - Students working } \\
\text { on the same task } \\
\text { at different levels } \\
\text { - Direct instruction } \\
\text { with student } \\
\text { engagement in } \\
\text { mathematical } \\
\text { practices at } \\
\text { certain points. }\end{array}$ & $\begin{array}{c}\text { meaning of } \\
\text { mathematica } \\
\text { l concepts, } \\
\text { processes or } \\
\text { relationships } \\
\text { - Draw } \\
\text { connections } \\
\text { among } \\
\text { different } \\
\text { representati } \\
\text { ons or } \\
\text { concepts } \\
\text { Make and test } \\
\text { conjectures } \\
\text { Look for } \\
\text { patterns } \\
\text { Examine } \\
\text { constraints } \\
\text { Explain and } \\
\text { justify } \\
\text { Talk about or } \\
\text { describe any } \\
\text { of the above. }\end{array}$ \\
\hline
\end{tabular}

Figure 11. The score points for the Student Engagement in Mathematical Practices and Enacted Task Cognitive Activation codes, with explicit references to the phrase "student engagement in mathematical practices" underlined and bolded

\section{Participants and Dataset}

I analyzed transcripts of discussions that took place in the group I facilitated. In particular, I analyzed transcripts of all discussions that occurred within the first six Fall sessions of the MQI PD that satisfied the criterion of being a video clip discussion in which the PD teachers had been asked to code a clip on the SEMP and ETCA codes. This yielded six discussions to be included in the analyses: two discussions in Week 2 of the PD, one in Week 3, one in Week 5, and two in Week 6. Immediately prior to each of these discussions having taken place, the PD teachers had: watched a video clip of instruction while also having a transcript of the clip for reference (see Appendix E for transcripts of all PD session video clips); and then 
they had decided individually on their initial scores for the ETCA and SEMP codes. The group discussions that followed were those that were transcribed.

Table 19 contains a brief description of each video clip the PD teachers scored and discussed in reference to the SEMP and ETCA codes, along with an overview of the instances of students' engaging in math practices that are evidenced in the clip (according to my own watching of the clip) and the master scores for SEMP and ETCA that are part of the MQI PD facilitator's materials.

Looking across these six clips, it is evident that none are saturated with instances of students' math practices. In one sense, this is a limitation of my study, since there were not actually very many instances of math practices for teachers to notice within the clips. On the other hand, it could also be considered an affordance; rather than selecting video clips of exceptional instruction, the designers of the MQI PD program selected video clips that were representative of the range of instruction they have typically observed over years of research. Thus, the fact that the PD teachers in my study were looking for instances of students engaging in math practices within instruction where those instances were not plentiful, could be considered to be a more authentic activity than if there were an atypically high amount of instances within the clip. 
Table 19

Description of video clips scored on the SEMP and ETCA codes during PD sessions 1-6

\begin{tabular}{|c|c|c|c|c|}
\hline $\begin{array}{l}\text { Clip Name } \\
\text { (Session } \\
\text { Number) }\end{array}$ & Brief Description & $\begin{array}{l}\text { Evidence of Students } \\
\text { Engaging in Mathematical } \\
\text { Practices }\end{array}$ & $\begin{array}{l}\text { SEMP } \\
\text { Score }\end{array}$ & $\begin{array}{l}\text { ETCA } \\
\text { Score }\end{array}$ \\
\hline $\begin{array}{l}\text { Ingrid: Area } \\
\text { and } \\
\text { Perimeter } \\
\text { (Week 2) }\end{array}$ & $\begin{array}{l}\text { This video clip features } \\
\text { one-on-one teacher- } \\
\text { student dialogue during } \\
\text { student work time. The } \\
\text { students have been } \\
\text { asked to respond to two } \\
\text { fictitious students' } \\
\text { responses to finding the } \\
\text { area and perimeter of a } \\
\text { rectangle. Specifically, } \\
\text { the students in the class } \\
\text { have been asked to } \\
\text { determine which } \\
\text { fictitious student is } \\
\text { correct and why. The } \\
\text { teacher is discussing } \\
\text { individual students' } \\
\text { work with them in the } \\
\text { clip. }\end{array}$ & $\begin{array}{l}\text { Some; brief instances of } \\
\text { students engaging in: } \\
\text { Constructing Viable } \\
\text { Arguments, and Critiquing } \\
\text { the Reasoning of Others (CC } \\
\text { MP3), and Attending to } \\
\text { Precision (CC MP6) }\end{array}$ & Mid & Mid \\
\hline $\begin{array}{l}\text { Wilma: } \\
\text { Corner } \\
\text { Market } \\
\text { (Week 2) }\end{array}$ & $\begin{array}{l}\text { This clip features a } \\
\text { whole-class discussion, } \\
\text { led by the teacher, in } \\
\text { which teacher and } \\
\text { students are discussing } \\
\text { how to find the unit } \\
\text { price in a word problem } \\
\text { about the cost of boxes } \\
\text { of pasta. }\end{array}$ & $\begin{array}{l}\text { None; no clear evidence of } \\
\text { students engaging in math } \\
\text { practices }\end{array}$ & Not Pres. & $\begin{array}{l}\text { Not } \\
\text { Pres. }\end{array}$ \\
\hline $\begin{array}{l}\text { Karen: Long } \\
\text { Division } \\
\text { (Week 3) }\end{array}$ & $\begin{array}{l}\text { In this clip, the teacher } \\
\text { is reviewing the US } \\
\text { standard long-division } \\
\text { algorithm for } 72 \text { divided } \\
\text { by } 4 \text {. She directs one } \\
\text { student to demonstrate } \\
\text { steps of the algorithm } \\
\text { with blocks as she } \\
\text { works through the } \\
\text { algorithm. }\end{array}$ & $\begin{array}{l}\text { None; no clear evidence of } \\
\text { students engaging in math } \\
\text { practices }\end{array}$ & Not Pres. & Mid* \\
\hline $\begin{array}{l}\text { Pamela: } \\
\text { School } \\
\text { Fundraiser } \\
\text { (Week 5) }\end{array}$ & $\begin{array}{l}\text { In a whole-class format, } \\
\text { the teacher in this clip } \\
\text { presents pictures drawn } \\
\text { by two students in the } \\
\text { class, meant to } \\
\text { represent a scenario } \\
\text { about a school } \\
\text { fundraiser. The class is }\end{array}$ & $\begin{array}{l}\text { Limited; there is limited } \\
\text { evidence to support that at } \\
\text { least one student engaged } \\
\text { in: Reasoning Abstractly } \\
\text { and Quantitatively (CC } \\
\text { MP2) }\end{array}$ & Low & Mid* \\
\hline
\end{tabular}




\begin{tabular}{|c|c|c|c|c|}
\hline & $\begin{array}{l}\text { asked respond to } \\
\text { determine whether } \\
\text { these students' pictures } \\
\text { accurately represent the } \\
\text { fundraising scenario. }\end{array}$ & & & \\
\hline $\begin{array}{l}\text { Toni: } \\
\text { Division and } \\
\text { Multiplicatio } \\
\text { n } \\
\text { (Week 6) }\end{array}$ & $\begin{array}{l}\text { In a whole-class } \\
\text { discussion format, the } \\
\text { teacher in this clip is } \\
\text { talking with the } \\
\text { students about the } \\
\text { problem } 72 \text { divided by } 4 \\
\text { and how multiplication } \\
\text { could be used to check } \\
\text { the answer to this } \\
\text { problem. }\end{array}$ & $\begin{array}{l}\text { None; no clear evidence of } \\
\text { students engaging in math } \\
\text { practices }\end{array}$ & Not Pres. & $\begin{array}{l}\text { Not } \\
\text { Pres. }\end{array}$ \\
\hline $\begin{array}{l}\text { Marcus: } \\
\text { Gumball } \\
\text { Problem } \\
\text { (Week 6) }\end{array}$ & $\begin{array}{l}\text { In a whole-class format, } \\
\text { the teacher in this clip is } \\
\text { reviewing solution } \\
\text { strategies for a gumball } \\
\text { probability problem. } \\
\text { There is brief back-and- } \\
\text { forth teacher-student } \\
\text { dialogue throughout the } \\
\text { clip. }\end{array}$ & $\begin{array}{l}\text { Limited; there is limited } \\
\text { evidence to support that at } \\
\text { least one student engaged } \\
\text { in: Reasoning Abstractly } \\
\text { and Quantitatively (CC } \\
\text { MP2) }\end{array}$ & Low & Mid* \\
\hline
\end{tabular}

*Note: ETCA is "Mid" for these clips, despite that SEMP is "Not Present" or "Low" due to the fact that there was evidence of student engagement in the clip that was not necessarily engagement in math practices. For example, if a student presented his or her solution strategy during the clip (but did not articulate an argument/justification about that solution), then that instance would count toward ETCA but not necessarily toward SEMP. 


\section{Analytic Procedures for Identifying Teachers' ‘Approaches'}

To analyze these data, I used thematic analysis (Braun and Clarke, 2006) to identify and explicate the different approaches teachers used as they took on the task of identifying instances of students engaging in Math Practices within a video clip. The details of the thematic analyses are described below, beginning with foundational decisions.

Foundational Decisions. Before conducting thematic analyses, I made decisions with respect to six foundational questions (Braun \& Clarke, 2006). The foundational decisions I made are shown in Table 20.

Table 20

Foundational decisions for the thematic analyses (Braun \& Clarke, 2006) I conducted for Research Question 2

\begin{tabular}{|l|l|}
\hline $\begin{array}{l}\text { Decisions-to-be- } \\
\text { made }\end{array}$ & My Decisions for RQ2 Analyses \\
\hline $\begin{array}{l}\text { Theoretical } \\
\text { Perspectives } \\
\text { Informing Analyses }\end{array}$ & $\begin{array}{l}\text { (1) Situated Cognition, and } \\
\text { 2) a two-part "what and how" conceptualization of } \\
\text { noticing } \\
\text { (Both of these perspectives are described in Chapter 3.) }\end{array}$ \\
\hline Research Question & $\begin{array}{l}\text { How do teachers approach the task of noticing students' } \\
\text { engagement in mathematical practices? }\end{array}$ \\
\hline $\begin{array}{l}\text { What will count as a } \\
\text { theme? }\end{array}$ & $\begin{array}{l}\text { A theme was considered to be a combination of what and } \\
\text { how teachers go about the task of identifying evidence to } \\
\text { support their MQI Scores. These combinations were } \\
\text { called an "approach". } \\
\text { I chose the term approach to capture the notion that } \\
\text { teachers were "coming at" this directed noticing task in } \\
\text { different ways. }\end{array}$ \\
\hline
\end{tabular}




\begin{tabular}{|l|l|}
\hline $\begin{array}{l}\text { Will themes be } \\
\text { semantic or latent? }\end{array}$ & $\begin{array}{l}\text { These levels were semantic themes, identified by the } \\
\text { explicit meanings as represented by the data, without } \\
\text { looking for underlying meanings or "reasons why" } \\
\text { teachers used the approaches that they did. }\end{array}$ \\
\hline $\begin{array}{l}\text { What will the scope } \\
\text { of the analysis be? }\end{array}$ & $\begin{array}{l}\text { In these analyses, I aimed to capture every approach that } \\
\text { teachers used during their discussions. }\end{array}$ \\
\hline $\begin{array}{l}\text { Will the analysis be } \\
\text { inductive or } \\
\text { theoretical? }\end{array}$ & $\begin{array}{l}\text { These analyses were inductive, with no pre-determined } \\
\text { ideas for how teachers would approach the task of } \\
\text { identify students' math practices. }\end{array}$ \\
\hline
\end{tabular}

Procedure for Analysis. The six phases below are Braun and Clarke's (2006) phases of thematic analysis, which I employed in order to understand the perspectives the teachers took on as they discussed potential instances of students' math practices within a video clip.

Phase 1: Processing and becoming familiar with the data. First, I read through the collection of all transcripts to familiarize myself with the content of the discussions. I also re-watched the video clips of instruction (see Appendix E for a transcript of each clip; see Chapter 6 for a summary description of each clip) that teachers discussed within the transcripts and reviewed the relevant master scores pertaining to students' math practices.

Phase 2: Generating Initial Codes. Next, I put initial codes on each conversation, describing what and how the teachers seemed to be noticing the students' Math Practices within the clips. I assigned these initial what and how codes at least every time the PD teachers discussed a new potential instance of a math practice within a conversation. On occasion, I gave more than one how code per 
instance when I identified more than one how in the conversation. Figure 12 is an example of the initial codes for two conversation excerpts.

\section{Excerpt A}

Michael: [Quoting dialogue between two students in the clip] 'I had a question: Is that right?' 'Yeah.' The students are constructing meaning together around the teacher. The students are actually trying to help each other figure out the math. I don't know if we can count it.

Hope: That's commenting on another student's work.

Michael: I was wondering, do we count that? I mean, it's just a 'yeah' but it's an affirmation that somebody is listening. If the student had said, 'I agree with Nolan', then would we count it then, as opposed to 'yeah'?

\section{Excerpt B}

Jackie: [justifying a "mid" score for the Enacted Task Cognitive Activation code of the MQI] I thought it started 'high' and then went into 'low'...I was really impressed with the 'oh yeah you're actually giving away that 40 ' [quoting the teacher, Karen, from the transcript] but then there was not really, a lot of, maybe a little bit. But I could be persuaded that it didn't start out 'high'.

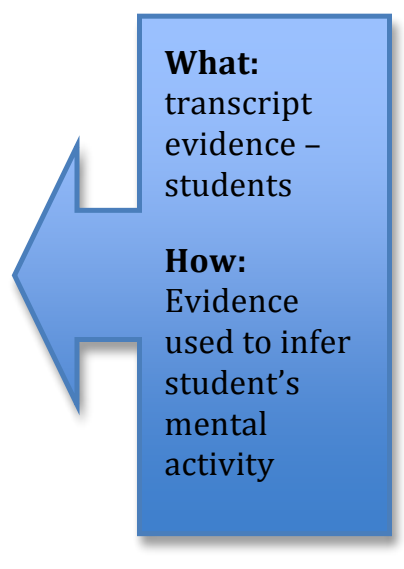

What: transcript evidence -

How: Evidence used to infer student's mental activity

Figure 12. Examples of initial codes for RQ 2 for Phase 2 of analysis

Phase 3: Searching for Potential Approaches. With the goal that "data

within themes should cohere together meaningfully, while there should be clear and identifiable distinctions between themes" (Braun \& Clarke, 2006, p. 91), I grouped codes to form approaches in relation to the data. For example, I grouped all codes in which the what included transcript excerpts of a student's utterance and the how was that the PD teacher was using the student's utterance as "indirect evidence" 
(this phrasing was refined in Phase 4) of a math practice. This resulted in a list of four provisional approaches.

Phase 4: Reviewing Approaches. After having created provisional approaches, I checked that they accurately reflected the data on two levels: (a) the level of coded statements, and (b) the level of the entire dataset of transcripts.

Phase 5: Defining and Naming Approaches. Next, I defined and named approaches with respect to the foundational categories I had identified in earlier analyses. For example, I first named one approach as: Student Focus with Indirect Evidence to capture in which the what included a focus on the student and the how was that the PD teacher was using the student's utterance as "indirect evidence". As I reviewed this approach and others, though, it was unclear what exactly was meant by "focus", "direct evidence", and "indirect evidence"; these terms were not clearly defining the approaches nor were they clearly distinguishing each from the others. To clarify exactly what each approach was capturing, I changed the term "focus" to instead be whose utterances the PD teacher was referring to. I changed "direct evidence" and "indirect evidence" to instead be "utterances as instances of a math practice" and "utterances that imply instances of math practices". Having a well-defined and clearly named set of perspectives, I went back and affirmed that perspectives represented the data well by re-reading through all of the transcripts of teachers' discussions.

Phase 6: Producing the Report. The results of these analyses are presented in the next chapter. 


\section{CHAPTER 6: TEACHERS' NOTICING OF STUDENTS' MATHEMATICAL PRACTICES WITHIN VIDEO CLIPS OF INSTRUCTION}

Through thematic analyses of one group of PD teachers' discussions, four approaches to noticing students' math practices emerged. They are: (1) Students' Utterances as Instances of Math Practices, (2) Students'Utterances that Suggest Cognitive Engagement in Math Practices, (3) Teachers'Utterances as Math Practices, (4) Teachers' Utterances that Prompt for Students' Engagement in Math Practices.

This collection of approaches can be characterized on two dimensions. The first dimension pertains to: whose utterances the PD teachers were using as evidence within the video transcripts - the utterances of the student(s), or the utterances of the teacher in the clip. (While it is possible to attend to both the clip teacher's and the student's utterances, it was always the case that PD teachers used one or the other as the centerpiece of their argument for the existence of a student' $s$ math practice in the clip.) The second dimension pertains to: how the teachers used the utterances when making an argument about whether a math practice had occurred in the clip. In some cases, teachers spoke about the utterances as instances of a math practice occurring, meaning that the utterance itself was the speaker's verbal articulation of a math practice. In other cases, teachers used the utterances $a s$ implications of a math practice, meaning that the utterances themselves did not explicitly contain the instance of the math practice.

The four possible combinations that result by crossing these two dimensions (whose utterances with how PD teachers used utterances) capture the approaches 
that teachers used when discussing potential instances of students' math practices.

The four approaches are represented within a two-by-two table accordingly, in

Figure 13 below.

\begin{tabular}{|c|c|c|c|}
\hline & \multicolumn{2}{|c|}{ How PD teachers used utterances } \\
\hline & & $\begin{array}{c}\text { Utterances as } \\
\text { instances of } \\
\text { Math practices }\end{array}$ & $\begin{array}{c}\text { Utterances that } \\
\text { imply instances of } \\
\text { Math practices }\end{array}$ \\
\hline \multirow{2}{*}{ 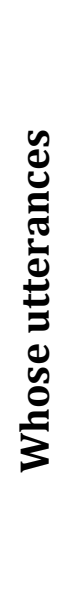 } & 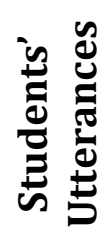 & $\begin{array}{c}\text { Students' } \\
\text { utterances as } \\
\text { instances of } \\
\text { math practices }\end{array}$ & $\begin{array}{c}\text { Students' utterances } \\
\text { that suggest } \\
\text { cognitive } \\
\text { engagement in } \\
\text { math practices }\end{array}$ \\
\hline & 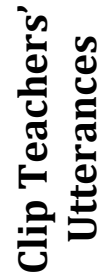 & $\begin{array}{c}\text { Clip teachers' } \\
\text { utterances as } \\
\text { instances of } \\
\text { math practices }\end{array}$ & $\begin{array}{c}\text { Clip teachers' } \\
\text { utterances that } \\
\text { prompt for students' } \\
\text { engagement in } \\
\text { math practices }\end{array}$ \\
\hline
\end{tabular}

Figure 13. PD teachers' approaches when discussing potential instances of students' engagement in math practices within a video clip

Below, I introduce each approach, illustrating it with representative transcript excerpts from the PD teachers' discussions. Each approach is introduced separately, but this is not meant to imply that the approaches are mutually exclusive - that is, at times, more than one approach was evident within the same discussion. I address the notion of overlapping approaches in the discussion section at the end of this chapter.

\section{Students' Utterances as Instances of Math Practices}




\begin{tabular}{|c|c|c|}
\hline & $\begin{array}{l}\text { Utterances as } \\
\text { instances of } \\
\text { math practices }\end{array}$ & $\begin{array}{c}\text { Utterances that } \\
\text { imply instances of } \\
\text { math practices }\end{array}$ \\
\hline 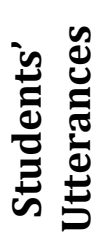 & $\begin{array}{c}\text { Students' } \\
\text { utterances as } \\
\text { instances of } \\
\text { math practices }\end{array}$ & $\begin{array}{c}\text { Students' utterances } \\
\text { that suggest } \\
\text { cognitive } \\
\text { engagement in } \\
\text { math practices }\end{array}$ \\
\hline 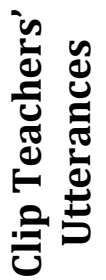 & $\begin{array}{l}\text { Clip teachers' } \\
\text { utterances as } \\
\text { instances of } \\
\text { math practices }\end{array}$ & $\begin{array}{c}\text { Clip teachers' } \\
\text { utterances that } \\
\text { prompt for students' } \\
\text { engagement in } \\
\text { math practices }\end{array}$ \\
\hline
\end{tabular}

Figure 14. Students' Utterances as Instances of Math Practices approach in relation to the other three approaches

One approach that became apparent through my analyses of the PD teachers' scoring discussions was Students' Utterances as Instances of Math Practices, in which participants attended to the students in the clip by pointing to utterances on the video transcript that they perceived to be direct instances of a math practice. For example, using this approach, the teachers might point to a student's articulation of a mathematical explanation within the clip, stating that that student's utterance is, explicitly, an instance of a math practice. In this way, this approach was, at face value, the most in line with the nature of the MQI PD; participants were tackling the task of looking for instances of students engaging in math practices by honing in on transcript evidence - specifically evidence that was an instance of a student doing so. The following excerpts are instances of this approach. 


\section{Excerpt 1: Do these students' utterances qualify as explanations and/or}

sense-making? In the excerpt below, Patty, Michael, and Jackie use the Students'

Utterances as Instances of Math Practices approach as they are discussing the

Marcus: Gumball Problem clip and whether two students' utterances are instances of engagement in explaining and/or sense-making:

Patty: I caught one: [quoting a student from the transcript] 'I got the 3 purple because purple is $1 / 12$ and so $12+12+12$ is 36 .' So that one is definite. Otherwise, I had a really hard time figuring out with the 'ums' yeahs'. Where did you find more than the one?

Michael: So that was the one that I noticed too. And then I think it was, that was one prolonged instance [of a student's math practice].

[The teachers have a short discussion about whether the MQI gives any guidance on the length of an 'instance'.]

Jackie: There's also the [quoting a student from a transcript] 'I was, mine is 6 because I knew 3 plus 6 equals 9.' I mean, that's really unclear, but I think that's commenting on like 'Yeah, this is how I did it because this and this and this'.

In the above excerpt, we see Patty and Jackie each point to a quote from the video transcript as a possible instance of a student engaging in a math practice (likely instances of the students' reasoning and/or sense-making). The quotes they are pointing to are utterances that the students made, and those utterances are 
students' verbal articulations of a math practice. For example, in the statement that Patty is using as evidence ("because purple is $1 / 12$ and so $12+12+12$ is 36 ") the mathematics in the utterance.

\section{Excerpt 2: Do these students' utterances qualify as conjectures? In this} excerpt, Hope, Michael, and Jackie also take on the Students' Utterances as Instances of Math Practices approach as they are discussing the Karen: Long Division clip and whether two students' utterances are instances of those students engaging in mathematical conjecturing:

Hope: I put low because the child at one point did say, 'I can split them in half,' which was a little bit of a conjecture. And up at the beginning, one of the children said - let's see - and when [the teacher] said, 'Can any one do it another way?' one child said 'yeah, long division.' So, I felt like there were one or two instances of students engaging in making a conjecture. You know, not that she really took it anywhere.

Michael: Yeah, one or two instances of students engaging in Mathematical Practices.

Hope: Because it wasn't just all [quoting students from the transcript] 'yeah, no, no, yes, yes, I'll try.'

Michael: I guess conjectures, right. 
Hope: [Quoting a student from the transcript] 'Because I can split them in half.' That was clearly a student giving his idea of how to do it, I thought.

Jackie: Agreed.

Michael: Good. Yeah.

In the above excerpt, we see Hope point to two examples of possible student conjectures: "I can split them in half," and "Yeah, long division." Although she mentions the teacher in the clip, she does so more in passing - as part of her reading of the transcript leading up to students' utterances, and as a commentary about what happened after the students made their conjectures ("Not that she really took it anywhere."). On the whole, her statements point to students' utterances, and these utterances are, in her opinion, mathematical conjectures. Michael and Jackie agree that these are indeed instances of students engaging in a math practice. The PD teachers are attending to students' utterances (as opposed to the clip teacher's utterances), and they are considering whether those utterances explicitly include a student's articulation of a math practice - in this case, a student's articulation of a conjecture ("I can split them in half").

\section{Students' Utterances that Suggest Cognitive Engagement in Math}

\section{practices}

\begin{tabular}{|c|c|c|}
\hline $\begin{array}{c}\text { Utterances as } \\
\text { instances of } \\
\text { Math practices }\end{array}$ & $\begin{array}{c}\text { Utterances that } \\
\text { imply instances of } \\
\text { Math practices }\end{array}$ \\
\hline
\end{tabular}




\begin{tabular}{|c|c|c|}
\hline 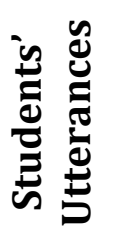 & $\begin{array}{c}\text { Students' } \\
\text { utterances as } \\
\text { instances of } \\
\text { math practices }\end{array}$ & $\begin{array}{c}\text { Students' } \\
\text { utterances that } \\
\text { suggest cognitive } \\
\text { engagement in } \\
\text { math practices }\end{array}$ \\
\hline 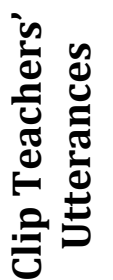 & $\begin{array}{c}\text { Clip teachers' } \\
\text { utterances as } \\
\text { instances of } \\
\text { math practices }\end{array}$ & $\begin{array}{c}\text { Clip teachers' } \\
\text { utterances that } \\
\text { prompt for students' } \\
\text { engagement in } \\
\text { math practices }\end{array}$ \\
\hline
\end{tabular}

Figure 15. Students' Utterances that Suggest Cognitive Engagement in Math Practices approach in relation to the other three approaches

A second approach that emerged from the teachers' scoring discussions was the Students' Utterances that Suggest Cognitive Engagement in Math Practices approach, in which the teachers pointed to the students' utterances, as they did in the previous approach, but those utterances did not articulate any mathematical practice explicitly. Instead, the PD teachers used students' utterances to make inferences about their engagement in a math practice as it might have happened within the student's mind. In this way, the focus was on identifying instances within the clip that were suggestive of students' cognitive engagement in the math practices. The excerpts below demonstrate this approach.

\section{Excerpt 3: Is a student's "yeah" evidence of student reasoning about the} mathematics in the clip? In the excerpt below, we see Hope and Michael, while scoring the Pamela: School Fundraiser clip on the CCSP dimension, consider a 
student's one-word utterance as potential evidence of a student cognitively engaging in a math practice:

Hope: Those [aforementioned instances] are the only two that I see. Unless, you know, [quoting from the clip transcript] 'hers took a long time' and then the student said 'yeah'. Is that analysis?

Facilitator: So is that 'yeah' an example of a student engaging in a mathematical practice?

Hope: Or is it just blindly saying, 'the teacher said it, so it must be, yeah'?

Michael: I thought I remembered on the clip that the student said it like 'yeah'.

Hope: Like a question?

Michael: As if it was a 'yeah' in this moment of dawning realization.

Facilitator: Was it a mathematical practice 'yeah'?

Hope: I think the kids were engaged and thinking. So for us, to just, based on the way it's written here, 'yeah', maybe you're right, Michael. The kids were thinking on the clip. They weren't just blindly agreeing.

In the above excerpt, we see Hope and Michael considering the possibility that a student's utterance of "yeah" is an indication that the student is thinking and reasoning about the mathematics of the problem. As they were in the previous 
approach, the teachers are referring to students' utterances as evidence within the video clip transcript. However, in contrast to the previous approach, the teachers are not arguing that the word the student uttered ("yeah") explicates a math practice; rather, they seem to be saying that the utterance is indicative of a math practice occurring within the student's mind ("a 'yeah' in this moment of dawning realization"). In this way, the mathematics is not explicitly stated. It is instead occurring within the student's mind, and the utterance of "yeah" is the evidence that the teachers are using to make this inference.

\section{Excerpt 4: Is a student's "yeah" evidence of reasoning about another}

student's solution? Three weeks after the above discussion, Michael and Hope again focus on a student's utterance of "yeah" within an entirely different video clip, but this time they consider whether the "yeah" suggests that the student has considered the validity of another student's solution strategy.

Michael: [Quoting dialogue between two students in the clip] 'I had a question: Is that right?' 'Yeah.' The students are constructing meaning together around the teacher. The students are actually trying to help each other figure out the math. I don't know if we can count it.

Hope: That's commenting on another student's work.

Michael: I was wondering, do we count that? I mean, it's just a 'yeah' but it's an affirmation that somebody is listening. If the student had said, 'I agree with Nolan', then would we count it then, as opposed to 'yeah'? 
In this excerpt, we see Hope and Michael consider the possibility that a student's utterance of "yeah" is an indication that the student has reasoned about another student's solution. Here, as in the last excerpt, the teachers do not seem to be saying that the student's utterance ("yeah") is a math practice, per se. Instead, they seem to be inferring that the student has considered the validity of the other student's solution in their head, and the "yeah" is evidence of that having happened.

Teachers' Utterances as Instances of Math Practices

\begin{tabular}{|c|c|c|}
\hline & $\begin{array}{c}\text { Utterances as } \\
\text { instances of } \\
\text { math practices }\end{array}$ & $\begin{array}{c}\text { Utterances that } \\
\text { imply instances of } \\
\text { math practices }\end{array}$ \\
\hline 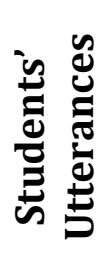 & $\begin{array}{c}\text { Students' } \\
\text { utterances as } \\
\text { instances of } \\
\text { math practices }\end{array}$ & $\begin{array}{c}\text { Students' utterances } \\
\text { that suggest } \\
\text { cognitive } \\
\text { engagement in } \\
\text { math practices }\end{array}$ \\
\hline 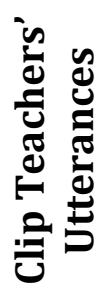 & $\begin{array}{c}\text { Clip teachers' } \\
\text { utterances as } \\
\text { instances of } \\
\text { math practices }\end{array}$ & $\begin{array}{c}\text { Clip teachers' } \\
\text { utterances that } \\
\text { prompt for students' } \\
\text { engagement in } \\
\text { math practices }\end{array}$ \\
\hline
\end{tabular}

Figure 16. Teachers' Utterances as Instances of Math Practices approach in relation to the other three approaches

In a third approach, Teachers' Utterances as Instances of Math Practices, in which participants attended to the clip-teacher's utterances - as opposed to students' utterances as in the previous two approaches - and as they do so, they are considering whether the clip teacher's utterance is itself an instance of a math 
practice, which is misaligned with the task of coding within the CCSP dimension as it is prescribed by the MQI instrument.

\section{Excerpt 5: Does the teacher's engagement in a Math Practice count?}

Across all discussions analyzed, the Teachers' Utterances as Instances of Math Practices approach was evidenced exclusively by Jackie ${ }^{9}$ (yet she did illustrate the other approaches as well, across different discussions). While this approach was only exhibited by one PD teacher in the group, it is nonetheless included in these results because I aimed to capture all approaches this group of PD teachers used during any of the PD discussions analyzed. Moreover, because there were only five teachers in this PD group, the approach of one teacher could represent that of other teachers outside of this particular group.

In the excerpt below, Jackie justifies her argument that the clip included students' engagement in a math practice by pointing to the clip teacher's mathematical sense-making.

Jackie: [justifying a "mid" score for the Enacted Task Cognitive Activation code of the MQI] I thought it started 'high' and then went into 'low'...I was really impressed with the 'oh yeah you're actually giving away that 40 ' [quoting the teacher, Karen, from the transcript] but then there was not

${ }^{9}$ Demographic info on Jackie: She was entering her $3^{\text {rd }}$ year teaching mathematics to children at the beginning of the PD. In the 2014-2015 school year, she was a fulltime multi-subject bilingual fifth grade teacher at a midsized K-5 elementary school in the same district as Michael and Hope. 
really, a lot of, maybe a little bit. But I could be persuaded that it didn't start out 'high'.

Michael: I thought that was a pretty good mathematical move. If it was student-generated, then I think maybe it could be a 'mid'....

In the above excerpt, we see Jackie pointing to the clip teacher's utterance as an instance of mathematical sense-making as a basis for arguments that the clip included a math practice. However, the task of the PD teachers, as indicated by the fact that they are scoring the clip on the CCSP dimension of the MQI, is to capture the degree to which students engaged in math practices. In a sense, Jackie is paying attention to the right thing (math practices) but the wrong person (the clip teacher). Presumably because of this misalignment, Michael pushed against Jackie's arguments in the excerpt above, and indeed, later in the discussion, Jackie agreed that her example was not, in fact, an instance of students engaging in a math practice.

\section{Teachers' Utterances that Prompt for Students' Engagement in Math Practices}




\begin{tabular}{|c|c|c|}
\hline & $\begin{array}{l}\text { Utterances as } \\
\text { instances of } \\
\text { math practices }\end{array}$ & $\begin{array}{c}\text { Utterances that } \\
\text { imply instances of } \\
\text { math practices }\end{array}$ \\
\hline 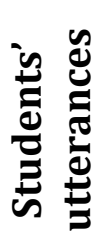 & $\begin{array}{c}\text { Students' } \\
\text { utterances as } \\
\text { instances of } \\
\text { math practices }\end{array}$ & $\begin{array}{c}\text { Students' utterances } \\
\text { that suggest } \\
\text { cognitive } \\
\text { engagement in } \\
\text { math practices }\end{array}$ \\
\hline 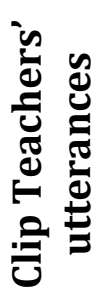 & $\begin{array}{l}\text { Clip teachers' } \\
\text { utterances as } \\
\text { instances of } \\
\text { math practices }\end{array}$ & $\begin{array}{l}\text { Clip teachers' } \\
\text { utterances that } \\
\text { prompt for } \\
\text { students' } \\
\text { engagement in } \\
\text { math practices }\end{array}$ \\
\hline
\end{tabular}

Figure 17. Teachers' Utterances That Prompt For Students' Engagement in Math Practices approach in relation to the other three approaches

A fourth approach, Teachers' Utterances that Prompt for Students'

Engagement in Math Practices, was exhibited during the participants' scoring discussions when the participants again focused on the actions and utterances of the teacher in the clip as in above the approach, yet they are considering the impact of those actions on students' engagement in math practices in the clip. The excerpt below exemplifies this approach in action.

\section{Excerpt 6: Did the impact of the teacher's scaffolding affect student} engagement in Math Practices? The Teachers' Utterances that Prompt for Students' Engagement in Math Practices approach was evidenced when the teachers inferred the impact that the clip teacher's utterances had on her students' engagement in math practices within the clip. For example, while discussing the Ingrid: Area and 
Perimeter clip on the ETCA code during week two of the PD, the teachers considered Ingrid's utterances in reference to whether she was encouraging or discouraging student engagement in mathematical reasoning:

Michael: It seemed like at the beginning, she was scaffolding enough that they weren't 'explaining or asking mathematically motivated questions' [quoting from the MQI instrument]. She's breaking it down so much for them. So I don't know, does that count? Breaking it down for them? It seemed like appropriate instruction...

Hope: I don't think you would do that unless you had a child who was not really secure with what they were doing. You know, the child can't do all the thinking if they have no idea what's going on. I don't know how they would have done that differently. So you think she should have waited and just let the child say something?

Michael: So I guess to me, to score a High, with those first two kids, we need to step back and ask a big picture question [trails off and begins reading from the clip transcript...] '28. 28. Show me 28.'

Hope: I guess I probably would have said, '28 what?' But if the child is counting squares, you could have said '28 squares,' and that was obvious between the two of them what the child was pointing at and counting. Well you could have said, '28 squares, so what does that mean?'

Hope \& Michael in unison: 'Is that the area or perimeter?' 
Michael: [reading from the transcript] 'Sure, you proved it.' She's scaffolding so much. Does it say scaffolding in there, or is that just me?

Hope: I don't feel like that's scaffolding. I feel like that's validating and modeling, in a way. So the child realizes: oh, that's how you prove it.

Patty: And she offered it in the context of 'show me the proof, show me'. Less scaffolding and more 'show me'.

In the above exchange, the participants focus on the utterances of the teacher in the clip and the impact that what she said (or did not say) had on students' engagement in math practices. In particular, they deliberate on the level of scaffolding the teacher exhibited in the clip (e.g., "She was breaking it down so much for them."), and in doing so, the teachers are only indirectly focusing on the students' engagement in math practices. The students' (observed or potential) engagement in math practices is being gauged via evidence of what the clip-teacher said and whether that encouraged the students' engagement in a math practice.

\section{Discussion of the Four Approaches}

I now discuss each of the approaches I identified, drawing connections to previous research and insights that are unique to each approach. Then, I move to looking at which approaches were evidenced on which weeks of the PD and conclude by considering implications of the four approaches together as a set.

\section{Students' Utterances as Instances of Math Practices}


This approach is most directly in line with the methods promoted by the MQI PD. During the MQI PD sessions, facilitators ask teachers to point to direct transcript evidence of students engaging in a math practice within the clip. Thus, when teachers use the Students' Utterances as Instances of Math Practice approach, it affords them a discussion with each other that involves less inference than some of the other approaches. Here, teachers are looking squarely at things the students said and then deciding whether what the student said is, at face value, a math practice.

This approach is in line with notions of advanced noticing and pedagogy. For example, in van Es' (2011) framework of teachers' learning to notice students' mathematical thinking, teachers attend to particular students' mathematical thinking and refer to specific events and interactions as evidence, at the higher levels of the framework, allowing them to connect their interpretations to broader instances of instruction and plan a pedagogical response accordingly. Leatham and colleagues' (2015) recent work, too, underscores the need for teachers to be able to identify, interpret and then leverage students' mathematical contributions during a lesson. Thus, a teacher who is looking for clear, explicit, evidence of students' mathematics based on what students say, might be well-positioned to take on these reflexive teaching tasks.

\section{Students' Utterances That Suggest Cognitive Engagement in Math Practices}

Like the approach discussed above, this approach is also in line with notions of advanced noticing in that it focuses on direct evidence of students' utterances that 
might indicate engagement in a math practice. However, with this approach there is an added level of complexity, comparatively speaking. With this approach, the teachers are trying to infer something that is occurring within a student's head when trying to judge whether he or she engaged in a math practice. And from this approach, the evidence that teachers are calling on might even be a student's utterance of a single word.

Connecting this to the teachers' own classrooms, one wonders if he or she would consider a "yeah" or a similar utterance sufficient evidence that his or her student has been engaging in a math practice. And if so, should it be? Some might argue that math practices can certainly occur entirely within students' minds and that a students' single word or indeed no words at all might accompany that math practice. Others might argue, though, that in the context gauging whether students have engaged in a math practice, such instances require too much inference. The master scoring of the MQI PD tend to only "count" student's utterances that are explicitly instances of a math practice, yet the existence of this more inferential approach raises the question of whether "silent" math practices merit more attention in the MQI PD.

\section{Clip Teachers' Utterances as Instances of Math Practices}

This approach in which PD participants focus on the clip teachers' utterances as instances of math practices might raise concerns about teachers' approaches to gauging students' engagement in math Practice - both within video clips and within 
their own classrooms - but it also highlights the affordances of teachers' peer collaboration and discussion. While Jackie's recurring focus on teachers' utterances as instances of a math practice is misaligned with the task of identifying instances of students' engagement math practices, her peer respectfully pointed to this misalignment which allowed Jackie to refocus; she was reminded that, despite the fact that she liked the strength of the mathematics within a teacher's utterance ("I was really impressed..."), the task was to look at the nature of the students' mathematics.

The tendency for teachers to attend to the teacher in a video clip rather than the students - even when the task explicitly calls for focusing on the students - is documented in previous research (e.g., Sherin \& Han, 2004; van Es \& Sherin, 2008). The above approach, then, is another example of this occurrence and shows that it is applicable even when the task at hand is, explicitly, to focus solely on the students' interaction with the content, as it is when teachers are scoring a clip on the CCSP dimension of the MQI instrument. Accordingly, this teacher-focused approach may suggest limitations in what teachers are able to gauge about students' engagement math practice within their own instruction. Specifically, that the teacher herself engaged in a math practice might be confused as evidence that math practices were sufficiently incorporated into the lesson.

\section{Clip Teachers' Utterances that Prompt for Students' Math Practices}

A similarly teacher-focused approach, this reflects an understandable struggle: PD teachers are not necessarily looking beyond the intentions and 
prompts of the teacher to notice how the students contributed mathematically. Instead of considering whether a student's utterance is or is not an instance of a math practice, here teachers are focused on more pedagogical considerations. Implications for teachers' own practices might be that they gauge their success in implementing the math practices by looking at whether they prompted students to engage in math practices, rather than looking also at whether the students did indeed engage in any math practices.

\section{Teachers' Math Practice Noticing Approaches Across Weeks of the PD}

Having established the four above approaches to noticing students' math practices that the PD teachers exhibited within the first six weeks' CCSP discussions of the PD, I also looked across weeks of the PD to see which approaches surfaced in which weeks of the PD, for each clip discussed. Below, I make preliminary observations about shifts within the groups' approaches across time.

\section{Approaches Week-by-Week}

Table 21 is a summary of which approaches were exhibited by the group of PD teachers on which weeks. Looking across weeks of the PD, I made the following observations:

- In Week 2 of the PD (the first week in which math practices were discussed), the teachers exclusively exhibited the two approaches that indicate the use of "utterances that imply math practices." 
- Only one of those approaches, however, was exhibited in Week 2 of the PD:

Teachers' Utterances that Prompt for Students' Math Practices

- All but the Teachers' Utterances that Prompt for Students' Math Practices

approach were exhibited in the subsequent weeks of the PD

Table 21

Summary of approaches exhibited by the group by week of the PD

\begin{tabular}{|c|c|c|c|c|c|c|}
\hline & $\begin{array}{l}\text { Week } 2 \\
\text { Wilma: } \\
\text { Corner } \\
\text { Market } \\
\text { clip }\end{array}$ & $\begin{array}{l}\text { Week } 2 \\
\text { Ingrid: } \\
\text { Area and } \\
\text { Perimeter } \\
\text { clip }\end{array}$ & $\begin{array}{l}\text { Week } 3 \\
\text { Karen: } \\
\text { Long } \\
\text { Division } \\
\text { clip }\end{array}$ & $\begin{array}{l}\text { Week } 5 \\
\text { Pamela: } \\
\text { School } \\
\text { Fundrai- } \\
\text { ser clip }\end{array}$ & $\begin{array}{l}\text { Week } 6 \\
\text { Toni: } \\
\text { Multipli- } \\
\text { cation } \\
\text { and } \\
\text { Division } \\
\text { clip }\end{array}$ & $\begin{array}{l}\text { Week } 6 \\
\text { Marcus } \\
\text { Gumball } \\
\text { Problem } \\
\text { clip }\end{array}$ \\
\hline $\begin{array}{l}\text { Math } \\
\text { practices in } \\
\text { the Clip }\end{array}$ & $\begin{array}{l}\text { None; no } \\
\text { clear } \\
\text { evidence } \\
\text { of students } \\
\text { engaging } \\
\text { in Math } \\
\text { practices }\end{array}$ & $\begin{array}{l}\text { Some; brief } \\
\text { instances of } \\
\text { students } \\
\text { engaging in: } \\
\text { Constructing } \\
\text { Viable } \\
\text { Arguments, } \\
\text { and } \\
\text { Critiquing } \\
\text { the } \\
\text { Reasoning of } \\
\text { Others (CC } \\
\text { MP3), and } \\
\text { Attending to } \\
\text { Precision (CC } \\
\text { MP6) }\end{array}$ & $\begin{array}{l}\text { None; no } \\
\text { clear } \\
\text { evidence of } \\
\text { students } \\
\text { engaging in } \\
\text { Math } \\
\text { practices }\end{array}$ & $\begin{array}{l}\text { Limited; } \\
\text { there is } \\
\text { limited } \\
\text { evidence to } \\
\text { support that } \\
\text { at least one } \\
\text { student } \\
\text { engaged in: } \\
\text { Reasoning } \\
\text { Abstractly } \\
\text { and } \\
\text { Quantitative- } \\
\text { ly (CC MP2) }\end{array}$ & $\begin{array}{l}\text { None; no } \\
\text { clear } \\
\text { evidence of } \\
\text { students } \\
\text { engaging in } \\
\text { math } \\
\text { practices }\end{array}$ & $\begin{array}{l}\text { Limited; } \\
\text { there is } \\
\text { limited } \\
\text { evidence to } \\
\text { support that } \\
\text { at least one } \\
\text { student } \\
\text { engaged in: } \\
\text { Reasoning } \\
\text { Abstractly } \\
\text { and } \\
\text { Quantitative- } \\
\text { ly (CC MP2) }\end{array}$ \\
\hline \multicolumn{7}{|c|}{ Approach(s) Evidenced } \\
\hline \multicolumn{7}{|l|}{$\begin{array}{l}\text { Students' } \\
\text { utterances } \\
\text { as instances } \\
\text { of MPs }\end{array}$} \\
\hline $\begin{array}{l}\text { Students' } \\
\text { utterances } \\
\text { that suggest } \\
\text { cognitive } \\
\text { engagement } \\
\text { in MPs }\end{array}$ & & & & & & \\
\hline
\end{tabular}




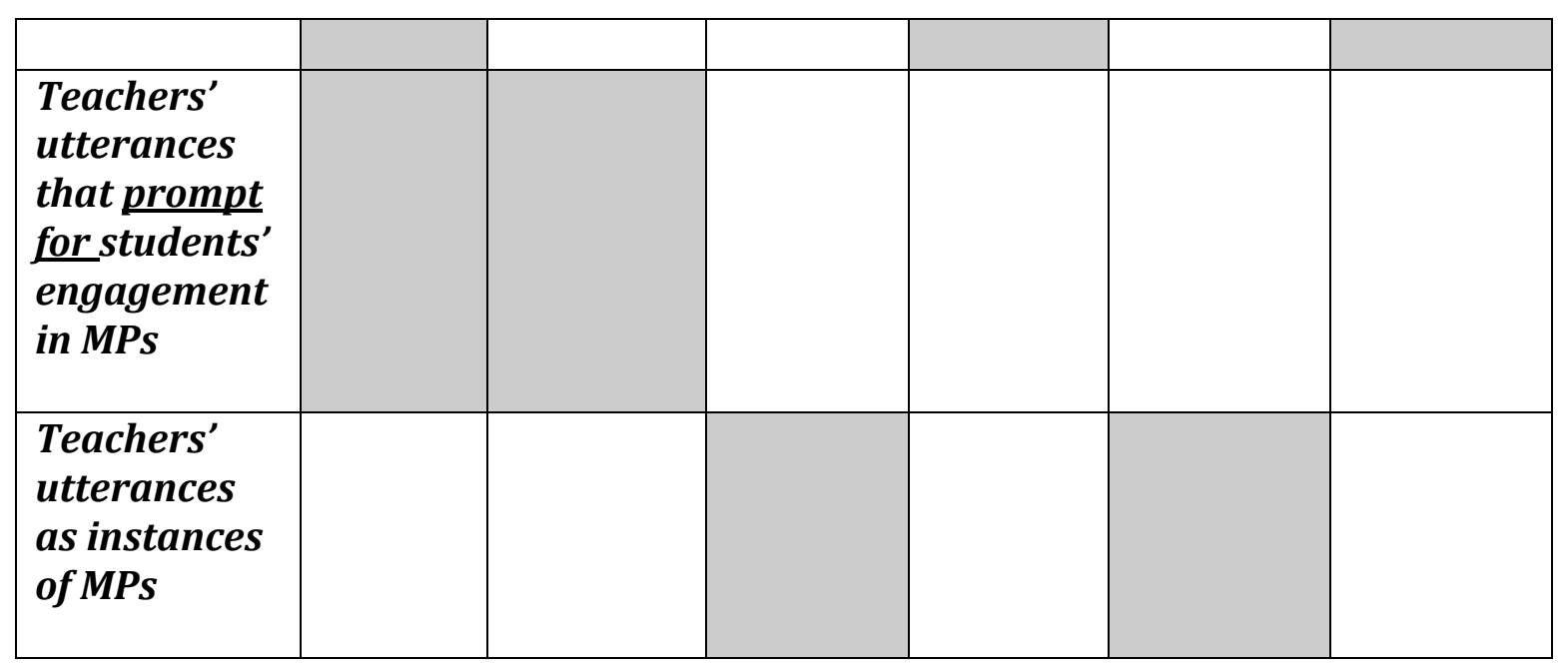

These observations come with the caveats that: (1) the lengths of the discussions varied, and perhaps more approaches would have emerged if some discussions were longer; (2) the attendance of group members varied, and if all teachers had been present at every discussion, perhaps different approaches would have emerged; and (3) again, none of the video clips was saturated with students' math practices, so we do not know what approaches teachers would have brought to such a video clip.

With these caveats in mind, the strongest implication of the week-by-week analyses is that the PD teachers, as a group, turned away (either intentionally or unintentionally) from using the Teachers' Utterances that Prompt for Students' Math Practices approach to argue for instances of students' math practices. The shift away from focusing on the clip teacher and the clip teacher's instructional moves to instead focusing on the student has been documented by Jacobs and colleagues (2011) in the context of teachers' noticing children's mathematical thinking. A 
similar shift seemed to have occurred during the MQI PD, suggesting that this trend happens in the context of MQI Noticing as well as noticing children's mathematical thinking.

\section{Conclusion}

Because students learn math by engaging in Math Practices, it is important that teachers be able to notice students' engagement in Math Practices in their own instruction. The ways in which teachers approach the task of identifying students' engagement in math practices within their own teaching likely has implications for their subsequent reactions in their own teaching. Specifically, it has implications for what teachers push for from their students before they are convinced that their students have engaged in math practices within a lesson.

Although the four approaches I identified in this chapter happened in the context of watching others' video clips (rather than the teachers' own clips), they demonstrate that teachers engage in the task of identifying instances of students' engagement in the math practices in markedly different ways. For example, sometimes teachers might only be looking at the teacher (either themselves or a different teacher, perhaps on video) when trying to gauge students' engagement in the math practices, and some teachers might gauge students' engagement in math practices based on what they believe might be happening within the students' minds.

These results, although derived from a small dataset, carry an important message to PD facilitators, administrators, and other math teacher leaders: these 
significantly different approaches exist, and it is worth clarifying with teachers how, exactly, they are gauging their own success (or lack thereof) in having students engage in the math practices. Relatedly - and at least as importantly - it is worth PD facilitators, administrators, and other math teacher leaders to closely examine how they themselves are gauging a teachers' success (or lack thereof) in having students engage in the math practices, as these professionals are likely to be observers and/or evaluators of teachers' enacted classroom lessons. 


\section{CHAPTER 7: CONCLUSIONS}

In this concluding chapter, I state an overview and synthesis of the findings presented in Chapters 4 and 6 of this dissertation. Then, I explicate the contributions of these findings in relation to existing literature, and I end the chapter with implications for PD and for research.

\section{Overview and Synthesis of Findings}

The findings presented in this dissertation were the results of my investigations into teachers' MQI Noticing as they went through a research-based MQI-focused PD program. In Chapter 4, I investigated shifts in the MQI Noticing of individual teachers in the PD by examining their typed responses to video clips of classroom mathematics instruction at three time points throughout the PD. In Chapter 6, I investigated a narrower slice of MQI Noticing - noticing instances of students' engagement in mathematical practices - at the level of the PD teachers' group discussions, exploring the approaches that teachers used to accomplish this directed noticing task.

My first set of findings were that degrees of teachers' MQI Noticing can be conceptualized via a multi-level framework that I developed, the MQI Noticing Framework. I used the framework to identify statistically significant shifts in teachers' MQI Noticing as the MQI PD progressed. Moreover, the follow-up qualitative analyses illuminated the nature of such shifts for two teachers whose MQI Noticing strengthened as the PD progressed: one teacher's journey ended at strong MQI Noticing that was focused on specific aspects of the MQI, while the other 
teacher's journey ended at strong MQI Noticing that was broad and spanned many aspects of the MQI with fewer specific examples.

My findings pertaining to the PD teachers' discussions of instances of students' mathematical practices resulted in the identification and explication of four approaches along two dimensions: whose utterances the PD teachers used as evidence of the instance (the clip teacher's or the students), and whether those utterances were used as articulations of the math practice or as implications of the math practice.

Taken together, my findings showed that:

(1) differences in teachers' MQI Noticing can be characterized at both the level of the individual teacher and at the group level;

(2) shifts in teachers' MQI Noticing can be detected as a result of focused MQI PD at the both at the level of the individual teacher and at the group level;

(3) at the individual level, these shifts trend significantly towards the highest level of MQI Noticing (noticing mathematical features of instruction with correct evidence) by the end of the PD, although this strong MQI Noticing post-PD can look different from participant to participant. For example, strong MQI Noticing might be more focused on a couple aspects of MQI in detail, or a more broad range of noticing many aspects of MQI; 
(4) at the group level, teachers' noticing of a specific aspect of MQI Noticing students' mathematical practices - can be characterized via (at least) four distinct approaches, and a trend away from looking at teacher moves that prompt for students' mathematical practices was observed with one group of teachers.

\section{Connections to Existing Research}

In the beginning chapters of this dissertation, I argued that Mathematical Quality is an important characteristic of a teacher's instruction. Previous research supports the notion that the MQI in a classroom is related to MKT, which is in turn related to student achievement outcomes (Charalambous et al., 2012; Hill et al., 2005, 2007, 2012; Hill \& Charlambous, 2012; Hill et al., 2008; Hill et al., 2012; Lewis \& Blunk 2012). Thus, in the interest of improving the mathematics education of children, $\mathrm{PD}$ centered on the $\mathrm{MQI}$ is a promising avenue. I further argued that an important way of studying teachers' understandings of MQI as they learn about it in a PD context, is through the lens of teachers' noticing. Previous studies have successfully demonstrated that changes in teachers' understandings of particular aspects of instruction can be illuminated through a noticing lens (e.g., Jacobs et al., 2011; Sherin \& van Es, 2005, 2009; Star \& Strickland, 2007; Star et al, 2011; van Es \& Sherin 2002, 2006, 2008), yet none of these studies focused on understanding teachers' noticing of MQI-related features of instruction. 
My findings extend the field of mathematics teacher noticing into the space of the MQI. Specifically, as a result of the research presented in this dissertation, we now know that MQI Noticing is learnable by individual teachers as they go through the MQI PD, and we have fine-grained examples of two teachers' MQI Noticing journeys under "ideal" conditions.

In the process of coming to these results, I found that the previously established conceptualization of mathematics teacher noticing as consisting of both Attending and Interpreting (Sherin et al., 2011) is fruitful for the study of individual teachers' MQI Noticing and for illuminating differences within and across participants. I also found that the approaches groups teachers' use with specific MQI Noticing tasks during the MQI PD can also be characterized by utilizing the notion of noticing as attending and interpreting, and that these approaches vary within and across PD discussions. From there, I was able to identify sub-dimensions of teachers' MQI Noticing within the larger headings of attending and interpreting that emerged from the particular datasets I analyzed.

The statistically significant shifts I identified using the MQI Noticing Framework (specifically, its mathematized version) lend strong support for the effectiveness of the MQI PD program. As I elaborated in Chapter 2 of this dissertation, the MQI PD program includes a wealth of research-based PD design features. For example, the MQI PD program is in line with research-based recommendations that PD programs be teacher-centered, collaborative, inquiryoriented, rooted in real artifacts of practice (e.g., classroom video), and sustained 
over time (Borko et al., 2008; Cohen \& Ball, 1999; Hiebert \& Morris, 2012; Little, 1993; Loucks-Horsley et al., 2009; Smith, 2001, Wei at al., 2010). Using my framework, I found that the MQI PD program, which has all of these features, likely supported teachers in a general shift towards an increased awareness of mathematical features of instruction and increased skill in picking out specific instances of mathematical features of instruction as they observe video clips of mathematics lessons.

Zooming out from the MQI PD to K-12 mathematics teacher PD in general, the findings I presented in Chapter 6 deepen our understanding of ways in which teachers might gauge success (or lack thereof) in having students engage in Math Practices, either within their own or others' lessons. In the current educational climate, teachers across the US are strongly encouraged to have students engage in rich mathematical practices (e.g., NCTM et al., 2010) such as those found in the Common Core (NGA \& CCSSO, 2010), yet we are only just beginning to understand teachers' interpretations of Math Practices (e.g., Stephens \& Barlow, 2015). My findings provide a take that is distinct from previous work on understanding teachers' thinking about Math Practices because I use a noticing lens. Regardless of teachers' interpretations of individual Math Practices, my findings showed that teachers focus on the actions or utterances of different people (teacher or students), and they use those utterances in different ways, when trying to gauge whether an instance of a Math Practice has indeed occurred within a lesson. 


\section{Implications for PD and Future Research}

The findings of my study can support future inquiries into teachers' MQI Noticing, and future implementations of the MQI PD program or similarly-focused PD programs, in various ways.

\section{Implications for PD}

Facilitators for, and developers of, the MQI PD (or similar PD) now have an idea of what individual teachers' noticing (and two teachers' specific journeys) looks like at pre-, mid-, and post-PD, and could emphasize features of the MQI PD that might support teachers' "leveling up" on the MQI Noticing Framework. For example, emphasizing the distinction between "noticing the mathematics" of the instruction in the clip and noticing "mathematical features of instruction" might be useful in supporting teachers in differentiating between the two - and in particular, that the later is what the MQI specifically pertains to.

Further, facilitators for, and developers of, the MQI PD (or similar PD) can also be watching for the different approaches that emerge in teachers' discussions of instances of students' mathematical practices. Having a framework for identifying which approaches teachers are exhibiting in their discussions might help facilitators think of potential helpful next moves in the discussion or later in the PD. For example, a facilitator might choose to highlight the fact that some PD teachers seem to be focusing on things the teacher in the clip is saying while other PD teachers seem to be focusing on things the students are saying. Then, without having to take 
a top-down approach, the PD facilitator could prompt the teachers to consider the reasoning behind both of these approaches and come to an agreement about which they intend to focus on going forward (or if they want to continue focus on both).

\section{The MQI Noticing Framework as a Tool for Future Research}

As I was developing the MQI Noticing Framework (along with its mathematized version), I intended for it to be a research tool for future studies of MQI Noticing. Specifically, I developed this framework in order to have a way to consistently categorize teachers' verbal or written responses to instruction, according to how closely the statement reflects MQI Noticing. As such, this framework could be used in research that:

- attempts to identify general trends in development of teachers' MQI Noticing over time;

- explores differences in MQI Noticing levels between MQI PD teachers and comparison teachers on a larger scale than was done above; or

- follows individual teachers' journeys over time, with respect to their MQI Noticing, using case study methodology.

\section{Ideas for Future Studies}

Opportunities for further research are many, but in this section, I focus in particular on ideas for future research that grow out of the limitations of the research presented in this dissertation. 
Connections to PD Teachers' Enacted Instruction. One limitation of my study is that the connections to PD teachers' actual, enacted instruction was not examined. It would be prudent for future research to include analyses of videorecordings of teachers' lessons to begin to explore whether there is an association between teachers' MQI Noticing and the MQI of their lessons.

More Teachers, More Groups. Another limitation of my study is that I only included two example teachers in my qualitative analyses of teachers' MQI Noticing journeys, and I only included on group of teachers in my analyses of teachers' discussions of potential instances of students' mathematical practices. An obvious direction for future research would be to broaden the number of teachers and groups investigated.

Deeper Inquiry into MQI Noticing Development. Throughout this dissertation, I have intentionally used the term shift to reflect changes in teachers' MQI Noticing as they went through the PD, rather than the term development. This is because the term development seems to include the inquiry into a more detailed "how" and "reasons why" with respect to the shifts I observed. Future research inquires could expand the notion of shifts to the notion of development by digging deeper into the teachers' MQI Noticing journeys and the forces affecting those journeys. For example, this inquiry might include analyses of interviews with individual teachers as they progress throughout the PD, and/or an analysis of teachers' MQI scoring sheets during the PD sessions and the transcripts of dialogue that took place during the sessions. 


\section{Concluding Remark}

The challenge for mathematics teacher educators and mathematics PD professionals is to continue to strengthen the PD experiences teachers have, to the point that teachers' instruction grows stronger and has a positive impact on the mathematical education of children. A critical piece of addressing this challenge involves researchers seeking to understand, through various lenses, the ways in which teachers engage in our most promising PD programs, such as the MQI PD. Understanding teachers' thinking, experiences, response, etc., can and should inform next steps in PD development and facilitation. The work I presented in this dissertation - though not without its limitations - is a contribution to this effort, establishing an initial understanding of teachers' Noticing in the context of the MQI PD. 


\section{References}

Ainley, J., \& Lutley, M. (2007). Towards an articulation of expert classroom practice. Teaching and Teacher Education, 23(7), 1127-1138.

American Educational Research Association. (2006). Standards for reporting on empirical social science research in AERA Publications. Educational Researcher, 35(6), 33-40.

Ball, D. L. (1991). Research on teaching mathematics: Making subject matter part of the equation. In J. Brophy (Ed.), Advances in research on teaching (Vol. 2, pp. 1-48). Greenwich, CT: JAI.

Ball, D., \& Cohen, D. (1999). Toward a Practice-Based Theory of Professional Education: Teaching as the learning profession. San Francisco: Jossey-Bass.

Bell, C. A., Wilson, S. M., Higgins, T., \& McCoach, D. B. (2010). Measuring the effects of professional development on teacher knowledge: The case of developing mathematical ideas. Journal for Research in Mathematics Education, 479512.

Bettany-Saltikov, J., \& Whittaker, V. J. (2014). Selecting the most appropriate inferential statistical test for your quantitative research study. Journal of Clinical Nursing, 23(11-12), 1520-1531.

Birman, B. F., Desimone, L., Porter, A. C., \& Garet, M. S. (2000). Designing professional development that works. Educational leadership, 57(8), 28-33. 
Borko, H., Jacobs, J., Eiteljorg, E., \& Pittman, M. E. (2008). Video as a tool for fostering productive discussions in mathematics professional development. Teaching and Teacher Education, 24(2), 417-436.

Boston, M., \& Wolf, M. K. (2004). Using the Instructional quality assessment (IQA) toolkit to assess academic rigor in mathematics lessons and assignments. Annual Meeting of the American Educational Research Association, San Diego, CA.

Braun, V., \& Clarke, V. (2006). Using thematic analysis in psychology. Qualitative Research in Psychology, 3(2), 77-101.

Charalambous, C. Y., Hill, H. C., \& Mitchell, R. N. (2012). Two negatives don't always make a positive: Exploring how limitations in teacher knowledge and the curriculum contribute to instructional quality. Journal of Curriculum Studies,44(4), 489-513.

Cicchetti, D. V. (1994). Guidelines, criteria, and rules of thumb for evaluating normed and standardized assessment instruments in psychology. Psychological Assessment, 6(4), 284-290.

Cohen, D. K., \& Ball, D. L. (1999). Instruction, capacity, and improvement. Corsortium for Policy Research in Education.

Cohen, D. K., \& Hill, H. C. (2001). Learning policy: When state education reform works. Yale University Press. 
Cohen, D. K., Raudenbush, S. W., \& Ball, D. L. (2000). Resources, instruction, and research: A CTP working paper. Center for the Study of Teaching and Policy, University of Washington.

Desimone, L. M., Porter, A. C., Garet, M. S., Yoon, K. S., \& Birman, B. F. (2002). Effects of professional development on teachers' instruction: Results from a threeyear longitudinal study. Educational Evaluation and Policy Analysis, 24(2), $81-112$.

Franke, M. L., Carpenter, T. P., Levi, L., \& Fennema, E. (2001). Capturing teachers' generative change: A follow-up study of professional development in mathematics. American Educational Research Journal, 38(3), 653-689.

Garet, M. S., Porter, A. C., Desimone, L., Birman, B. F., \& Yoon, K. S. (2001). What makes professional development effective? Results from a national sample of teachers. American Educational Research Journal, 38(4), 915-945.

Ginsburg, H. (1997). Entering the child's mind: The clinical interview in psychological research and practice. Cambridge University Press.

Goodwin, C. (1994). Professional vision. American Anthropologist, 96, 6-633.

Granheim, U.H., \& Lundman, B. (2004). Qualitative content analysis in nursing research: concepts, procedures and measures to achieve trustworthiness. Nurse Education Today, 24 (2) (2004), pp. 105-112.

Greeno, J. G. (1991). Number sense as situated knowing in a conceptual domain. Journal for Research in Mathematics Education. 
Halgren, K. A. (2012). Computing inter-rater reliability for observational data: An overview and tutorial. Tutor of Quantitative Methods in Psychology, 8(1), 2334.

Hanushek, E. A. (1996). A more complete picture of school resource policies. Review of Educational Research, 66(3), 397-409.

Henningsen, M., \& Stein, M. K. (1997). Mathematical tasks and student cognition: Classroom-based factors that support and inhibit high-level mathematical thinking and reasoning. Journal for Research in Mathematics Education, 28(5), 524-549.

Hendrickson, S., Hilton, S. C., Bahr, D. (2007). The Comprehensive Mathematics Instruction (CMI) Framework: A new lens for examining teaching and learning in the mathematics classroom

Hiebert, J., \& Morris, A. K. (2012). Teaching, rather than teachers, as a path toward improving classroom instruction. Journal of Teacher Education, 63(2), 92102.

Hill, H. C., \& Ball, D. L. (2004). Learning mathematics for teaching: Results from California's mathematics professional development institutes. Journal for Research in Mathematics Education, 330-351.

Hill, H. C., Ball, D. L., Blunk, M., Goffney, I. M., \& Rowan, B. (2007). Validating the ecological assumption: The relationship of measure scores to classroom teaching and student learning. Measurement, 5(2-3), 107-118. 
Hill, H. C., Beisiegel, M., \& Jacob, R. (2013). Professional Development Research Consensus, Crossroads, and Challenges. Educational Researcher,42(9), 476487.

Hill, H. C., Beisiegel, M., \& Mitchell, R. (2012). Exploring Methods for Improving Teachers' Mathematical Quality of Instruction. Funding proposal to the National Science Foundation.

Hill, H. C., Blunk, M. L., Charalambous, C. Y., Lewis, J. M., Phelps, G. C., Sleep, L., \& Ball, D. L. (2008). Mathematical knowledge for teaching and the mathematical quality of instruction: An exploratory study. Cognition and Instruction, 26(4), 430-511.

Hill, H. C., \& Charalambous, C. Y. (2012). Teaching (un)Connected Mathematics: Two teachers' enactment of the Pizza problem. Journal of Curriculum Studies, 44(4), 467-487.

Hill, H., \& Herlihy, C. (2011). Prioritizing teaching quality in a new system of teacher evaluation. Education Outlook, (9).

Hill, H. C., Rowan, B., \& Ball, D. L. (2005). Effects of teachers' mathematical knowledge for teaching on student achievement. American Educational Research Journal, 42(2), 371-406.

Hill, H. C., Schilling, S. G., \& Ball, D. L. (2004). Developing measures of teachers' thematics knowledge for teaching. The Elementary School Journal,105(1), 11-30. 
Hill, H.C., Sleep, L. \& Lewis, J.M. \& Ball, D.L. (2007) Assessing Teachers' Mathematical Knowledge: What Knowledge Matters and What Evidence Counts? In F. Lester (Ed.), Handbook for Research on Mathematics Education (2nd ed), p. 111-155. Charlotte, NC: Information Age Publishing.

Hill, H. C., Umland, K., Litke, E., \& Kapitula, L. R. (2012). Teacher quality and quality teaching: Examining the relationship of a teacher assessment to practice. American Journal of Education, 118(4), 489-519.

Horizon Research. (2000). Inside the classroom observation and analytic protocol. Chapel Hill, NC: Horizon Research, Inc.

Kazemi, E., \& Franke, M. L. (2004). Teacher learning in mathematics: Using student work to promote collective inquiry. Journal of Mathematics Teacher Education, 7(3), 203-235.

Kilpatrick, J., Swafford, J., \& Findell, B. (2001). Adding it up. Mathematics Learning Study Committee, Center for Education, Washington, DC: National Academy Press.

Lampert (2001). Teaching problems and the problems of teaching. New Haven: Yale University Press.

Learning Mathematics for Teaching Project. (2011). Measuring the mathematical quality of instruction. Journal of Mathematics Teacher Education, 14, 25-47. Lewis, J. M., \& Blunk, M. L. (2012). Reading between the lines: Teaching linear algebra. Journal of Curriculum Studies, 44(4), 515-536. 
Little, J. W. (1993). Teachers' professional development in a climate of educational reform. Educational Evaluation and Policy Analysis, 15(2), 129-151.

Loucks-Horsley, S., Stiles, K. E., Mundry, M. S. E., Love, N. B., \& Hewson, P. W. (2009). Designing professional development for teachers of science and mathematics. Corwin Press.

Mason, J. (2002). Researching your own practice: The discipline of noticing. London: Routledge Falmer.

Maxwell, J. A. (2002). Understanding and validity in qualitative research. In A. M. Huberman \& M. B. Miles (Eds.), The Qualitative Researcher's Companion (pp. 37-64). Thousand Oaks, CA: Sage.

National Center for Education Statistics. (2012). The nation's report card: Trends in academic progress 2012 (NCES 2013-456). Washington, DC: National Center for Education Statistics, Institute of Education Sciences, U.S. Department of Education.

National Council of Teachers of Mathematics (2000). Principles and standards for school mathematics. National Council of Teachers of Mathematics, Restin, VA,

Rhoads, K., \& Weber, K. (2014). Exemplary high school mathematics teachers' reflections on teaching: A situated cognition perspective. Manuscript submitted for publication.

Rowland, T., Huckstep, T., \& Thwaites, A. (2005). Elementary teachers' mathematics subject knowledge: The knowledge quartet and the case of Naomi. Journal of Mathematics Teacher Education, 8, 255-281. 
Santagata, R., \& Angelici, G. (2010). Studying the impact of the lesson analysis framework on preservice teachers' abilities to reflect on videos of classroom teaching. Journal of Teacher Education, 61(4), 339-349.

Santagata, R., Zannoni, C., \& Stigler, J. W. (2007). The role of lesson analysis in preservice teacher education: An empirical investigation of teacher learning from a virtual video-based field experience. Journal of Mathematics Teacher Education, 10(2), 123-140.

Sawada, D., \& Pilburn, M. (2000). Reformed teaching observation protocol (RTOP). Arizona State University: Arizona Collaborative for Excellence in the Preparation of Teachers.

Sfard, A. (2000). Symbolizing mathematical reality into being-or how mathematical discourse and mathematical objects create each other. Symbolizing and communicating in mathematics classrooms: Perspectives on discourse, Tools, and instructional design, 37-98.

Sherin, M. G., \& Han, S. Y. (2004). Teacher learning in the context of a video club. Teaching and Teacher Education, 20(2), 163-183.

Sherin, M., Jacobs, V., \& Philipp, R. (Eds.). (2011). Mathematics teacher noticing: Seeing through teachers' eyes. Routledge.

Sherin, M. G., \& van Es, E. A. (2005). Using video to support teachers' ability to notice classroom interactions. Journal of Technology and Teacher Education, 13, 475-491. 
Sherin, M. G., \& van Es, E. A. (2009). Effects of video club participation on teachers' professional vision. Journal of Teacher Education, 60, 20-37.

Shulman, L. S. (1986). Those who understand: Knowledge growth in teaching. Educational Researcher,15(2), 4-14.

Simons, D. J. (2000). Attentional capture and inattentional blindness. Trends in Cognitive Sciences, 4, 147-155.

Smith, M. S. (2001). Practice based professional development for teachers of mathematics. National Council of Teachers of Mathematics.

Star, J.R., \& Strickland, S. K. (2007). Learning to observe: Using video to improve preservice teachers' ability to notice. Journal of Mathematics Teacher Education, 11, 107-125.

Stigler, J. W., \& Hiebert, J. (2004). Improving mathematics teaching. Educational Leadership, 61(5), 12-17.

van Es., E. A. (2011). A framework for learning to notice student thinking. In M. G. Sherin, V. C. Jacobs, \& R. A. Philipp (Eds.), Mathematics teacher noticing: Seeing through teachers' eyes. New York: Routledge.

van Es, E. A., \& Sherin, M. G. (2002). Learning to notice: Scaffolding new teachers' interpretations of classroom interactions. Journal of Technology and Teacher Education, 10, 571-596.

van Es, E. A., \& Sherin, M. G. (2006). How different video club designs support teachers in "learning to notice." Journal of Computing in Teacher Education, $22,125-135$. 
van Es, E. A., \& Sherin, M. G. (2008). Mathematics teachers' "learning to notice" in the context of a video club. Teaching and Teacher Education, 24, 244-276.

Walter, J. G., \& Maher, C. A. (2002). Student-to-student questioning in the development of mathematical understanding: six high school students mathematizing a shell. In the Proceedings of the 24th Annual Meeting of the Psychology of Mathematics Education North-American Chapter (PME-NA), 998.

Wayne, A. J., \& Youngs, P. (2003). Teacher characteristics and student achievement gains: A review. Review of Educational Research, 73(1), 89-122.

Weaver, D., Dick, T., Higgins, K., Marrongelle, K., Foreman, L., Miller, N., et al. (2005). OMLI classroom observation protocol. Portland, OR: RMC Research Corporation.

Wei, R. C., Darling-Hammond, L., \& Adamson, F. (2010). Professional development in the United States: Trends and challenges. Dallas, TX: National Staff Development Council.

Wei, R. C., Darling-Hammond, L., Andree, A., Richardson, N., \& Orphanos, S. (2009). Professional Learning in the Learning Profession: A Status Report on Teacher Development in the US and Abroad. Technical Report. National Staff Development Council. 


\section{Richness of the Mathematics}

This dimension attempts to capture the depth of the mathematics offered to students. Rich mathematics is either a) focused on the meaning of facts and procedures OR b) focused on key mathematical practices. Rich mathematics allows students to build a conceptual mathematical base and/or also illustrates mathematical practices and habits.

For all codes within this dimension, the aspect of instruction must be substantially correct to count as low, mid or high. Richness elements that are not correct should be ignored (though the segment can be still credited for correct elements within the same code). 


\section{Linking Between Representations}

This code captures explicit links and connections that are drawn between different representations of a mathematical idea or procedure across representational "families".

- By across families, we mean table to graph, graph to equation, etc.

\begin{tabular}{|c|c|c|c|}
\hline Not present & Low & Mid & High \\
\hline $\begin{array}{l}\text { No linking is } \\
\text { present or it is } \\
\text { incorrect. } \\
\text { Representatio } \\
\text { ns may be } \\
\text { present, but } \\
\text { connections } \\
\text { are not } \\
\text { actively made. }\end{array}$ & $\begin{array}{l}\text { Links are } \\
\text { present in a } \\
\text { pro forma way; } \\
\text { teacher may } \\
\text { draw a diagram } \\
\text { of } 1 / 4^{\text {th }} \text { and } \\
\text { state that one } \\
\text { quarter is one } \\
\text { part out of four. } \\
\text { These links will } \\
\text { not be very } \\
\text { explicit or } \\
\text { detailed; only } \\
\text { one } \\
\text { representation } \\
\text { s needs to be } \\
\text { visible. }\end{array}$ & $\begin{array}{l}\text { Links and } \\
\text { connections have } \\
\text { features noted } \\
\text { under High, but } \\
\text { they occur as an } \\
\text { isolated instance } \\
\text { in the segment. } \\
\text { The } \\
\text { representations } \\
\text { that are being } \\
\text { linked must be } \\
\text { visually present. }\end{array}$ & $\begin{array}{l}\text { Links and connections are present } \\
\text { with sustained, careful work } \\
\text { characterized by one of the } \\
\text { following features: } \\
\text { - Explicitness about how two or } \\
\text { more representations are } \\
\text { related (e.g., pointing to specific } \\
\text { areas of correspondence) OR } \\
\text { Detail and elaboration about } \\
\text { how two mathematical } \\
\text { representations are related to } \\
\text { one another (e.g., providing } \\
\text { information about under what } \\
\text { conditions the relationship } \\
\text { occurs; noting meta-features; } \\
\text { discussing implications of } \\
\text { relationship) } \\
\text { They need not take up the majority } \\
\text { or even a significant portion of the } \\
\text { segment; however, they will offer } \\
\text { significant insight into the } \\
\text { mathematical material. }\end{array}$ \\
\hline
\end{tabular}




\section{Multiple Procedures or Solution Methods}

This code intends to capture multiple procedures or solution methods that occur or are discussed in the segment.

- Multiple solution methods for a single problem (including shortcuts)

- Multiple procedures for a given problem type

Defined as, e.g.:

- Taking different mathematical approaches to solving a problem (e.g., comparing fractions by finding a common denominator AND comparing fractions by finding a common numerator)

- The teacher or students discuss how to solve or solve a (word) problem using two different strategies.

\begin{tabular}{|c|c|c|c|}
\hline Not present & Low & Mid & High \\
\hline $\begin{array}{l}\text { No evidence of } \\
\text { multiple } \\
\text { procedures or } \\
\text { solution } \\
\text { methods or if } \\
\text { they are present, } \\
\text { but one is } \\
\text { incorrect. }\end{array}$ & $\begin{array}{l}\text { Teacher or } \\
\text { student briefly } \\
\text { mentions a } \\
\text { second } \\
\text { procedure or } \\
\text { method, but the } \\
\text { method is not } \\
\text { discussed at } \\
\text { length or } \\
\text { enacted ("we } \\
\text { also showed } \\
\text { yesterday that } \\
\text { you can do it } \\
\text { XYZ"). }\end{array}$ & $\begin{array}{l}\text { Multiple } \\
\text { procedures or } \\
\text { solution methods } \\
\text { occur or are } \\
\text { discussed in the } \\
\text { segment, but the } \\
\text { feature under } \\
\text { High occur only } \\
\text { briefly (e.g., "this } \\
\text { method is easier } \\
\text { than the other" } \\
\text { without explicit } \\
\text { discussion of } \\
\text { why). }\end{array}$ & $\begin{array}{l}\text { The special feature } \\
\text { below occur at some } \\
\text { length: } \\
\text { - Explicit extended } \\
\text { comparison of } \\
\text { multiple procedures } \\
\text { or solution methods } \\
\text { for efficiency, } \\
\text { appropriateness, } \\
\text { ease of use, or other } \\
\text { advantages and } \\
\text { disadvantages } \\
\text { Explicit discussion of } \\
\text { features of a problem } \\
\text { that cues the } \\
\text { selection of a } \\
\text { particular procedure } \\
\text { Explicit links } \\
\text { between multiple } \\
\text { procedures or } \\
\text { solution methods } \\
\text { (e.g., how one is like } \\
\text { or unlike the other) }\end{array}$ \\
\hline
\end{tabular}




\section{Explanations and Mathematical Sense-Making}

This code captures any teacher or student statements that focus on why as well as when teachers or students are making sense of a mathematical idea or procedure.

Focus on WHY, for example:

- why a procedure works (or doesn't work)

- why a solution method is appropriate (or inappropriate)

- why an answer is true (or not true)

Focus on MAKING SENSE of mathematics, for example:

- the meaning of numbers (e.g. size, value)

- the meaning of operations (e.g. division means...)

- the relationship between numbers (7/8 $8^{\text {th }}$ is closer to 1 than $\left.1 / 2\right)$

- the connection between representations (e.g. pattern blocks) and the underlying idea (e.g. part of a whole)

- making sense of word problems (how to model them, whether an answer makes sense)

\begin{tabular}{|l|l|l|l|}
\hline \multicolumn{1}{|c|}{ Not present } & \multicolumn{1}{c|}{ Low } & \multicolumn{1}{c|}{ Mid } & \multicolumn{1}{c|}{ High } \\
\hline $\begin{array}{l}\text { No mathematical } \\
\text { explanations or } \\
\text { sense-making } \\
\text { utterances in the } \\
\text { segment. Or } \\
\text { statements are } \\
\text { incorrect or } \\
\text { incomplete. }\end{array}$ & $\begin{array}{l}\text { A brief explanation } \\
\text { and/or } \\
\text { mathematical sense- } \\
\text { making utterance } \\
\text { occurs, but as an } \\
\text { isolated instance in } \\
\text { the segment. }\end{array}$ & $\begin{array}{l}\text { An explanation } \\
\text { and/or focus on } \\
\text { mathematical sense- } \\
\text { making is more than } \\
\text { briefly present, but } \\
\text { not the focus of } \\
\text { instruction. }\end{array}$ & $\begin{array}{l}\text { Explanation(s) } \\
\text { and/or } \\
\text { mathematical sense- } \\
\text { making are a major } \\
\text { feature of the } \\
\text { teacher-student } \\
\text { work. }\end{array}$ \\
\hline
\end{tabular}




\section{Mathematical Language}

This code captures how fluently the teacher (and students) use mathematical language and whether the teacher supports students' use of mathematical language.

- Mathematical language includes technical mathematical terms such as "angle," "addition," "distributive property," "equal," and "parallelogram"

- Saying numbers does not count as mathematical language

\begin{tabular}{|c|c|c|c|}
\hline Not present & Low & Mid & High \\
\hline $\begin{array}{l}\text { Score here when } \\
\text { NO mathematical } \\
\text { terms are used. } \\
\text { Teacher uses non- } \\
\text { mathematical } \\
\text { terms to describe } \\
\text { mathematical ideas } \\
\text { and procedures } \\
\text { AND/OR teacher } \\
\text { talk is } \\
\text { characterized by } \\
\text { sloppy/incorrect } \\
\text { use of } \\
\text { mathematical } \\
\text { terms. }\end{array}$ & $\begin{array}{l}\text { Low density of } \\
\text { mathematical } \\
\text { language. Not } \\
\text { necessarily an } \\
\text { indication that } \\
\text { teacher is not } \\
\text { "fluent" in } \\
\text { mathematics, but } \\
\text { simply a segment } \\
\text { where few } \\
\text { mathematical } \\
\text { terms are used, or } \\
\text { the same term is } \\
\text { used over and over } \\
\text { without features of } \\
\text { high. } \\
\\
\text { Also score low } \\
\text { when segment has } \\
\text { middling density, } \\
\text { but sloppy use }\end{array}$ & $\begin{array}{l}\text { Teacher uses } \\
\text { mathematical } \\
\text { language as a } \\
\text { vehicle for } \\
\text { conveying content, } \\
\text { with middling } \\
\text { density. However, } \\
\text { the segment has } \\
\text { few or none of the } \\
\text { special features } \\
\text { listed under high. }\end{array}$ & $\begin{array}{l}\text { Teacher uses } \\
\text { mathematical } \\
\text { language correctly } \\
\text { and fluently. Can be } \\
\text { achieved in two } \\
\text { ways: } \\
\text { 1. Density of } \\
\text { mathematical } \\
\text { language is high } \\
\text { during periods of } \\
\text { teacher talk. } \\
\text { 2. Moderate } \\
\text { density, but } \\
\text { explicitness about } \\
\text { terminology, } \\
\text { reminding } \\
\text { students of } \\
\text { meaning, pressing } \\
\text { students for } \\
\text { accurate use of } \\
\text { terms, encouraging } \\
\text { student use of } \\
\text { mathematical } \\
\text { language. }\end{array}$ \\
\hline
\end{tabular}


APPENDIX B: QUESTIONS AND VIDEO LINKS FOR INDIVIDUAL TYPED RESPONSES

\section{Lesson Reflection Questions:}

Think of the last mathematics lesson that you have taught. Please answer the following questions about that lesson:

1. What were you hoping students would learn during this lesson?

2. What activities did you engage students in to learn this content?

3. What went well in this lesson?

4. Did you or your students provide any mathematical explanations during this lesson? If so, please...

5. How much did students engage in mathematical reasoning and inquiry during today's lesson?

6. What, if anything, did not go well during the lesson?

7. Was there anything that you struggled with mathematically during this lesson? What was it?

8. If you teach this lesson again next year, will you change anything? If so, what? 


\section{Video Response Questions}

Links to video clips that teachers responded to:

Pre-PD Clip 1: http://www.kaltura.com/tiny/q1rkx

Pre-PD Clip 2: http://www.kaltura.com/tiny/tr99c

Mid-PD Clip 3: http://www.kaltura.com/tiny/uebo2

Mid-PD Clip 4: http://www.kaltura.com/tiny/xbb2a

Post-PD Clip 5: http://www.kaltura.com/tiny/w059z

Post-PD Clip 6: http://www.kaltura.com/tiny/lnmnr

1. What stood out to you about the mathematics in the clip?

2. What stood out to you about the teaching in the clip?

3. What seems significant to you about this mathematics instruction?

4. In your view, is this teaching likely to lead to students learning the content? Why or why not? 


\section{APPENDIX C: INDIVIDUAL INTERVIEWS}

Given that none of the parent study data afforded me the opportunity to investigate the teachers' thinking about mathematics instruction, I added 30-to-60minute individual interviews for the teachers in the group I facilitated, at multiple time points. A team of two graduate student researchers ${ }^{10}$ interviewed the teachers, one-on-one, three times during the study (pre-PD, mid-PD, and post-PD). I chose to have graduate students conduct the interviews - as opposed to conducting them myself - in order to increase the likelihood that participants would give unhindered responses that were not simply "what I might want to hear" as their PD facilitator.

The goal of each of the interviews was to gain a deep understanding of the teachers' current thinking about mathematics instruction - particularly pertaining to his or her general descriptions of strong mathematics instruction, as well as reflections on his or her own math instruction. The interviews were semistructured, meaning that the main questions of the interview protocol were standardized across participants and across time points, but particular follow-up questions were flexible, depending on the teacher's response to the main question (Ginsberg, 1997). This allowed the interviewer to probe and clarify the teacher's understandings as needed.

\section{Interview Questions}

Table 8 lists the interview questions that were asked at every interview. I provide the full protocols for all three interviews in Appendix D. These questions

\footnotetext{
${ }^{10}$ One graduate student researcher is a practicing high school mathematics teacher with a Master's degree in Mathematics Education, and the other graduate student researcher is a third-year student in a Mathematics Education PhD program.
} 
were developed via an interview-question-pilot project in early 2014. All of my pilot participants were practicing teachers who were not in my study. All interviews were conducted straight through, as though they were actual interviews for my study, and they were audio-recorded.

The primary goal of the pilot interviews was to evaluate whether or not the teachers' responses to the main interview questions addressed the intended aspects of their conceptualizations of quality math instruction. A secondary goal of the interview pilots was to generate ideas for follow-up questions.

In order to accomplish these goals, I systematically tested and modified the interview questions, one teacher at-a-time. First, I wrote a draft of interview questions and piloted those questions with one teacher. During the interview I took notes on potential modifications to the questions. I also tried out additional interview questions on-the-fly after I had gone through my planned questions. After the interview, I listened to the full audio-recording of the interview and added to my notes on potential modifications. Then, I modified the interview questions accordingly and proceeded to pilot those questions with a second teacher. This modification cycle continued until the questions elicited the intended types of responses from the teachers. In all, I interviewed four teachers - three teachers who are not trained on the MQI and one teacher who is trained on the MQI.

Through the question-modification cycles, the most challenging and unexpected issue was whether to use the phrase "quality of math instruction" or "mathematical quality of instruction" in the questions. During the first pilot interview, I discovered that using one of these two phrases in otherwise identical 170 
questions yielded significantly different responses from the teacher. In particular, "quality of math instruction" seemed to elicit general qualities or outcomes of instruction (e.g., "the students would be busy doing activities" or "the kids would have learned something,"), whereas "mathematical quality of instruction" seemed to more frequently elicit more mathematically-focused qualities of instruction (e.g., "having students explaining and justifying during math").

Ultimately I decided to tackle this issue by writing questions with both phrasings, calling the teachers' attention to the difference in phrasing in the second version. For example, one interview question is, "What features describe highquality math instruction in elementary school (or middle school)?" This question is followed with a similar question with explicit reference to the slightly different phrasing: 'If I asked you to consider the 'mathematical quality of instruction' instead, would you answer any differently? So, what features describe high mathematical quality of instruction in elementary school (or middle school)?" This strategy seemed to elicit responses that helped me understand the teachers' conceptualization of quality math instruction, while also alerting me as to whether the teacher treats the phrases "quality math instruction" and "mathematical quality of instruction" differently in her responses.

Below are the main questions that were asked at every interview, along with a rationale for each, with respect to my research questions. A full interview protocol, including follow-up questions for each main question, is included in Appendix D. Table 8 Main interview questions to be asked during every interview, and a rationale for each question 


\begin{tabular}{|c|c|}
\hline Main Question & Rationale \\
\hline $\begin{array}{l}\text { 1) To start, I'd like you to imagine } \\
\text { that you just watched someone else's } \\
\text { elementary (or middle) school class } \\
\text { and saw a math lesson that you } \\
\text { thought was really good. You were } \\
\text { really impressed by it. Can you tell } \\
\text { me about this lesson? }\end{array}$ & $\begin{array}{l}\text { The purpose of this question was to see how } \\
\text { the teacher describes an instance of high- } \\
\text { quality instruction. }\end{array}$ \\
\hline $\begin{array}{l}\text { 2) In general, what features does } \\
\text { high-quality math instruction have in } \\
\text { elementary (or middle) school? (To } \\
\text { ensure that the teacher gives an } \\
\text { exhaustive list of features, the } \\
\text { interviewer will follow up by asking: } \\
\text { "Are there any other features that } \\
\text { high-quality math instruction has?" } \\
\text { as needed.) }\end{array}$ & $\begin{array}{l}\text { The purpose of this question was to directly } \\
\text { ask the teacher to describe features of high- } \\
\text { quality math instruction. }\end{array}$ \\
\hline $\begin{array}{l}\text { 3) If I asked you to consider the } \\
\text { "mathematical quality of instruction", } \\
\text { would you answer any differently? } \\
\text { What features make the } \\
\text { mathematical quality of instruction } \\
\text { high, in elementary (or middle) } \\
\text { school? (If applicable: To ensure that } \\
\text { the teacher gives an exhaustive list of } \\
\text { features, the interviewer will follow } \\
\text { up by asking: "Are there any other } \\
\text { features that make the mathematical } \\
\text { quality of instruction high?" as } \\
\text { needed.) }\end{array}$ & $\begin{array}{l}\text { The purpose of this question was to directly } \\
\text { ask the teacher to describe features of a } \\
\text { classroom with high "mathematical quality } \\
\text { of instruction", while calling attention to the } \\
\text { difference in phrasing between this question } \\
\text { and question 2). The teacher may or may } \\
\text { not have any features to add to their } \\
\text { response to question 2). }\end{array}$ \\
\hline $\begin{array}{l}\text { 4) Are you wrestling with anything } \\
\text { lately, in terms of the math } \\
\text { instruction in your classroom? }\end{array}$ & $\begin{array}{l}\text { The purpose of this question was to get the } \\
\text { teacher to reflect on her own math } \\
\text { instruction by asking about things she is } \\
\text { currently working on. }\end{array}$ \\
\hline $\begin{array}{l}\text { 5) What is going well, in terms of the } \\
\text { math instruction in your classroom? }\end{array}$ & $\begin{array}{l}\text { The purpose of this question was to prompt } \\
\text { the teacher to further reflect on her own } \\
\text { math instruction by asking about current } \\
\text { strong points. }\end{array}$ \\
\hline
\end{tabular}




\begin{tabular}{|l|l|}
\hline & \\
\hline $\begin{array}{l}\text { 6) What about the math instruction } \\
\text { in your classroom contributes to it } \\
\text { being high quality? (Follow-up } \\
\text { question: What about the math } \\
\text { instruction in your classroom } \\
\text { contributes to it being of high } \\
\text { "mathematical quality"? Would you } \\
\text { answer this question any differently } \\
\text { than the last one where I just asked } \\
\text { about general "quality"?) }\end{array}$ & $\begin{array}{l}\text { The purpose of this question was to ask to } \\
\text { the teacher to reflect on her own math } \\
\text { instruction, in explicit reference to "high } \\
\text { quality" instruction and instruction of "high } \\
\text { mathematical quality". }\end{array}$ \\
\hline $\begin{array}{l}\text { 7) The purpose of this interview is to } \\
\text { gain insight into how you're thinking } \\
\text { about high-quality math instruction. } \\
\text { Is there anything that you haven't } \\
\text { mentioned so far that you think } \\
\text { would further help us in } \\
\text { understanding your current thinking } \\
\text { about high-quality math instruction? }\end{array}$ & $\begin{array}{l}\text { This question gives the teacher the } \\
\text { opportunity to add anything that they think } \\
\text { would help me understand their thinking } \\
\text { about high-quality math instruction. }\end{array}$ \\
\hline
\end{tabular}

\section{Interview Protocols}

\section{INTERVIEW 1}

Before the interview: Make sure you have a reliable audio-recording device (with extra batteries, if applicable)

Thank the participant for coming.

Ask the participant for permission to audio-record their responses and remind them that their participation is always voluntary. The recording and/or the interview can be stopped at any time.

Let the participant know that the primary purpose of this interview is for us to gain insight into their current thinking about quality math instruction. There are no right or wrong answers, and you aren't judging their responses.

Ask the participant if they have any questions of me before we begin.

Begin the recording. 
1) To start, I'd like you to imagine that you just sat in on someone else's class - let's say in one of the intermediate grades, $3^{\text {rd }}, 4^{\text {th }}$, or $5^{\text {th }}$ - and saw a math lesson that you thought was really strong. You were really impressed by it. Can you tell me about this lesson?

Optional follow-up questions:

- What made you like this lesson so much?

- Are there any other important aspects of the lesson that you haven't mentioned?

- What might you find impressive about a math lesson?

2) So I heard you mention ...\{\{here, I'd like you to list back ideas you've heard them mention in the last question\}\}. Are there any other features that you would add to that list to capture your understanding of high-quality math instruction?

3) If I asked you to consider a specific term: the "mathematical quality of instruction", would you answer the last question any differently? So, what features can make the mathematical quality of instruction high in a lesson?

[After initial response] Are there any other features that make the mathematical quality of instruction high?

4) Are you wrestling with anything lately, in terms of the math instruction in your own classroom?

[After initial response] Is there anything else you're wrestling with, in terms of the math instruction in your classroom?

Optional follow-up questions:

- What are you working on lately, in terms of your math instruction?

- What do you find to be challenging about teaching math right now?

- What are you trying to improve right now, in terms of your math instruction?

5) What is going well, in terms of the math instruction in your classroom?

[After initial response] Is there anything else that you think is going well, in terms of the math instruction in your classroom?

$\{\{$ Go for it with the follow-up questions here. Try to get the teacher to talk about their own math teaching for a few minutes, if they haven't already done so.\}\}

Optional follow-up questions:

- What do you think the strong points of your math instruction are, right now?

- What are you proud of, in terms of the quality of the math instruction in your classroom?

- What do you like about your math teaching lately? 
6) Ideally, what do you hope your students take away from your math lessons after a year in your class?

$\{\{$ Be prepared to ask some "what do you mean by that" follow-up questions here. $\}\}$

7) The purpose of this interview is to gain insight into how you're thinking about high-quality math instruction. Is there anything that you haven't mentioned so far that you think would further help us in understanding your current thinking?

8) If, at a later time, we find that we would like clarification on something you said during this interview, do we have your permission to contact you for clarification?

Stop the audio recording. Thank the participant and ask them if they have any questions or concerns about the interview or the study in general.

\section{INTERVIEW 2}

1) To get us started here: Do you think your thinking about math teaching has changed since we last spoke, before you were introduced the MQI? [If yes:] In what ways? [This is an intentionally open-ended question, and they can answer it however they see fit. However, please follow-up to clarify the participants' ideas here, as needed.]

2) [This can be skipped if the participant has already addressed this in question 1] Do you think your math teaching has changed since you were introduced to the MQI? In what ways? [Try to ask if the participant attributes the changes to any specific aspect of the MQI - or not.]

3) When we last spoke, I asked you to imagine that you just sat in on someone else's class and saw a math lesson that you thought was really strong. You were really impressed by it. And then I asked you to describe the features of this lesson. How would you answer this question today?

Optional follow-up questions:

- What made you like this lesson so much?

- Are there any other important aspects of the lesson that you haven't mentioned?

- What might you find impressive about a math lesson?

- So I heard you mention ...\{\{here, I'd like you to list back ideas you've heard them mention in the last question\}\}. Are there any other features that you would add to that list to capture your understanding of high-quality math instruction? 
5) What does the phrase "mathematical quality of instruction" mean to you now?

Optional follow-up questions:

- What idea or ideas do you think the phrase "mathematical quality of instruction" captures?

- How would you define the phrase "mathematical quality of instruction" to a colleague in your building?

6) Do you have a favorite MQI dimension/code? Why?

7) What is going well, in terms of the math instruction in your classroom?

[After initial response] Is there anything else that you think is going well, in terms of the math instruction in your classroom?

Optional follow-up questions:

- What do you think the strong points of your math instruction are, right now?

- What are you proud of, in terms of the quality of the math instruction in your classroom?

- What do you like about your math teaching lately?

8) Are you wrestling with anything lately, in terms of the math instruction in your own classroom? [After initial response] Is there anything else you're wrestling with, in terms of the math instruction in your classroom?

Optional follow-up questions:

- What are you working on lately, in terms of your math instruction?

- What do you find to be challenging about teaching math right now?

- What are you trying to improve right now, in terms of your math instruction?

9) Is there anything that you haven't mentioned so far that you think would further help us in understanding your current thinking about math instruction?

10) If, at a later time, we find that we would like clarification on something you said during this interview, do we have your permission to contact you for clarification?

\section{INTERVIEW 3}

1) To get us started here: What have you been thinking about lately, with respect to math teaching? [This is an intentionally open-ended question, and they can answer it however they see fit. However, please follow-up to clarify the participants' ideas here, as needed.] 
2)a) Do you think your thinking about math teaching has changed since we last spoke? [If yes, in what ways.] [Try to clarify if the participant attributes the changes to any specific aspect of the MQI - or not.]

b) Do you think your math teaching has changed since we last spoke? [If yes:] In what ways? [Try to clarify if the participant attributes the changes to any specific aspect of the MQI - or not.]

3) a) At the last two interviews, I asked you to imagine that you just sat in on someone else's class and saw a math lesson that you thought was really strong. You were really impressed by it. And then I asked you to describe the features of this lesson. How would you answer this question today?

Optional follow-up questions:

- What made you like this lesson so much?

- Are there any other important aspects of the lesson that you haven't mentioned?

- What might you find impressive about a math lesson?

b) So I heard you mention ...\{\{here, I'd like you to list back ideas you've heard them mention in the last question\}\}. Are there any other features that you would add to that list to capture your understanding of high-quality math instruction?

4) a) What is going well, in terms of the math instruction in your classroom?

[After initial response] Is there anything else that you think is going well, in terms of the math instruction in your classroom?

Optional follow-up questions:

- What do you think the strong points of your math instruction are, right now?

- What are you proud of, in terms of the quality of the math instruction in your classroom?

- What do you like about your math teaching lately?

b) Are you wrestling with anything lately, in terms of the math instruction in your own classroom?

[After initial response] Is there anything else you're wrestling with, in terms of the math instruction in your classroom?

Optional follow-up questions:

- What are you working on lately, in terms of your math instruction?

- What do you find to be challenging about teaching math right now?

- What are you trying to improve right now, in terms of your math instruction?

5) How would you describe what the MQI instrument is, to a colleague? 
Optional clarification question:

- If a colleague asked you what the MQI instrument is, what would you say to them?

6) a) Are there any codes on the MQI that you don't feel are necessary? [If yes:] Which ones, and why?

7) For this next question, I'm going to ask you for your thoughts about specific codes on the MQI. This isn't a quiz by any means. I'm only interested in what comes to mind when you think about the meaning of each code.

[For each code listed below:] How would you describe the code and what it's trying to capture?

a) Linking Representations

b) Explanations and sense-making

c) Mathematical language

d) Remediation

e) Using students' mathematical ideas

f) Student engagement in mathematical practices

g) enacted task cognitive activation

h) use of contextualized problems

8) a) What has been surprising, challenging, or useful for you as you have gone through this professional development program?

b) Would you recommend this professional development to your colleagues? Why?

9) Is there anything that you haven't mentioned so far that you think would further help us in understanding your current thinking?

10) If, at a later time, we find that we would like clarification on something you said during this interview, do we have your permission to contact you for clarification? 


\section{APPENDIX D: RAW QUANTITATIVE DATA FOR CHAPTER 4}

Maximum MQI Noticing statement scores for each participant at pre, mid, and post-PD

\begin{tabular}{|c|c|c|c|}
\hline Participant ID & Max. Pre & Max. Mid & Max. Post \\
\hline 1111 & 3 & 4 & 1 \\
\hline 1151 & 3 & 3 & 3 \\
\hline 1152 & 1 & 4 & 4 \\
\hline 1153 & 1 & 2 & 2 \\
\hline 1156 & 2 & 2 & 4 \\
\hline 1158 & 1 & 2 & 1 \\
\hline 1351 & 2 & 3 & 3 \\
\hline 1352 & 3 & 2 & 3 \\
\hline 1353 & 1 & 3 & 4 \\
\hline 1354 & 2 & 3 & 3 \\
\hline 1355 & 2 & 4 & 4 \\
\hline 1357 & 2 & 4 & 4 \\
\hline 1359 & 0 & 2 & 3 \\
\hline 1360 & 3 & 3 & 4 \\
\hline 1361 & 1 & 3 & 3 \\
\hline 1362 & 2 & 3 & 3 \\
\hline 1363 & 0 & 4 & 4 \\
\hline 1364 & 2 & 4 & 4 \\
\hline 1365 & 2 & 4 & 4 \\
\hline 1368 & 2 & 3 & 3 \\
\hline 1370 & 2 & 2 & 1 \\
\hline 1371 & 1 & 1 & 4 \\
\hline 1607 & 0 & 3 & 2 \\
\hline 1608 & 1 & 3 & 3 \\
\hline 1609 & 0 & 4 & 4 \\
\hline 1701 & 0 & 3 & 3 \\
\hline 1702 & 0 & 3 & 4 \\
\hline 1703 & 1 & 3 & 4 \\
\hline 1704 & 4 & 2 & 2 \\
\hline 1705 & & & \\
\hline
\end{tabular}




\begin{tabular}{|c|c|c|c|}
\hline 1706 & 1 & 2 & 3 \\
\hline 1708 & 1 & 2 & 1 \\
\hline 1709 & 0 & 3 & 3 \\
\hline 1710 & 1 & 4 & 3 \\
\hline 1711 & 1 & 3 & 1 \\
\hline 1712 & 1 & 2 & 3 \\
\hline 1713 & 1 & 4 & 3 \\
\hline 1714 & 1 & 2 & 2 \\
\hline 1715 & 1 & 4 & 4 \\
\hline 1716 & 1 & 4 & 1 \\
\hline 1717 & 1 & 4 & 3 \\
\hline 1718 & 4 & 2 & 1 \\
\hline 1720 & 4 & 3 & 3 \\
\hline 1721 & 1 & 4 & 4 \\
\hline 1722 & 0 & 3 & 4 \\
\hline 1723 & 3 & 2 & 2 \\
\hline 1724 & 2 & 3 & 3 \\
\hline 1725 & 1 & 2 & 1 \\
\hline 1801 & 3 & 4 & 3 \\
\hline 1802 & 3 & 2 & 2 \\
\hline 1804 & 4 & 4 & 4 \\
\hline 1807 & 3 & 4 & 4 \\
\hline 1808 & 0 & 1 & 3 \\
\hline 1809 & 0 & 4 & 1 \\
\hline 1810 & 1 & 3 & 4 \\
\hline 1811 & 1 & 4 & 1 \\
\hline 1812 & 2 & 3 & 2 \\
\hline
\end{tabular}




\section{APPENDIX E: TRANSCRIPTS OF VIDEO CLIPS SCORED ON THE CCSP DIMENSION DURING PD SESSIONS 1-6}

\section{Ingrid: Area and Perimeter}

Ingrid: So what does the 28 mean? What does the 28 actually mean? STUDENT: It's the area. Ingrid: And can you prove it? Can you show that in the picture? Yeah.... Nice. TEACHER2: Don't forget to share with your partner! Remember, we want to hear your thinking!

[00:30]

Ingrid: Nice. And then what do you have there?

STUDENT: What?

Ingrid: What do you have there?

STUDENT: 1,2,3,4,5... (inaudible) 28.

Ingrid: 28 ? 28 squares inside? So that's the area? Or the perimeter?

STUDENT: It's the area.

Ingrid: Sure! And you proved it! So then, what's his friend thinking? His friend said, what did his friend say?

STUDENT: That the area is 22 .

[01:00]

Ingrid: And do you agree?

STUDENT: No.

ingrid: No. What was the friend confused about?

STUDENT: I think it's because he, um, accidentally added.

Ingrid: So if he added, what did he find? What was he doing?

STUDENT: Um, figuring out the perimeter?

Ingrid: Maybe, yeah! Can you figure out the perimeter, then?

STUDENT: Yeah.

Ingrid: What's the perimeter of that?

[01:30]

Ingrid: So what was his friend thinking?

STUDENT: That the area was...that you're supposed to add.

Ingrid: To find the area? So then, you just proved that this is what?

STUDENT: 22.

Ingrid: And that's the.. 
STUDENT: Perimeter.

Ingrid: The perimeter? Can you show me the perimeter on that? Show me the perimeter on your rectangle.

STUDENT: How?

[02:00]

Ingrid: I don't know. How can you prove it? 'Cause you proved your area for me. Do you know how to prove the perimeter? What did we do with the first picture?

STUDENT: We colored the outside?

Ingrid: Sure. So could you show me the perimeter?

STUDENT: Like this?

Ingrid: Yeah! Perfect! Great! I just wanted to make sure. Wonderful! Good job. Good job! Make sure you share. And make sure with your partner, too.

[02:30]

Ingrid: Ah! I like your proof. What did you do there?

STUDENT: I... um, showed the numbers, the number in square inches, and added the numbers, like, 28 ?

Ingrid: So you actually counted 'em, huh? So then you agreed with... Robbie?

STUDENT: Mmm hmm.

Ingrid: Yeah? And so what was his friend thinking?

STUDENT: I think his friend was thinking....Yeah. I think he was counting the perimeter instead.

[03:00]

Ingrid: $\mathrm{Mmm}$ hmm.

STUDENT: 'Cause 7, 'cause... he was adding instead of multiplying.

Ingrid: Mmmm!

STUDENT: He was adding all the length and width.

Ingrid: Absolutely! Good job. I like that proof. 


\section{Wilma: Corner Market}

Wilma: In this problem the questions will help you decide which way to divide when you are finding a unit rate. So Mariah, this should answer your question about what to divide. The question will also help you with the meaning of the quotient after you divide. Getting ready for problem 3.4. Are you guys there? Psst, turn the page back. Dario has two options for buying boxes of pasta. At Corner Market he can buy 7 boxes of pasta for \$6. So what information do we have from that statement?

Student: $\quad$ That, um, he can buy 7 boxes of pasta for $\$ 6$ and at the other place...

Wilma: Wait, let's start with the first statement. So Corner Market, he has what?

Student: $\quad$ He can buy 7 boxes of pasta for $\$ 6$.

Wilma: $\quad$ So 7 boxes for $\$ 6$, right? At Super Foods he can buy 6 boxes of pasta for \$5. So Anthony, what do we know there? At Super Foods.

Anthony: He can buy 6 boxes for $\$ 5$.

Wilma: $\quad$ For how much? I'm sorry.

Anthony: $\$ 5$.

Wilma: Good. So here's the information we do know, correct? At Corner Market he divided 7 by 6 and got 1.166667. You'll survive. He then divided 6 by 7 and got .85714286 . He was confused. What do these numbers tell him about the price of boxes of pasta at Corner Market? 
$[\ldots]$

Wilma: $\quad$ So what does this answer tell me, 1.17. Is it the price or the box?

Students: The price.

Wilma: It's the price?

Students: It's both.

Wilma: $\quad$ OK, how many of you agree it's price? How many of you think its boxes?

Student: I think it's boxes.

Wilma: How many of you agree it's the price for a box? How many of you agree you don't know what it is?

Student: That's for a [inaudible].

Wilma: That's a good answer. At least we're on one page.

Wilma: $\quad$ All right. We have $\$ .86$, box or price? How many of you say price? How many of you say box? How many of you still don't know. Okay. At least you're honest and that's good. All right. So let's look. When we switch this around, what it's showing me - this is actually price. So each box is going to cost what? 
Student: \$1.17.

Wilma: Yeah, somebody did. $\$ 7.00$. What's the answer? So $\$ 1.17$ is going to be the price. This is going to tell me box for price, is that really how we usually figure that out?

Student: Yes.

Wilma: If we want to know the price of a box, one box, how do we usually do that?

Student: We divide the boxes by the price.

Wilma: We divide the boxes by the price, right, to find a unit rate. Because we want to know how much one box costs, so am I going to divide the box by the price, the price by the box?

Student: No.

Wilma: So, I'm going to use this one, correct? And that's going to tell me how many 1 costs? Okay. SO this is kind of like he shouldn't have used this. 


\section{Karen: Long Division}

Karen: $\quad J a c o b$, could you put them in the middle? We're going to show our division as we go. We've been doing our division for a long time, and I don't think we are still getting the point, why we're doing this subtracting.

Student: $\quad$ Can I get a ruler?

Karen: Okay, so we have seventy-two, right?

Student: Yeah.

Karen: If we wanted to divide seventy-two by four, what does that mean? What does that mean?

Student: How many fours are in seventy-two?

Karen: It means how many fours are in seventy-two, but what else does it mean?

Student: $\quad \mathrm{Hmmm}$.

Karen: $\quad$ Can I do it another way?

Student: Yeah, long division. 
Karen: How can I do it? But when I am doing long division, what am I doing? I can make-what I am finding out is four groups, right? Alright, so let's find our four groups. So, let's see. The girls are four girls, right?

Student: $\quad$ Yes.

Karen: Jacob, you're not paying attention to me. The girls are four girls. So can you divide these up among the girls, Jacob?

Student: $\quad$ Yes.

Karen: $\quad$ Let me see you do that without taking anything apart.

Student: $\quad$ I'll try.

Karen: $\quad$ One for Natalie. Timmy? Can you give them each a ten? You can't do it can you?

Student: $\quad$ No.

Karen: $\quad$ Alright, so how many tens could you give them, Jacob?

Student: One each.

Karen: $\quad$ You could give them one each. That's why we put a one in the answer spot here. I can give them one ten each, right?

Student: $\quad$ Yes. 
Karen: $\quad$ Okay Jacob, how many did you give away?

Student: $\quad$ Forty.

Karen: $\quad$ You gave away forty- That's why we put it here. We're going to give it away. We already know there's one ten worth, right?

Student: Yes.

Karen: Okay, subtract.

Student: $\quad$ Two.. .and three...

Karen: How many cubes do you have here?

Student: Thirty-two.

Karen: $\quad$ You have three then and two ones. Thirty-two, right?

Student: $\quad$ Yeah.

Karen: Jose, could pay attention for a minute?

Student: Yeah. 
Karen: $\quad$ Thanks! Okay Jacob, how can you give those to the girls? How can you divide them up?

Student: $\quad$ You...I can split them in half.

Karen: $\quad$ You have to take them all apart, don't you?

Student: $\quad$ Yeah, but I...

Karen: $\quad$ Okay, can I see you do that? Okay Jessica, he'll be fine-leave him be. You still have some more honey.

Student: $\quad$ I got it. Three, three, three, and ...three.

Karen: Do they all have the same amount now?

Student: $\quad$ Yes.

Karen: $\quad$ How many do they have that are not in a tens cube?

Student: Eight.

Karen: If I believe that, then I have to believe that there are four eights in thirtytwo.

Student: Yup. 
Karen: Do you believe that?

Student: Yeah.

Karen: $\quad$ So we put that in our answer. So we want to know how many fours are in seventy-two all together. Right?

Student: $\quad$ Yeah...

Karen: Jose...We put the answer up in the answer spot up in the quotient. There you go. Now we want to know how many are gone. So four times eight was thirty-two and there is none left, are there?

Student: $\quad$ No.

Karen: $\quad$ Anybody see any left?

Student: $\quad$ No.

Karen: $\quad$ None left. So we're all finished aren't we?

Student: Yes.

Karen: That's how those cubes go with this problem. 


\section{Pamela: School Fundraiser}

Teacher:

Teacher:

Student:

Teacher:

Student:

Teacher:

Student:

Teacher:

Multiple:
Student A, come show yours first. I'm going to show two examples, and you tell me which one actually matches the problem exactly, all right? Here's Student A's and Student K, show yours.

All right, take a look at these two models. This one and this one. Someone explain to me what you see the difference between them. It looks like they both come up with the same answer. What's the difference? Student $Z$, what do you notice?

That on Student A's she has 54 groups with $\$ 12.00$ each, and Student $\mathrm{K}$ has 12 with 54 [inaudible] 54 [inaudible].

All right, now, they both come up with the same answer. They both come up with the correct answer, right? And remember, 12 times 54 is exactly the same thing as 54 times 12 . It doesn't matter how you write it.

But I just want to kind of draw your attention to the fact that if you're going to go strictly by which one matches the problem exactly, which one of those actually matches the problem? Student J?

Student A's.

Student A's. Because it actually said 54 families, and each family donated $\$ 12.00$. His is not wrong, he came up with the right answer, but what his is showing is 12 families donating $\$ 54.00$. Same answer, different model.

Now, that being said, hers matches the problem exactly, but hers took a long time, didn't it?

Yeah.

Yeah, it took her longer. But if you're having a hard time seeing it, Student A's is the one you want to model.

That way you can write exactly what the problem is saying. Does everyone understand that?

Yes. 


\section{Marcus: The Gumball Problem}

Marcus: $\quad$ Okay. Let's go to B. Maggie, what did you get for B?

Student: $\quad$ Mmmm, B.

Marcus: I'll read the question first. "If there's 36 gum balls in the machine, how many are purple? How many are yellow? How many are orange?"

Student: $\quad$ Three purple...

Marcus: Shhh! Quiet!

Student: $\quad$ I got stuck on it.

Marcus: $\quad$ You got stuck on that one.

Student: $\quad$ Can I do it?

Marcus: Okay, Nolan. Tell us how you got it.

Student: $\quad 3$ purple, 6 orange...

Marcus: $\quad$ Hold on! How did you get the 3 purple. 
Student: $\quad$ Okay, so. I got the 3 purple cause purple is $1 / 12$ and so $12+12+12$ is 36 , so I just multiplied the denominator and the numerator by 3 , so it's 3 . And for 6,1 just did the same thing with $2 / 12 \ldots$

Student: You mean yellow.

Student: $\quad$ Um, yeah, and orange, and for yellow I just did the same thing for $9 / 12$.

Marcus: $\quad$ Okay, did anybody else do it differently?

Student: $\quad$ Yellow was 2/12.

Student: Let me show you a simple way of doing it.

Student: It said the probability of getting a yellow (inaudible)

Marcus: $\quad$ You got the $1 / 12$ for $A$, right Maggie.

Student: Um hmm.

Marcus: $\quad$ Okay. So, if you take that $1 / 12$ and you say $1 / 12$ of the 36 , you can multiply because of means times. So, a simple way to do it is that way.

Student: $\quad$ Equals three!

Marcus: $\quad$ Okay? And when they ask you for yellow, you could do the same thing. $1 / 6$ times the 36 and you get 6 by cross-multiplying. You divide the 6 into this, you get 1 . You divide the 6 into that and you get 6 . Okay? And then 
you do the other one the same way. The $3 / 4$ for the orange times 36 and you get 27 .

Student: $\quad$ Yeah. I was minus then, 'cause I knew $3+6=9$.

Marcus: $\quad$ You could do that, too. That's another way to do it. Once you know these two, you can subtract that from the 1 , I mean the 36 , and you'll get what's left. So, you can take the 3 plus the 6 and you'll get 9 . 9 from 36 is 27. Okay? Any questions?

Student: I have a question. Was I right?

Student: Yeah. 


\section{Toni: Division and Multiplication B}

Student: Eighteen times four.

Toni: Why, why can I do eighteen times four to check this answer?

Student: Because

Toni: Think about what we said about groups and what division is and what multiplication is. Somebody help him out. Take a look at this division problem and explain to me why what Carlos says is correct. Dianna. What does this problem tell me? In this division problem I what.

\section{Student: Dividing [inaudible]}

Toni: Is my quotient? No. What's a quotient? Good fancy word that you are using. What is it?

Student: It's a group of words in division.

Toni: The quotient is not the group in division the quotient is the answer that you get in division. What is seventy-two here? Chantel. My total Dianna seventy-two. I'm starting with my total and doing what to my total. I'm taking my total and doing what to it. Yes.

\section{Student: Dividing [inaudible]}

Toni: That's my total. I'm taking seventy-two objects, am I multiply it is that what I just did here. This was our multiplication now what did I do.

Student: Divide it.

Toni: Into

Student: Four groups.

Toni: Into four groups to get in

Student: Total.

Toni: I thought this was my total. Think about what is happening don't think about filling in my answers. Think about what is happening. If you are starting with a total of seventy-two and you are breaking it up in to four groups then what does the eighteen 
tell me. What does the eighteen tell me? Don't worry about this yet either. What does the eighteen tell me? I am going to give you a simpler problem. If I start out with eight a total of eight and I break it up in to two groups what does this four mean. It's what's inside

\section{Student: Of your circle.}

Toni: Of my circle of my group right? The four tells me what is inside each group. So back here, if I have seventy-two total and I'm breaking it up in to four groups what is the eighteen going to tell me.

Student: The eighteen is the one that's inside of the circle.

Toni: Excellent. Eighteen tells me how many I have in each circle or in each group okay. Now if I wanted to check this answer with multiplication how would I do it?

Student: Eight times

Toni: What is multiplication? What do I end up with multiplication? What do I end up with in multiplication?

Student: A total.

Toni: A total good. My answer is always my total and what am I using to make my total. Andy could you go work over there please. Thank you. Now. Calvin warning, warning.

Student: Working with eight.

Toni: You are working with a total of eight. Two groups of.

Student: Four

Toni: So if I am dividing I am starting with a total. Breaking it up in to groups and figuring out how many in each group. So when I multiply I can take the number in each group times the number of groups to give me back my

Student: Total.

Toni: So here I divided, I started with my total; I divided into groups and figured out how many in each group. I am now going to take my answer and if I multiply it what should I end up with again. What should I end up with? I should end up with.

Student: Seventy-two. 
Toni: I should end up right back with my total. So, when we check we know we are starting with a total breaking it up in to groups. When we multiply back we should end up again with our total just like we do in multiplication anyway. 